\title{
RIPARIAN MARSHLAND COMPOSITION AND PRODUCTIVITY MAPPING USING IKONOS IMAGERY
}

\author{
By \\ Kristie A. Dillabaugh, BES (Hons.) \\ A thesis submitted to \\ the Faculty of Graduate Studies and Research \\ in partial fulfilment of the requirements of the degree of \\ Master of Science \\ Department of Geography and Environmental Studies \\ Carleton University \\ Ottawa, Ontario \\ September, 2006
}

(c) Kristie Dillabaugh, 2006 


$\begin{array}{ll}\begin{array}{l}\text { Library and } \\ \text { Archives Canada }\end{array} & \begin{array}{l}\text { Bibliothèque et } \\ \text { Archives Canada }\end{array} \\ \begin{array}{l}\text { Published Heritage } \\ \text { Branch }\end{array} & \begin{array}{l}\text { Direction du } \\ \text { Patrimoine de l'édition }\end{array} \\ \begin{array}{l}\text { 395 Wellington Street } \\ \text { Ottawa ON K1A 0N4 } \\ \text { Canada }\end{array} & \begin{array}{l}\text { 395, rue Wellington } \\ \text { Ottawa ON K1A ON4 } \\ \text { Canada }\end{array}\end{array}$

Your file Votre référence ISBN: 978-0-494-18360-1 Our file Notre référence ISBN: 978-0-494-18360-1

NOTICE:

The author has granted a nonexclusive license allowing Library and Archives Canada to reproduce, publish, archive, preserve, conserve, communicate to the public by telecommunication or on the Internet, loan, distribute and sell theses worldwide, for commercial or noncommercial purposes, in microform, paper, electronic and/or any other formats.

The author retains copyright ownership and moral rights in this thesis. Neither the thesis nor substantial extracts from it may be printed or otherwise reproduced without the author's permission.
AVIS:

L'auteur a accordé une licence non exclusive permettant à la Bibliothèque et Archives Canada de reproduire, publier, archiver, sauvegarder, conserver, transmettre au public par télécommunication ou par l'Internet, prêter, distribuer et vendre des thèses partout dans le monde, à des fins commerciales ou autres, sur support microforme, papier, électronique et/ou autres formats.

L'auteur conserve la propriété du droit d'auteur et des droits moraux qui protège cette thèse. $\mathrm{Ni}$ la thèse ni des extraits substantiels de celle-ci ne doivent être imprimés ou autrement reproduits sans son autorisation.
In compliance with the Canadian

Privacy Act some supporting forms may have been removed from this thesis.

While these forms may be included in the document page count, their removal does not represent any loss of content from the thesis.
Conformément à la loi canadienne sur la protection de la vie privée, quelques formulaires secondaires ont été enlevés de cette thèse.

Bien que ces formulaires aient inclus dans la pagination, il n'y aura aucun contenu manquant.

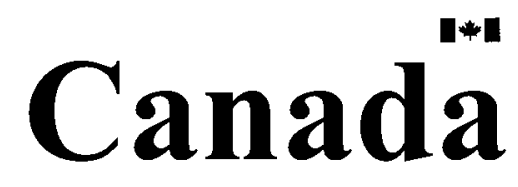




\begin{abstract}
The Ontario Wetland Evaluation System (OWES) employs a visual assessment of wetland extent, composition and biomass as primary indicators in determining which wetlands should be considered provincially significant and subsequently protected. High resolution satellite remote sensing offers the potential to provide more quantitative analysis at greater spatial detail within a given wetland using spectral and spatial image information. In this study, Ikonos imagery was used to map vegetation composition and productivity in three riparian marshes located along the Rideau River near Ottawa, Ontario. Separability and correlation analyses aided in the selection of an optimum set of spectral and spatial data, which were used in classification tests, with training and validation data being randomly selected from a set of 107 field sites. Terrestrial and aquatic vegetation was classified comparing maximum likelihood $(\mathrm{ML})$ and neural network classifications, with a ML classification using a Transformed Vegetation Index (TVI), visible bands, A2M5grn and CON5nir textures resulting in the highest accuracy of $88 \%$ and a $\mathrm{K}_{\text {hat }}$ statistic of 0.72 . For biomass mapping, a 1 $\mathrm{m}^{2}$ sample frame was used to collect green and senescent vegetation at 75 locations within the various vegetation classes. Dry biomass was modelled against the spectral and textural image measures using forward stepwise regression. Log green biomass modelled by a combination of texture and spectral variables provided the best result. The absolute error of this model in predictive biomass mapping was $213 \mathrm{~g} / \mathrm{m}^{2}$ or approximately $40 \%$ of the mean field measured biomass.
\end{abstract}




\section{Acknowledgements}

This has been a long and challenging journey and I have been blessed with a lot of help from many wonderful people.

I would first like to thank my supervisor, professor Douglas King, for his patience when this research was delayed and slow to progress. He has encouraged independent thought and development of my research ideas, from the very beginning, and has guided the development and progression of those ideas. As a result, I have gained tremendous experience in the processes of research design and development. I am also thankful for the financial support he has given me especially during the last two years when progress has been especially sluggish.

Secondly, I would like to thank professor Mike Pisaric for providing me with excellent TA work experiences, for allowing me to use his refrigerator to store my LARGE quantities of vegetation, and for being approachable and kind enough to listen whenever I needed to talk.

I believe I am the last to graduate out of those that began this journey with me and it has been difficult to finish this journey alone. The one person that is still around is my great friend RAVS. You have braved the wetland with me and were the most outstanding field assistant I could ever have had. It was hard work and never once did you complain. You spent countless hours in the lab chopping, 
weighing and drying vegetation, and helping me edit my final draft and I could not have completed this research without you. I am, however, most appreciative of your friendship, it has meant the world to me over the last few years.

I would also like to thank my family who has endured this experience with me. Special thanks firstly to my momma who has often helped me by taking care of baby Eden so I could work on my thesis. I believe one of the greatest things you have ever taught me is to never quit...finish what you start! You have sacrificed so much for me and I am grateful that you have always been there for me (even when we share the same roof). Despite the severe allergic reaction to Common cattail (Typha latifolia) and the subsequent day's delay in collecting field data l'm so grateful for my brother Drew and for the encouragement he has given me. A HUGE thank-you also goes to Sondra and Derlin for taking care of Eden when I had deadlines to meet finishing this work. I would also like to thank Binga and Reegan for being like another set of parents for me and grandparents for Eden. A BIG thank-you to my wonderful friend Heather for being such a shining example to me I could always call for help when I needed somewhere for Eden to play, we'll miss you guys TONS!

I would be remiss if I didn't thank Hazel Anderson for being so supportive and encouraging over the last four years. Has it really been four years? Hazel is the most helpful graduate secretary l've ever known! Robby Bemrose began my field work with me and I'm thankful for his help in selecting my field plots and 
helping me traverse the wetlands. My regression analysis couldn't have been accomplished without Jon Pasher's condensed SPSS course-THANKS!

Professor Scott Mitchell provided me with valuable information on the collection and processing of biomass, and contributed insight during the final editing stage of this thesis (thank-you so much for your contributions).

Second to last I would like to thank Craiger for encouraging me to finish this insurmountable task. You have been my personal technical support line, my extra field assistant, and my best friend and I couldn't have done this without you. Thank you for being patient and understanding when life was tough.

Lastly I would like to thank baby Eden, who interrupted this research process, for being my ray of sunshine, for making me laugh and reminding me of the true blessings in life. I just hope you learn how to SLEEP soon!

I would like to dedicate this thesis to baby Eden. Despite the difficulties associated with having children and completing a graduate degree I wouldn't trade you for anything in the world! 


\section{Table of Contents}

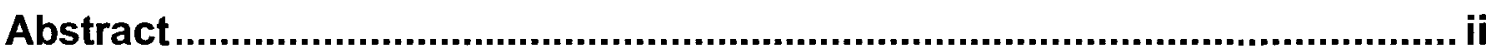

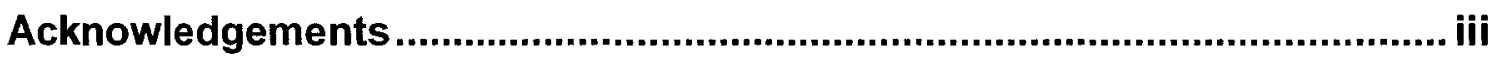

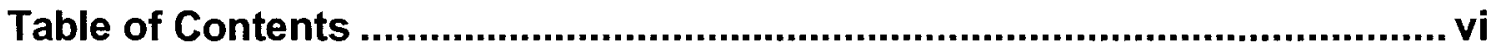

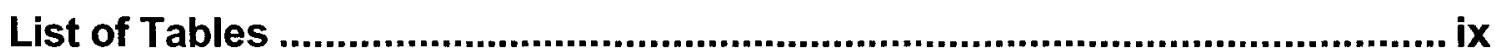

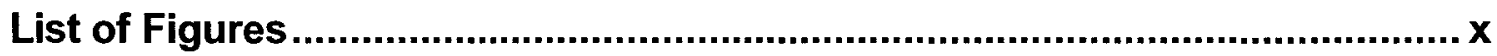

List of Acronyms

Chapter One: Introduction ............................................................................ 1

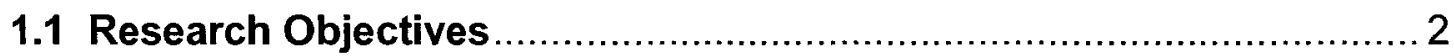

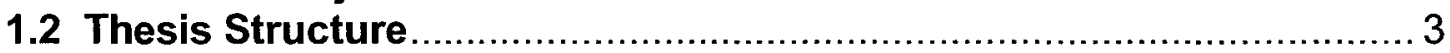

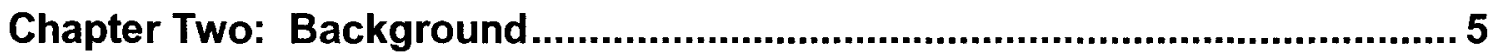

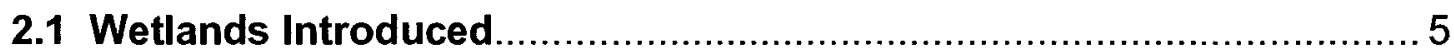

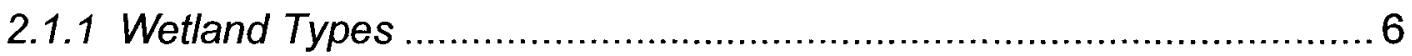

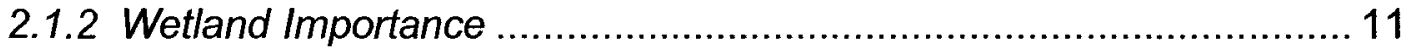

2.1.3 Wetland Distribution and Disturbance ........................................ 12

2.2 Classification of Wetland Composition .......................................... 13

2.2.1 Sensor Data Types.............................................................. 15

2.2.1.1 Moderate Resolution Sensors............................................ 15

2.2.1.2 High Resolution Sensors ..................................................... 16

2.2.1.3 Radar Systems .................................................................. 17

2.2.2 Image Data Transformations used in Classification ........................ 18

2.2.2.1 Vegetation Indices .............................................................. 18

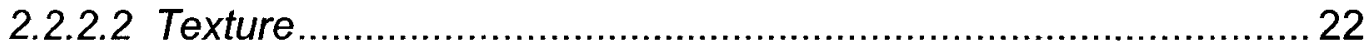

2.2.2.3 Principal Component Analysis ................................................ 26

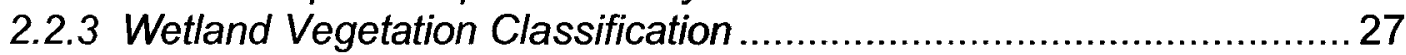

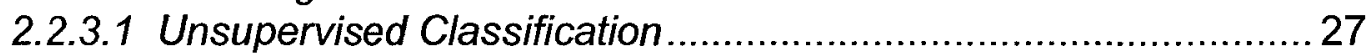

2.2.3.2 Supervised Classification ...................................................... 27

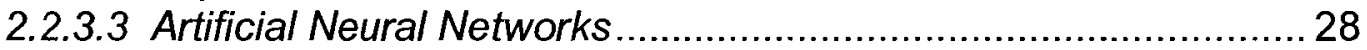

2.2.4 Accuracy Assessment of Classified Maps ...................................... 29

2.2.5 Previous Wetland Classification Studies ...................................... 30

2.2.5.1 Previous Wetland Studies using Moderate Resolution Optical

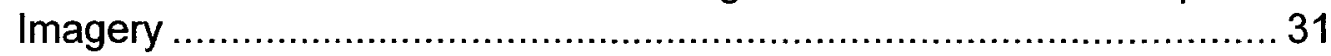

2.2.5.2 Wetland Studies using High Resolution Imagery..................... 33

2.2.5.3 Use of Vegetation Indices in Image Classification ...................... 35

2.2.5.4 Use of Texture in Image Classification ..................................... 36 
2.2.5.5 Use of Principal Components in Image Classification ................. 38

2.2.5.6 Studies using Unsupervised Classification ............................... 39

2.2.5.7 Studies using Supervised Classification ................................. 40

2.2.5.8 Studies using Neural Networks ............................................. 41

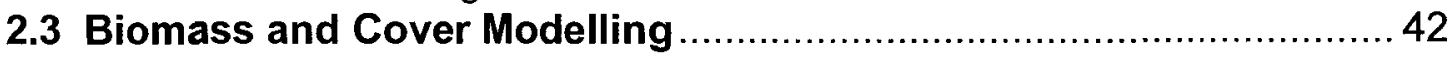

2.3.1 Forward Stepwise Regression ..................................................... 43

2.3.2 Assessment of Model Quality and Predictive Accuracy ................... 44

2.3.3 Previous Biomass and Cover Modelling Studies ............................. 46

2.3.3.1 Use of Vegetation Indices in Biomass and Cover Modelling ....... 47

2.3.3.2 Use of Texture in Biomass Modelling ........................................ 49

2.3.3.3 Use of Principal Components in Biomass Modelling .................. 49

Chapter Three: Methods ........................................................................... 51

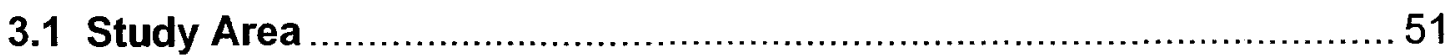

3.2 Selection of Field Plots and Field Sampling Methods ......................53

3.2.1 Field Sampling for Image Classification of Wetlands......................... 53

3.2.2 Field Sampling for Biomass and Cover Modelling ….........................5 57

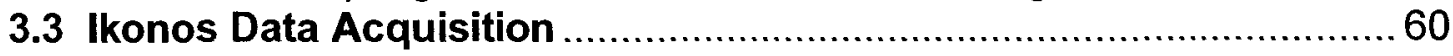

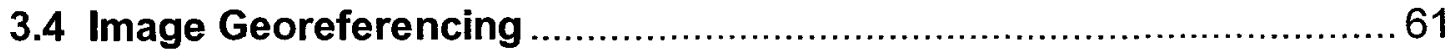

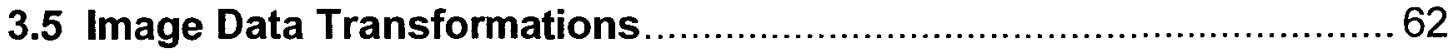

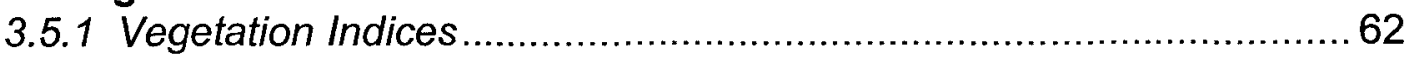

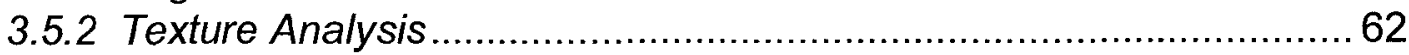

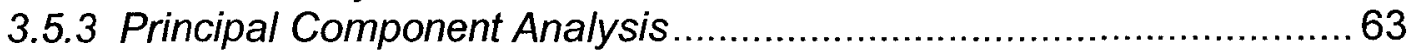

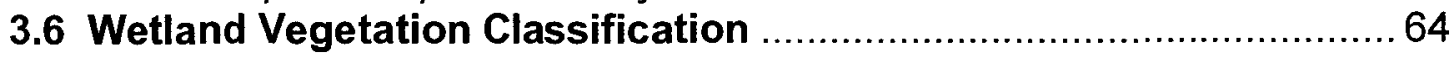

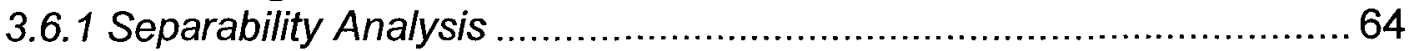

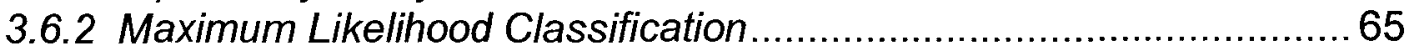

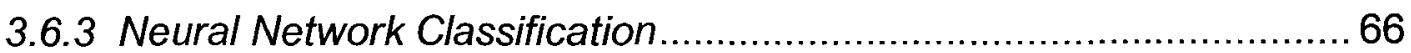

3.6.4 Classification Accuracy Assessment ...........................................69

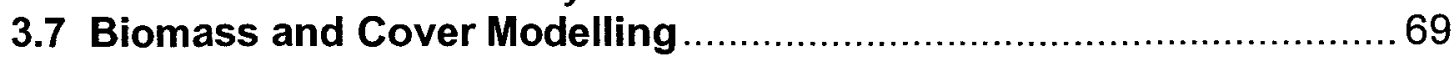

3.7.1 Biomass Model Assessment and Validation ................................... 71

Chapter Four: Results ............................................................................ 72

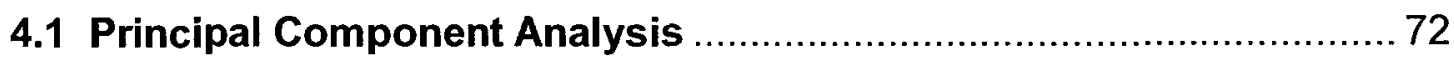

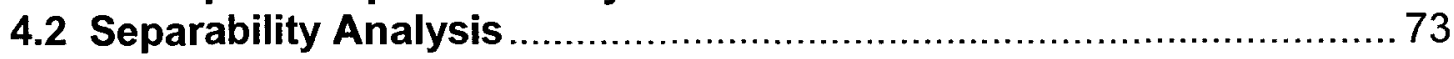

4.2.1 Spectral Bands versus Principal Components................................74

4.2.2 Determining the Best Texture Variables for Classification ................. 76

4.2.3 Determining Appropriate Vegetation Indices for Classification ........... 77

4.2.4 Merging Wetland Classes based on Separability ............................ 78

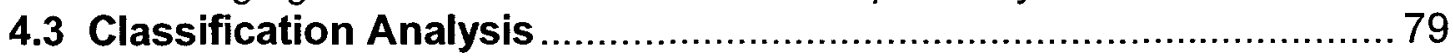

4.3.1 Maximum Likelihood Classification ............................................. 80

4.3.1.1 Classification using Seven Classes ....................................... 80

4.3.1.2 Classification using Six Classes............................................... 83 
4.3.1.3 Classification using Five Classes....................................... 87

4.3.2 Summary of Classification Results ........................................... 91

4.3.3 Additional Maximum Likelihood Classifications ............................ 94

4.3.4 Neural Network Classification ................................................. 97

4.4 Biomass and Cover Modelling ............................................. 100

4.4.1 Biomass Modelling ............................................................ 100

4.4.1.1 Biomass Model Assessment and Validation .......................... 104

4.4.1.2 Cover Modelling ......................................................... 106

Chapter Five: Discussion and Conclusions ............................................ 110

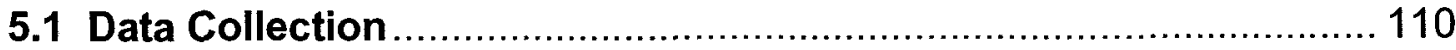

5.2 Wetland Vegetation Classification ........................................ 111

5.3 Biomass and Cover Modelling ............................................ 116

5.4 Overall Conclusions ......................................................... 119

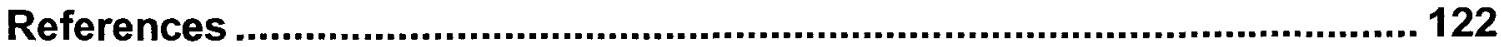




\section{List of Tables}

Table 1. Correlation matrix (showing $r$ values) for Ikonos spectral bands. ....... 63

Table 2. Neural network configurations. ..................................................68

Table 3. Variations for biomass regression analysis ................................. 70

Table 4. PCA of spectral data: Factor loadings table ................................... 72

Table 5. Separability results for different combinations of spectral bands and 7

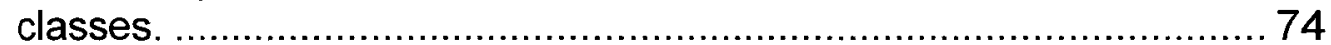

Table 6. Separability results for spectral bands and PCs combined with A2M5grn and CON5nir with varying number of wetland classes. ................... 75

Table 7. Separability results for selected $3 \times 3$ and $5 \times 5$ textures based on 7

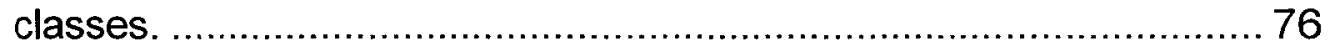

Table 8. Individual textures showing highest separability based on 7 classes. . 77

Table 9. Separability results for top three data combinations for 7,6 and 5 wetland classes based on $50 \%$ training $3 \times 3$ clusters. ...................... 79

Table 10. Error matrix for 7 class MSAVI classification. ................................ 80

Table 11. Producer and user accuracies for 7 class MSAVI classification. ....... 82

Table 12. Error matrix for 6 class TVI classification...................................... 84

Table 13. Producer and user accuracies for 6 class TVI classification. ............. 85

Table 14. Error matrix for 5 class Spectral bands, A2M5grn and CON5nir classification. ...................................................................... 88

Table 15. Producer and user accuracies for 5 class spectral bands, A2M5grn and CON5nir classification..................................................... 89

Table 16. Number of pixels per wetland class for 5 classes using approximately $50 \%$ training and $50 \%$ validation $3 \times 3$ clusters........................... 93

Table 17. Error matrix for 5 class TVI classification...................................... 95

Table 18. Producer and user accuracies for 5 class map derived from TVI classification. ...................................................................... 96

Table 19. Neural network convergence................................................... 98

Table 20. Error matrix for 5 class neural network (\#14) classification................ 99

Table 21. Producer and user accuracies for 5 class map derived from neural network (\#14) .................................................................... 99

Table 22. Variance accounted for by models of total combined biomass, total green biomass and total senescent biomass............................. 101

Table 23. $R^{2}$ contribution of independent variables in log green biomass model.

Table 24. Single variable model validation results.......................................... 105

Table 25. Multiple variable model validation results................................. 105

Table 26. Comparing field estimates and calculated estimates of percent cover.

Table 27. Variance accounted for by models of aquatic green field cover....... 108 


\section{List of Figures}

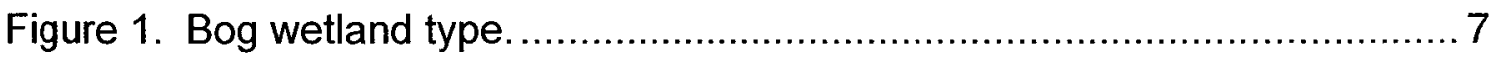

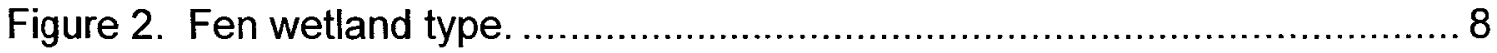

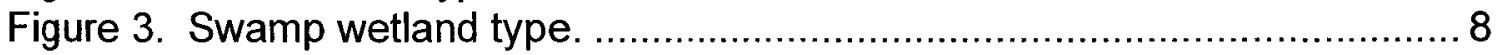

Figure 4. Marsh wetland type. ............................................................ 10

Figure 5. Shallow open water environment. ............................................ 10

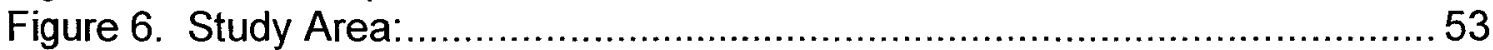

Figure 7. Emergent terrestrial vegetation. ..............................................56

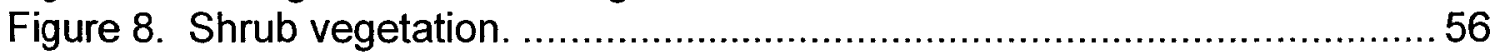

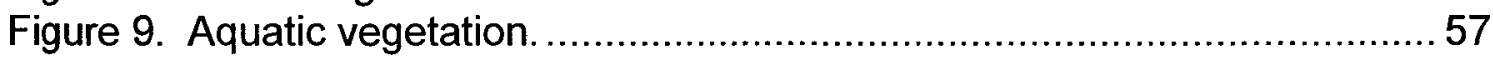

Figure 10. Grasses/sedges and forest vegetation. ..................................... 57

Figure 11. Terrestrial and Aquatic Field Plots............................................58

Figure 12. Drying Curve for green floating aquatic vegetation.........................59

Figure 13. Drying curve for green emergent terrestrial vegetation.....................6 60

Figure 14. MSAVI classification for 7 classes with mode filter applied. ............. 82

Figure 15. TVI classification for 6 classes with mode filter applied................... 86

Figure 16. Spectral band classification for 5 classes with mode filter applied. .. 89

Figure 17. Emergent aquatic vegetation................................................... 90

Figure 18. Emergent terrestrial versus emergent aquatic vegetation. ...............93

Figure 19. TVI classification for 5 classes with mode filter applied...................96

Figure 20. Neural Network 14 for five wetland classes................................ 100

Figure 21. Gradient map of biomass. ......................................................... 103

Figure 22. Biomass map showing three levels of biomass........................... 104

Figure 23. Floating aquatic plot and corresponding classified image. ............ 107

Figure 24. Emergent aquatic plot and corresponding classified image............ 107 


\section{List of Acronyms}

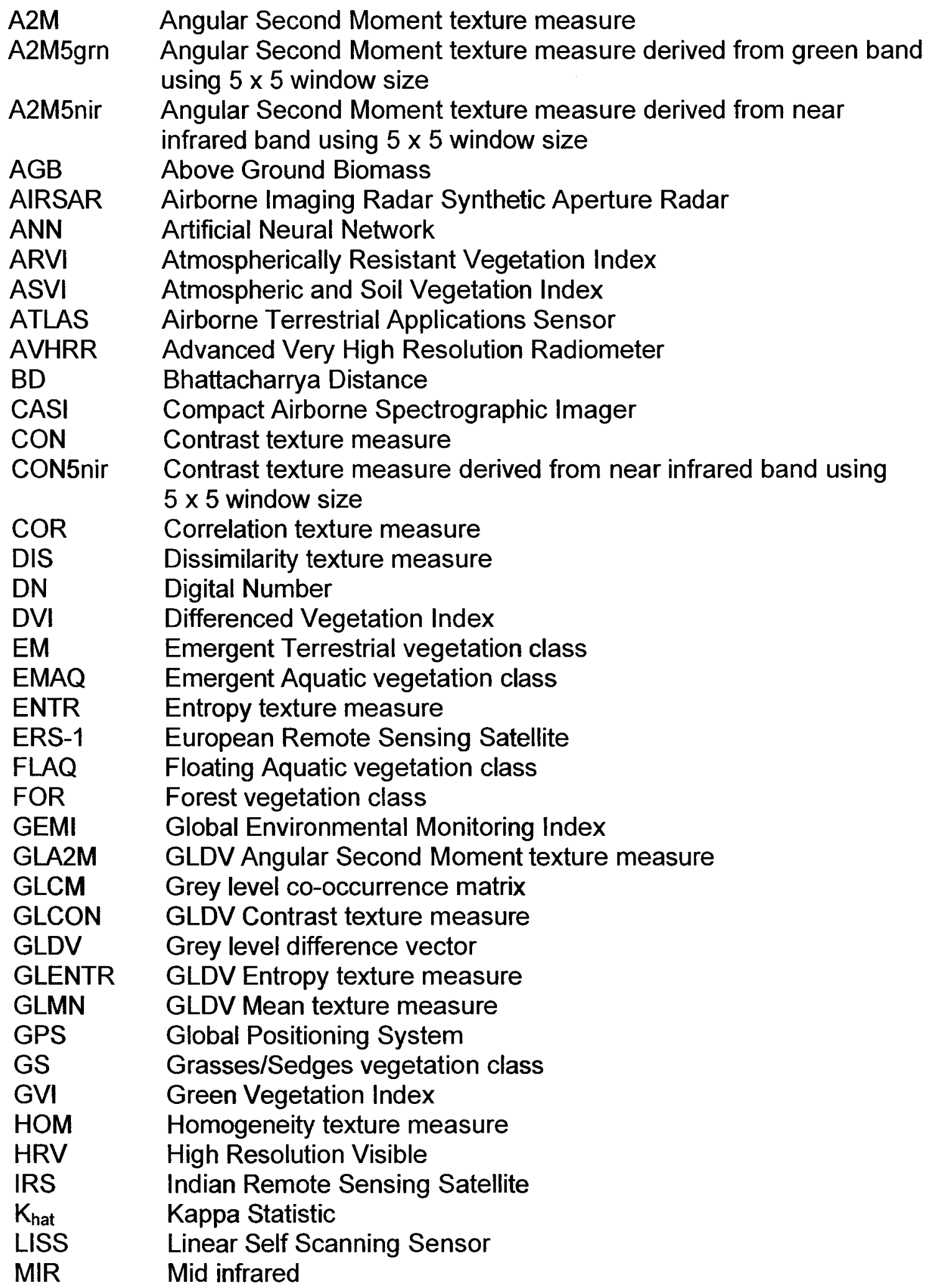




\begin{tabular}{|c|c|}
\hline ML & Maximum Likelihood classifier \\
\hline MN & Mean texture measure \\
\hline MN3nir & $\begin{array}{l}\text { Mean texture measure derived from near infrared band using } 3 \times 3 \\
\text { window size }\end{array}$ \\
\hline MN5grn & $\begin{array}{l}\text { Mean texture measure derived from green band using } 5 \times 5 \text { window } \\
\text { size }\end{array}$ \\
\hline MN5nir & $\begin{array}{l}\text { Mean texture measure derived from near infrared band using } 5 \times 5 \\
\text { window size }\end{array}$ \\
\hline MSAVI & Modified Soil Adjusted Vegetation Index \\
\hline MSS & Multispectral Scanner \\
\hline NAD & North American Datum \\
\hline NDVI & Normalized Difference Vegetation Index \\
\hline NIR & Near infrared \\
\hline OMNR & Ontario Ministry of Natural Resources \\
\hline OW & Open Water class \\
\hline OWES & Ontario Wetland Evaluation System \\
\hline$p$ & statistical significance \\
\hline PAN & Panchromatic \\
\hline PC & Principal Component \\
\hline PCA & Principal Component Analysis \\
\hline $\mathrm{PCl}$ & Image processing software \\
\hline$R^{2}$ & Coefficient of determination \\
\hline$R_{a d j}^{2}$ & Adjusted coefficient of determination \\
\hline RMS & Root mean square \\
\hline RMSE & Root mean square error \\
\hline RVI & Ratio Vegetation Index \\
\hline SAVI & Soil Adjusted Vegetation Index \\
\hline $\mathrm{Se}$ & Standard error of the estimate \\
\hline SHR & Shrub vegetation class \\
\hline SPOT & Système pour l'Observation de la Terre \\
\hline STDEV & Standard Deviation texture measure \\
\hline TERm & Terrestrial Marsh vegetation class \\
\hline TEX & Texture \\
\hline TIR & Thermal infrared \\
\hline TM & Landsat Thematic Mapper \\
\hline TSAVI & Transformed Soil Adjusted Vegetation Index \\
\hline TVI & Transformed Vegetation Index \\
\hline UTM & Universal Transverse Mercator projection \\
\hline VI & Vegetation Indices \\
\hline VIF & Variance Inflation Factor \\
\hline
\end{tabular}




\section{Chapter One: Introduction}

Vegetation plays a key ecological role within all wetland environments. Marshes, chosen as the focal wetland type for this research, are dominated by emergent and aquatic vegetation, although peripheral trees and low shrubs also occur. Due to increased pressures on wetlands from urbanization and agriculture, it has become necessary to develop protection policies, which have in turn initiated the development of an evaluation system within Ontario to identify priority wetlands for protection. The purpose of the Ontario Wetland Evaluation System (OWES) is to rate the potential significance of a wetland based on four components including hydrology, biology, social benefits and special features. The assessment of wetlands by the OWES is conducted on the ground with the aid of air photos and existing maps. These methods typically introduce observer bias and are labour intensive for large wetlands. Field investigations are generally very expensive and access to wetland environments is often difficult due to uneven and unstable terrain, tall vegetation and deep water.

Remote sensing technology can be used to identify wetland type, extent, spatially associated resources and vegetation communities (Lyon and McCarthy, 1995). Though moderate resolution imagery has been used extensively for regional wetland mapping applications it has not been successfully used for detailed wetland mapping. With higher resolution capabilities remote sensing offers a unique way to identify and map vegetation composition and structure associated with riparian wetlands which are often narrow and linear in form. This type of 
image data could allow for greater attribute precision, so that smaller vegetation classes and wetland boundaries would be more easily detectable. Thematic land-cover maps derived from satellite image classification techniques can aid in the analysis of spatial patterns and help identify unevaluated wetland areas that are susceptible to development and agricultural pressures.

Remote sensing has traditionally been used as a tool for land use and land cover mapping, though increasingly it is being used for collecting biophysical information such as vegetation and soil moisture contents, percent vegetation cover and vegetation biomass. Multispectral satellite imagery can be analysed to produce distribution maps per unit area that are useful for modelling plant stress and yield (Jensen, 1983). Typically, a relation between spectral data or transformations such as vegetation indices and biomass is developed for sample data using regression-based methods and the regression equation is applied to other non-sampled areas to produce biomass maps (Campbell, 1996).

\subsection{Research Objectives}

There were two primary objectives to this research:

1) To determine if Ikonos imagery can be used to map riparian marsh vegetation composition.

2) To model biomass and cover within riparian marsh wetlands. 
Associated with the first objective was a need to determine the best combination of image inputs for use in a comparison of a traditional supervised classification technique versus a neural network approach and to evaluate the accuracy of classified maps using separate validation data not input to the classification process.

For the second objective harvested biomass in $\mathrm{g} / \mathrm{m}^{2}$ was used as the dependent variable in forward stepwise regression against image variables, including raw spectral bands, vegetation indices, textures and principal components, to determine the best predictors of biomass. The best biomass model was validated and accuracy was assessed.

\subsection{Thesis Structure}

This thesis is organized into six chapters. Chapter one introduces the importance of wetland mapping and modelling, defines the research objectives, and outlines the structure of the thesis. Chapter two gives the background information for this research derived from the literature including: an introduction to wetlands, descriptions of data transformations, classification techniques and accuracy assessment used in this thesis, and a discussion of techniques for modelling wetland biomass and vegetation cover and for model assessment. Chapter three describes the study area, explains methods used for field plot selection and field sampling techniques, discusses image acquisition and data processing for wetland classification and accuracy assessment, and finally 
reviews biomass and cover modelling techniques and model validation and assessment used in this research. The results for wetland classification and modelling are presented in Chapter four. Chapter five situates the major findings of this research in relation to the literature, discusses significant contributions and recommendations for future research, and finally outlines the overall conclusions of this research. 


\section{Chapter Two: Background}

\subsection{Wetlands Introduced}

Wetlands are transitional zones located between terrestrial and aquatic ecosystems, which experience seasonal or permanent above surface water. As a result, saturated soils and hydrophytic (water tolerant) vegetation predominate. Defining wetland environments, however, has long been a challenge. Wetlands are not static systems, as they undergo natural succession, experience fluctuating water levels and vary in form and process with differences in size and location. Formal wetland definitions have been developed by many agencies in the United States and Canada and through an international treaty known as the Ramsar convention (Mitsch and Gosselink, 1993). The Ramsar convention was initially adopted at an international conference in Ramsar, Iran in 1971. The global treaty provides the framework for the international protection of wetlands that provide habitat for migratory birds. Wetland definitions can be used for both scientific and management purposes (Mitsch and Gosselink, 2000). In Canada wetlands are formally defined as, "land that is saturated with water long enough to promote wetland or aquatic processes as indicated by poorly drained soils, hydrophytic vegetation which is periodically deficient in oxygen and various kinds of biological activity adapted to a wet environment" (National Wetlands Working Group Canada Committee on Ecological Land Classification, 1988, p.416). 


\subsubsection{Wetland Types}

There are five major wetland types recognized and defined in Canada by the National Wetlands Working Group (1988): bogs, fens, swamps, marshes and shallow open water. Wetlands are organized into these five types as each one exhibits a unique form, has varying relative primary productivity rates and provides habitat to different animals and plants (Ontario Ministry of Natural Resources, 1993).

Bogs are most commonly found in northern Canada where peat accumulation exceeds $40 \mathrm{~cm}$ in depth. Bogs have a high water table and contain vegetation adapted to nutrient poor conditions. The bog surface is often raised and isolated from mineralized soils, but remains flat or level with the surrounding wetlands. As a result, the surface water of bogs is extremely acidic and the upper layers are nutrient deficient, which results in poor plant diversity. Bogs are typified by sphagnum moss and ericaceous shrub vegetation such as leatherleaf (Chamaedaphne calyculata) and bog laurel (Kalmia polifolia). Black spruce (Picea mariana) is the dominant tree found within bogs though tree cover does not exceed $25 \%$. Figure 1 shows a typical northern bog environment. 


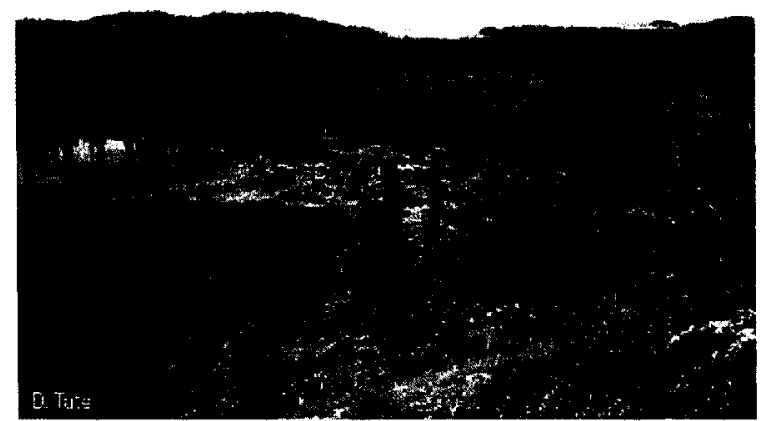

Figure 1. Bog wetland type.

www.aquatic.uoguelph.ca/wetlands/chapter2/bogs.htm; Hebert PDN (2002a).

Fens are peatlands that have a high water table but very slow internal drainage, as a result of low gradient slopes. The oxygen level is low and mineral supply is limited. Plant diversity is higher in fens than in bogs with sedges as the predominant vegetation community, though mosses, vascular plants, shrubs and sparse trees are also found. Sedge species such as creeping sedge (Carex chordorrhiza), livid sedge (Carex livida) and candle lantern sedge (Carex limosa), and a shrub known as bog willow (Salix pedicellaris) are considered to be common fen indicator species (Newmaster et al., 1997). Tree species such as white cedar (Thuja occidentalis L.) and tamarack (Larix laricina) less than 6 metres in height are common. Within fen communities vascular plant species such as pitcher plant (Sarracenia purpurea) and buckbean (Menyanthes trifoliata) are often found. A fen environment is shown in Figure 2. 


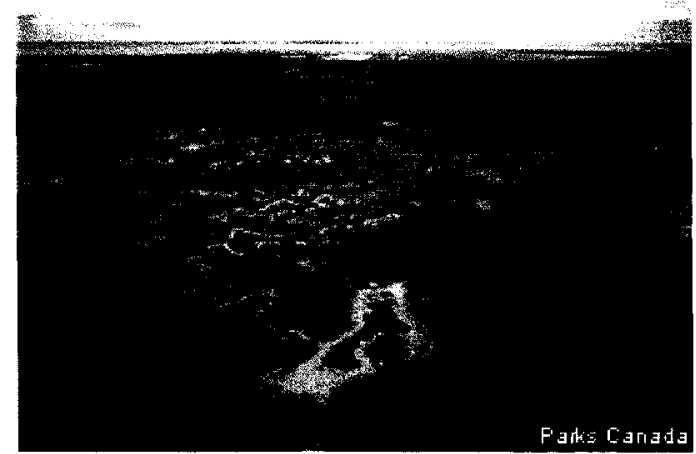

Figure 2. Fen wetland type.

www.aquatic.uoguelph.ca/wetlands/chapter2/fens.htm; Hebert PDN (2002b).

A swamp has trees and tall shrubs ( $>6$ metres in height) that dominate at least $25 \%$ of the area and the subsurface is continuously waterlogged as a result of standing or gently moving water. The water table may drop seasonally below the vegetation root zone, creating aerated conditions at the surface. Swamp waters are neutral to moderately acidic and show little deficiency in oxygen or mineral nutrients. Treed swamps may have either deciduous or coniferous species such as silver maple (Acer saccharinum), black ash (Fraxinus nigra), yellow birch (Betula alleghaniensis), and black spruce (Picea mariana). Thicket swamps are dominated by shrub species such as dogwood (Cornaceae spp.) and speckled alder (Alnus rugosa). A typical treed swamp environment is shown in Figure 3.

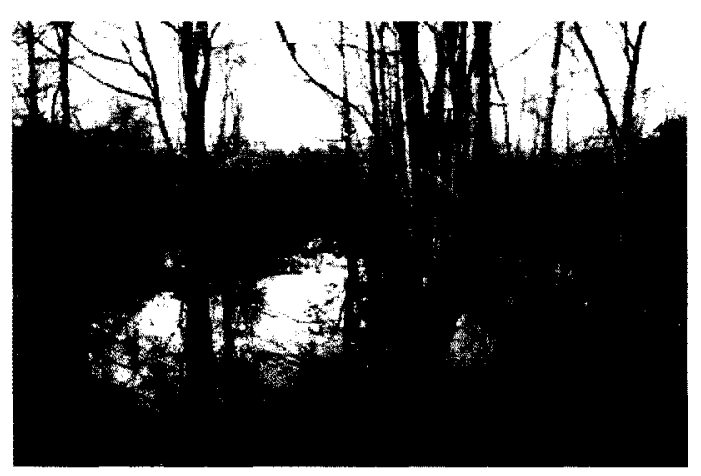

Figure 3. Swamp wetland type. www.aquatic.uoguelph.ca/wetlands/chapter2/swamps.htm; Hebert PDN (2002c). 
Marshes are nutrient rich areas that are periodically inundated by standing or slow moving water. Wet mineral soil areas predominate, but shallow well decomposed peat may be present. They are subject to a fluctuating water table, but water remains within the plant rooting zone for most of the growing season. Waters are usually neutral to slightly alkaline, with high oxygen levels. Tall emergent vegetation such as common cattail (Typha latifolia) and common reed (Phragmites australis) predominate, although low shrubs such as sweet gale (Myrica gale) and red osier dogwood (Cornus stolonifera) are commonly found while tree species such as black ash (Fraxinus nigra) often form the periphery. Broad leaved plants such as Sagittaria spp. and floating aquatic plants such as fragrant white water lily and yellow pond lily (Nymphaea odorata and Nuphar variegatum) are also prevalent in open water areas. Ecologically, marshes are considered as initial successional wetlands. If left undisturbed, marshes will naturally succeed into swamps, while fens will succeed into bogs over many years. As wetlands age, they become more sensitive to disturbance. A marsh environment is shown in Figure 4 (one of the marshes of this study) with floating aquatic vegetation and open water in the foreground and an abrupt vegetation change to emergent vegetation in the background. 


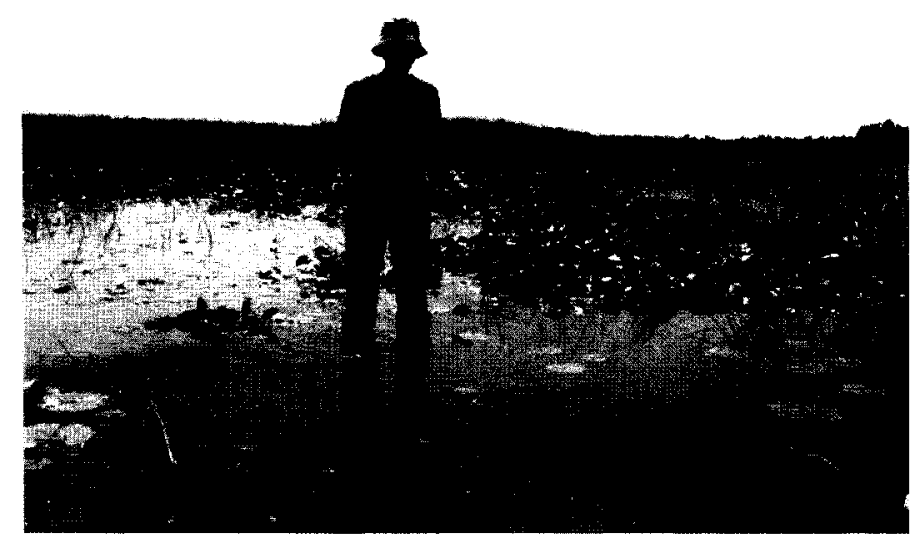

Figure 4. Marsh wetland type.

Shallow open waters are relatively small, non-fluvial bodies of standing water representing a transitional stage between lakes or rivers and marshes (see Figure 5). Submerged (Potamogeton spp.) and floating plants (Lemna spp., Spirodela spp., Wolffia spp., Nuphar and Nymphaea spp.) flourish in areas of open water.

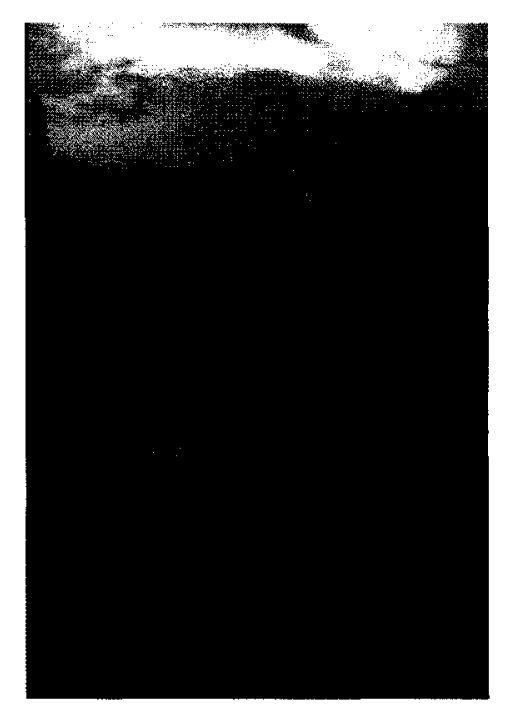

Figure 5. Shallow open water environment.

www.aquatic.uoguelph.ca/wetlands/chapter2/shallow.htm; Hebert PDN (2002d). 
Riparian marshes were chosen as the wetland type for this research as they are considered extremely productive environments and generally support several vegetation communities including emergent terrestrial, shrub, grasses/sedges, floating aquatic and emergent aquatic.

\subsubsection{Wetland Importance}

Wetlands provide many environmental functions such as playing a vital role in the carbon cycle, as plants convert inorganic carbon into organic compounds through the process of photosynthesis. Wetland plants also help to circulate essential nutrients such as phosphorus and nitrogen, which are absorbed through plant roots from soil and water and excreted as the plants and their consumers die. As wetlands are typically located between terrestrial and aquatic systems, they play an important role in regulating water flow. Water is absorbed and temporarily stored when water levels are high and groundwater is recharged by wetlands during drier periods. Water quality improvement is also another important function of wetlands, as they act as natural filters, with wetland plants removing sediments and debris from the water and absorbing nutrients and heavy metals. Soil erosion is reduced as wetland plant root systems act as stabilising agents. Wetlands are highly productive ecosystems and therefore provide habitat for many plant and animal species. Plant nutrients can be utilized by wetland wildlife forming the basis of complex food chains (Twolan-Strutt, 1995; Mitsch and Gosselink, 1993; Larson and Newton, 1981; Lewis, 2001; Williams, 1990; Hammer, 1997). 
The physiographic position of a wetland within a landscape is an important ecological factor in determining its function, importance and productivity. Riparian wetlands are greatly influenced by adjacent rivers or streams and as a result are typically linear in form and process large fluxes of energy and materials from upstream systems (Mitsch and Gosselink, 2000). The productivity of riparian wetlands has been found to increase with distance downstream from the river mouth (Ontario Ministry of Natural Resources, 1994). Riparian wetlands are particularly important for increasing riparian habitat and stabilizing river banks.

The preservation of shoreline vegetation and wetlands is critical for maintaining a river's health and biodiversity.

\subsubsection{Wetland Distribution and Disturbance}

Wetlands can be found on every continent except Antarctica. According to Mitsch and Gosselink (1993) approximately $6 \%$ or 8.6 million $\mathrm{km}^{2}$ of the earth's surface is wetland, with more than half of those being located in tropical and subtropical regions, and the remaining wetlands being found primarily in boreal and subarctic areas. Environment Canada (1986) indicated that 1.27 million $\mathrm{km}^{2}$ of Canada is covered by wetlands with the most extensive wetland concentration occurring in the central provinces of Ontario and Manitoba.

Historically wetlands were regarded as wastelands having little or no value, yet today they are recognized for their numerous ecological, hydrological and recreational values. Wetland losses, however, have occurred in southern 
Ontario since the time of settlement. By 1982 , approximately $68 \%$ of the wetlands in southern Ontario south of the Canadian Shield had been lost to urbanization and agricultural expansion (Snell, 1987). Changes in wetland water levels caused by urbanization can negatively influence wetland plants that are adapted to specific water depths. As the ecology of a wetland is disturbed this can have serious implications for the viability of the wetland itself (McBean et al., 1996). Conversion of wetlands to other land uses by drainage, dyking and infilling is typically irreversible. In addition to conversion for agriculture and urban development, wetland types such as bogs and fens, which accumulate peat, are often subject to intense peat extraction and subsequent drainage and conversion. Due to these increased pressures on wetlands, it has become necessary to develop protection policies, which have in turn initiated the development of evaluation systems such as the OWES to identify priority wetlands for protection.

\subsection{Classification of Wetland Composition}

Wetland mapping traditionally relied on extensive site investigations and analysis of aerial photographs. These methods typically introduce observer biases and can become extremely daunting tasks for large-area wetland studies. Field investigations are generally very expensive and access to wetland environments is often difficult due to uneven and unstable terrain, tall vegetation and deep water. 
Remote sensing offers the potential to provide spatially complete data coverage of wetlands at any scale. Image based methods are also more suited to temporal monitoring of wetlands than field based methods because such methods can be standardized, alleviating the subjectivity caused by differences between observers. Field based methods provide a horizontal perspective while remote sensing provides a vertical view with less spatial distortion and more detail in areas that would be far from the observer's position, such as water and vegetation hidden by taller vegetation. In addition, satellite images provide an effective visual archive of temporal change that is not easily obtainable from field assessment. Remote sensing technology is capable of detecting wetland extent, identifying wetland type and their associated resources, and identifying vegetation communities in a less intrusive manner than field surveys (Lyon and McCarthy, 1995). Thematic land-cover maps derived from satellite image classification techniques can aid in the analysis of spatial patterns and help identify wetland areas that are susceptible to developmental and agricultural pressures. Furthermore, land cover is an important determinant of species abundance and diversity, with different species relying upon different vegetation communities for cover and food (Griffiths et al., 1993).

The following subsections discuss the background to the data types and classification methods used in this research, as well as previous wetland classification studies. 


\subsubsection{Sensor Data Types}

Satellite system characteristics such as spectral sensitivity and viewing capability for moderate and high resolution sensors, and radar systems will be compared. Some of the sensors that have successfully been used for wetland mapping will be discussed.

\subsubsection{Moderate Resolution Sensors}

Satellite systems such as the Landsat Thematic Mapper (TM), Système pour l'Observation de la Terre (SPOT), and the Indian Remote Sensing Satellite (IRS) Linear Self-scanning sensor (LISS) operate in the optical portion of the spectrum and are considered to be moderate resolution satellites. These sensors are briefly summarized to provide context for the literature review on wetland mapping that follows.

Landsat TM has 7 spectral bands; blue $(0.45-0.52 \mu \mathrm{m})$, green $(0.52-0.60 \mu \mathrm{m})$, red

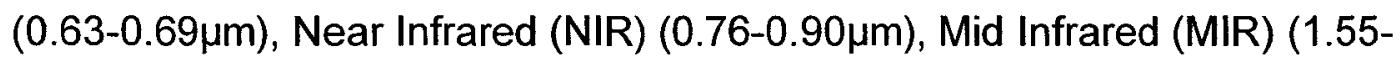
$1.75 \mu \mathrm{m})$, thermal $(10.4-12.5 \mu \mathrm{m})$ and MIR $(2.08-2.35 \mu \mathrm{m})$. The spatial resolution is $30 \mathrm{~m}$ for all bands except the thermal which is $120 \mathrm{~m}$. When Landsat TM imagery is used for wetland mapping bands 3 (red), 4 (NIR) and 5 (MIR) have been found to be the best combination for wetland detection. The MIR band is particularly important for discriminating between wetland types (Jensen et al., 1993). 
SPOT was the first earth observation satellite to have pointable off nadir viewing capabilities. This satellite has 3 high resolution visible (HRV) bands sensing in the green $(0.50-0.59 \mu \mathrm{m})$, red $(0.61-0.68 \mu \mathrm{m})$ and NIR $(0.79-0.89 \mu \mathrm{m})$ portions of the spectrum with $20 \mathrm{~m}$ spatial resolution. In addition, SPOT panchromatic (PAN) senses between $0.51-0.73 \mu \mathrm{m}$ and has a $10 \mathrm{~m}$ spatial resolution. SPOT-4 also has a MIR band $(1.58-1.75 \mu \mathrm{m})$ in addition to the other bands.

The IRS-1B LISS-II system has four multispectral bands spectrally similar to Landsat TM but with $72.5 \mathrm{~m}$ and $36.25 \mathrm{~m}$ spatial resolution.

When coarser resolution imagery is used to identify and delineate wetlands it has generally been found that the use of multi-temporal data produces higher accuracy but at greater cost (Ozesmi and Bauer, 2002; Ramsey and Laine, 1997; Lunetta and Balogh, 1999).

\subsubsection{High Resolution Sensors}

In recent years a number of commercial high resolution satellites, such as QuickBird and Ikonos, have been launched that provide spatial resolutions approaching those of aerial photography. High resolution satellite imagery has the ability to resolve greater detail such that smaller features on the ground are identifiable in an image. This may specifically benefit wetland monitoring applications, as spatial variations of vegetation species and structure as well as small irregular patterns of degradation may be detectable from high resolution 
imagery. Riparian wetlands are often narrow and linear in form and increased resolution could allow for greater attribute precision, so that smaller vegetation classes and wetland boundaries would be more easily detectable.

Ikonos and Quickbird each acquire multispectral imagery of approximately $4 \mathrm{~m}$ resolution in the blue $(0.45-0.52 \mu \mathrm{m})$, green $(0.52-0.60 \mu \mathrm{m})$, red $(0.63-0.69 \mu \mathrm{m})$ and NIR $(0.76-0.90 \mu \mathrm{m})$ portions of the spectrum, as well as panchromatic $(0.45-$ $0.90 \mu \mathrm{m}) 1 \mathrm{~m}$ resolution data. They also have off nadir viewing capabilities unlike most moderate resolution sensors. Despite the increased spatial resolution of these sensors, however, they lack spectral detail, not having MIR or thermal bands.

All of the above capabilities mentioned for moderate and high resolution sensors are also available in airborne hyperspectral remote sensing with smaller pixel sizes and greater numbers of bands. For example, the Compact Airborne Spectrographic Imager (CASI) is a sensor allowing for the number and width of spectral bands to be programmed with a minimum bandwidth of $2.6 \mathrm{~nm}$.

\subsubsection{Radar Systems}

Radar systems transmit and receive radiation in the microwave portion of the spectrum. They offer two advantages over optical sensors, including: 1) the ability to acquire data at any time of day and under cloudy conditions; 2) radar reflections or backscatter provide different information than optical data. For 
Radarsat-1, depending on the beam mode or image size, different spatial resolutions are achieved varying from $8 \mathrm{~m}$ to $100 \mathrm{~m}$ as the beam mode is varied from fine to ScanSAR wide. With higher resolution satellite radar such as Radarsat-2, or airborne radar, pixel size can be $3 \mathrm{~m}$ or less. Radar can detect wetness and roughness related to vegetation structure and standing trees in uniform wetland areas and can penetrate cloud cover (Kasischke and BourgeauChavez, 1997; Kushwaha et al., 2000; Austin et al., 2003; Sokol, 2003). It was, however, not considered further because the spatial resolutions of satellite radar are currently not fine enough for the highly detailed mapping requirements of this research, and presently airborne radar imagery is very expensive.

\subsubsection{Image Data Transformations used in Classification}

Besides spectral data produced directly by each of the sensors, data transformations are often used to produce additional or improved image information for classification. The following subsections discuss the background to transformations utilized in this research, including vegetation indices $(\mathrm{Vl})$, texture analysis and Principal Component Analysis (PCA).

\subsubsection{Vegetation Indices}

A vegetation index is typically a specific formulation of spectral bands that emphasizes the contrast between vegetation reflectance and reflectance of other land cover types in different parts of the spectrum. Most commonly, they have 
been derived from the red and near infrared due to the large contrast of vegetation with soil and water in these bands, although some indices include the blue, green or mid infrared.

This sub-section focuses on defining the vegetation indices that were used in this research which include: Ratio Vegetation Index (RVI), Normalized Difference Vegetation Index (NDVI), Transformed Vegetation Index (TVI), Differenced Vegetation Index (DVI), Soil Adjusted Vegetation Index (SAVI), Modified Soil Adjusted Vegetation Index (MSAVI), and Atmospheric and Soil Vegetation Index (ASVI). Many other indices have been developed and evaluated but these were deemed to be most relevant to this study.

The Ratio Vegetation Index (RVI), first proposed by Pearson and Miller (1972), was one of the first ratio-based indices and was developed with the intent of enhancing the contrast between bare ground and vegetation.

$$
R V I=\frac{R}{N I R}
$$

where, $R$ is the reflectance in the red channel and NIR is the reflectance in the near infrared channel.

NDVI was developed by Rouse (1973) and has become widely used because it is computationally simple and is less sensitive to various illumination effects, such as varying sun angle, slope and aspect (Lillesand and Kiefer, 2000). 
$N D V I=\frac{(N I R-R)}{(N I R+R)}$

Ratio-based indices such as RVI and NDVI utilize the characteristic response of vegetation in the red and near infrared portions of the spectrum, as shown by chlorophyll absorption of vegetation in the red and high reflectance by vegetation in the near infrared portions.

Perry and Lautenschlager (1984) proposed the formulation of the Transformed Vegetation Index $(\mathrm{TVl})$ to avoid the negative values resulting from the traditional NDVI calculation.

$T V I=\frac{(N D V I+0.5)}{[N D V I+0.5]} \sqrt{|N D V I+0.5|}$

where, NDVI is the normalized difference vegetation index.

The Differenced Vegetation Index (DVI) was developed by Clevers (1986) as $D V I=(N I R-R)$

NDVI has been found to be sensitive to variations in soil reflectance in canopies of less than $100 \%$ cover and to atmospheric variations, so modified indices have been proposed (Eastwood et al., 1997). Those used in this research include: the Soil Adjusted Vegetation Index (SAVI), the Modified Soil Adjusted Vegetation Index (MSAVI) and the Atmospheric and Soil Vegetation Index (ASVI). Bare soils and senescent vegetation have similar reflectance characteristics, so it was hypothesized that these indices, which were developed primarily for agriculture, 
might be useful for marsh wetlands where there are often large amounts of senescent vegetation and/or exposed soil between the foliage and stalks of the vegetation.

The Soil Adjusted Vegetation Index (SAVI) was developed by Heute (1988) and is defined as

$$
S A V I=\frac{(N I R-R)}{(N I R+R+L)}(1+L)
$$

where, $L$ is a soil adjustment factor. Huete (1988) found that $L=0.5$ minimized the effects of soil background reflectance the best.

Qi et al. (1994a) proposed the Modified Soil Adjusted Vegetation Index (MSAVI) to show that the adjustment factor $L$ is not a constant but a function that varies inversely with the amount of vegetation present (Bannari et al., 1995).

$$
M S A V I=\frac{2 N I R+1-\sqrt{(2 N I R+1)^{2}-8(N I R-R)}}{2}
$$

The Atmospheric and Soil Vegetation Index (ASVI) developed by Qi et al., (1994b) is a modification of MSAVI and accounts for atmospheric scattering effects by including the blue band in the formulation.

$$
A S V I=\frac{2 N I R+1-\sqrt{(2 N I R+1)^{2}-8(N I R-2 R+B)}}{2}
$$

where, $B$ is the reflectance in the blue channel. 


\subsubsection{Texture}

Tone and texture are important recognition elements, which are used in the process of image interpretation. Image tone can be described as the brightness at a given point, as represented by a pixel in digital imagery, or as the average brightness within a region. Texture is the spatial variation in brightness around a given point (Arzandeh and Wang, 2002; Avery and Berlin, 1992). It is often difficult to distinguish between a desired set of cover types based on pixel intensity or tone alone, therefore, texture measures can be calculated and used in the classification process.

Texture can be derived as a first order measure directly from the imagery (data variance in a region) or as a second order measure derived from some representation of pixel data variation. A popular second order data representation used to calculate texture is the grey level co-occurrence matrix (GLCM), a two dimensional matrix that tabulates the co-occurrence probability of pairs of grey-level pixels within a local window around a given pixel (Haralick et al., 1973). When a GLCM is generated, window size, inter-pixel angle, inter-pixel distance and quantization are factors that must be considered. Window size refers to the region of contiguous pixels within which the GLCM is computed. The selection of window size should be based on the size and adjacency of existing classes within the study area (Arzandeh and Wang, 2002). Smaller window sizes have been found to maximize information on local texture (Cosmopoulos and King, 2004), but larger window sizes provide a more stable 
co-occurrence matrix and better representation of the probability density function for grey level pairs due to the increased number of sample pairs. In addition, some texture measures can be computed from a grey level difference vector (GLDV), which is derived from the GLCM, by counting the absolute difference between reference and neighbour pixels.

Within the texture window, inter-pixel angle and inter-pixel distance, respectively, define the direction and distance between pixel pairs.

Quantization refers to the range of possible grey-level values to be considered within the window. The $\mathrm{PCl}$ implementation of GLCM texture sets the quantization level to 32 by default to reduce computational time.

From the co-occurrence matrix many texture measures can be derived. Commonly used GLCM texture measures that were applied in this research are Homogeneity, Contrast, Dissimilarity, Mean, Standard Deviation, Entropy, Angular Second Moment and Correlation. These are described below.

Homogeneity measures the degree to which pixels within the window have similar values. Larger values of homogeneity indicate uniformity between grey level pairs (Baraldi and Parmiggiani, 1995).

$$
\text { Homogeneity }=\sum_{i, j=0}^{N-1} \frac{P i j}{1+(i-j)^{2}}
$$


where, $\mathrm{i}$ and $\mathrm{j}$ are the grey levels of the two pixels, $\mathrm{Pij}$ is the probability of grey levels $\mathrm{i}$ and $\mathrm{j}$, and $\mathrm{N}$ is the total number of grey level pairs.

Entropy measures the disorganization of pairs of pixel values within the window, with high entropy values indicating greater disorder or heterogeneity (Baraldi and Parmiggiani, 1995).

$$
\text { Entropy }=\sum_{i, j=0}^{N-1} P i j(\log P i j)
$$

Angular Second Moment (A2M) also measures texture uniformity, or the regularity of common pixel pairs within the GLCM (Haralick et al., 1973). It is the opposite of entropy. Areas with homogeneous grey tones will have larger computed angular second moment values.

$$
A 2 M=\sum_{i, j=0}^{N-1}(P i j)^{2}
$$

The amount of local variation within an image is measured by Contrast (Haralick et al., 1973). Within a given window edges show larger local variation, therefore they have larger computed contrast values, as the digital number (DN) difference $(i-j)$ is squared.

$$
\text { Contrast }=\sum_{i, j=0}^{N-1} P i j(i-j)^{2}
$$


Dissimilarity is similar to contrast where high local variation results in high computed dissimilarity values, but it increases linearly with increasing differences in pixel values (Clausi, 2002).

$$
\text { Dissimilarity }=\sum_{i, j=0}^{N-1} P i j|i-j|
$$

Mean consists of both tone and texture information by incorporating the grey level value of each GLCM line into the calculation (Arzandeh and Wang, 2002).

$$
\text { Mean }=\sum_{i, j=0}^{N-1} P i j(i)
$$

Standard Deviation (STDEV) measures heterogeneity, based on the square root of the GLCM variance (Haralick et al., 1973). When grey level values differ from their mean, the variance increases (Arzandeh and Wang, 2003).

$$
S T D E V=\sqrt{\sum_{i, j=o}^{N-1} P i j\left(\mathrm{i}-\mu_{\mathrm{i}}\right)^{2}}
$$

Correlation measures the linear dependencies of adjacent pixel pairs within the GLCM window (Haralick et al., 1973). High correlation values denote linear structure and more varied grey tones (Baraldi and Parmiggiani, 1995).

$$
\text { Correlation }=\sum_{i, j=0}^{N-1} \frac{P i j\left(i-\mu_{i}\right)\left(j-\mu_{j}\right)}{\sqrt{\sigma_{i} \sigma_{j}}}
$$




\subsubsection{Principal Component Analysis}

The bands associated with multispectral data are often statistically correlated, which creates redundancy of information. PCA eliminates this redundancy by linearly transforming the data through rotation and translation to a set of axes or components that are orthogonal and uncorrelated (Lillesand and Kiefer, 2000; Gibson and Power, 2000). For multispectral image data, the first principal component (PC1) contains the largest percentage of the total scene variance and succeeding components each contain a decreasing percentage of the scene variance (Jensen, 1996). Often, it is found that most of the total data variance is represented by fewer numbers of components than the original variables. Data dimensionality and noise can be reduced if only the non-noise components are retained for analysis. Components are considered significant if either the eigenvalue is greater than 1 or the total scene variance of the component accounts for at least 70\% (Kaiser, 1960; Stevens, 1996). PCA can either be used as a visual enhancement technique or as a pre-processing procedure prior to image classification, in the latter case reducing computational processing time. For statistical classifiers, PCA provides a set of orthogonal variables that satisfy data independence requirements. In analysis, it is often seen that individual PCs represent specific gradients such as amounts of vegetation or moisture (Lillesand and Kiefer, 2000). 


\subsubsection{Wetland Vegetation Classification}

Classification is the process by which image pixels having similar spectral characteristics are identified and assigned to a unique land cover or land use class. Traditional image classifiers are categorized as either unsupervised or supervised.

\subsubsection{Unsupervised Classification}

Unsupervised classification assigns pixels to clusters having similar spectral values, commonly using a measure of the distance of each pixel from cluster means in an iterative process (Lillesand and Kiefer, 2000). The unsupervised classifier does not require training data. Once clusters are produced, the operator aggregates them and labels them as land cover classes.

\subsubsection{Supervised Classification}

Training data, which can be delineated as single pixel or polygon, are a fundamental element of the supervised classification process as they provide a description of the range and distribution of pixel values representing each land cover class of interest (Rees, 2001). The human operator defines training sites for each land cover class which can be a source of bias in the classification process. Image classification is performed by assigning each pixel to the class it most closely resembles, commonly using measures of statistical similarity such as probability or distance to class means, though many non-parametric 
classifiers have also been developed, including frequency based and neural network classifiers (Lillesand and Kiefer, 2000; Gibson and Power, 2000).

Maximum likelihood (ML) is the most commonly used supervised classification technique as it takes into account the data covariance and produces better results than either minimum distance to means or parallelepiped classifiers (Ozesmi and Bauer, 2002). ML classification evaluates both the means and variances of the training data to estimate the probability that a pixel is a member of a class. The pixel is then placed in the class with the highest probability of membership. An assumption of the classifier is that training data are normally distributed.

\subsubsection{Artificial Neural Networks}

In addition to the above classifiers that typically rely on parametric data assumptions, there are many non-parametric classifiers. Artificial neural networks (ANNs) are commonly used in remote sensing for classification purposes because they can analyse and accurately classify complex datasets and they do not assume that the data are normally distributed. A common type of neural network for classification purposes is the multilayer perceptron or feed forward back-propagation network (Rumelhart et al., 1986). A network has three types of layers: one or more input layers, one or more hidden layers and an output layer, where each layer is composed of a number of nodes. The input nodes contain the remote sensing data, such as the training data means in each 
band, and distribute the values they receive forward to nodes of the hidden layers. At each hidden layer node, the data are summed in a sigmoid function using assigned weights that are initially arbitrarily defined for each input. The result at a given node is passed to all nodes in a subsequent hidden layer, or if none exists, to the output layer. The hidden layers guide the network information flow, and as the number of hidden layers increases the network's ability to resolve complex patterns also increases (Skidmore et al., 1997). The nodes within the output layer correspond to desired output classes. The back propagation phase occurs when the error measure, calculated at the output nodes, is fed backward through the network to modify the weights of the connections in the previous layer in proportion to the error. This backward phase repeats iteratively until the total system error converges to a pre-defined level or further iterations do not produce any reduction in the error (Berberoglu et al., 2004; Augusteijn and Warrender, 1998).

\subsubsection{Accuracy Assessment of Classified Maps}

Classification accuracy is typically assessed using a standard error matrix, which expresses the number of sample pixels assigned to a particular category relative to the actual category as verified using field or some other reference data (Congalton, 1991). Three important measures are derived from an error matrix including producer, user and overall accuracies. Producer's accuracy indicates the probability of a reference pixel being correctly classified and is a measure of omission error. User's accuracy indicates the probability that a classified pixel 
actually represents that category on the ground and is a measure of commission error. Overall accuracy is calculated by dividing the total number of correct pixels (found along the diagonal) by the total number of pixels in the matrix. Another measure of classification accuracy is the Kappa $\left(K_{\text {hat }}\right)$ statistic (Rosenfield and Fitzpatrick-Lins, 1986). The $\mathrm{K}_{\text {hat }}$ statistic for the overall map is computed as:

$$
K_{h a t}=\frac{N \sum_{i=1}^{r} x_{i i}-\sum_{i=1}^{r}\left(x_{i+} x_{+i}\right)}{N^{2}-\sum_{i=1}^{r}\left(x_{i+} x_{+i}\right)}
$$

where, $r$ is the number of rows in the matrix, $x_{i j}$ is the number of observations in row $i$ and column $i, x_{i+}$ and $x_{+j}$ are the marginal totals for row $i$ and column $i$, respectively, and $N$ is the total number of observations. It indicates the agreement of map and reference data after accounting for chance agreement. The overall accuracy and $K_{\text {hat }}$ statistic may differ as the first measure only incorporates the major diagonal whereas as the second measure incorporates the non-diagonal row and column marginals (Jensen, 1996).

\subsubsection{Previous Wetland Classification Studies}

The following section will focus on wetland studies using different sensor types, vegetation indices, textures, PCA, unsupervised and supervised classifications, and neural networks. 
2.2.5.1 Previous Wetland Studies using Moderate Resolution Optical Imagery Optical imagery such as Landsat has been widely utilized to map foraging and nesting habitat for wetland birds (Hodgson et al., 1988; Luman, 1990; Herr and Queen, 1993); and to map wetlands for conservation purposes (Green et al., 1998; Rogers and Kearney, 2003; Berberoglu et al., 2004).

Multidate Landsat TM data from May 1984 and April 1985 were used by Hodgson et al. (1988) to map foraging habitat for Wood Stork (Mycteria Americana). A tasseled cap transformation was applied to the data to reduce dimensionality to measures of brightness, greenness, and wetness (Kauth and Thomas, 1976; Crist and Cicone, 1984). An unsupervised classification of 7 classes was conducted, including: deep water, shallow water, macrophytes (marsh), cypress/mixed wetland, bottomland/hardwood, pine/mixed uplands and agriculture/clearings, where shallow water and macrophytes were considered as foraging cover. Overall classification accuracies for the 1984 and 1985 datasets were $74 \%$ and $88 \%$, respectively. Shallow water and marsh environments were found to be detectable with TM data.

Herr and Queen (1993) classified Landsat TM imagery to produce a map of vegetation communities important for nesting of greater Sandhill cranes (Grus Canadensis tabida). Nine land cover classes (emergent wetland, sedge fen, shrub fen, shrub swamp, deciduous forest, coniferous forest, agriculture, disturbed grass and water) were used producing an overall accuracy of $81 \%$. 
Accuracies for some of the wetland classes were low, including $62 \%$ for shrub fen and $61 \%$ for shrub swamp. However, a broad level classification of emergent wetland and sedge fen was successful with class accuracies of $100 \%$ and $94 \%$, respectively.

Rogers and Kearney (2003) have stated that Landsat TM imagery is the most widely used image source for conventional satellite sensor-based studies on wetlands. The spatial resolution of Landsat imagery for detecting wetland loss is, however, insufficient as mixed pixels occur at wetland edges and where small wetland features are present, and characterization of landscape heterogeneity is difficult. Spectral mixture modelling, which is a technique that addresses the problems associated with pixels of mixed cover types, was attempted and was successful at separating water from non-water, where an increase in water coverage would denote a decrease in marsh. Separation of vegetation and soil was not analysed.

Ozesmi and Bauer (2002) have stated that detailed changes in wetland extent and form are not readily detectable from TM imagery. With coarser resolution imagery it is also difficult to spectrally separate different wetland types and identify small or long narrow wetlands. Jensen et al. (1986) compared Landsat and airborne MSS data with $3 \mathrm{~m}$ pixels to classify wetland vegetation and found that detailed wetland vegetation maps were produced using high resolution 
airborne MSS data, whereas a regional wetland map could be achieved from Landsat MSS data.

\subsubsection{Wetland Studies using High Resolution Imagery}

Detailed wetland mapping has been conducted using high resolution airborne and satellite data.

Jensen et al. (1984) used high resolution airborne multispectral scanner (MSS) data with $2.8 \mathrm{~m}$ pixels to map non-tidal wetland vegetation. Four spectral bands representing the green/yellow $(0.55-0.60 \mu \mathrm{m})$, red $(0.65-0.70 \mu \mathrm{m})$, and near infrared $(0.70-0.79 \mu \mathrm{m}$ and $0.92-1.10 \mu \mathrm{m})$ portions of the spectrum were selected and used in a supervised classification of 6 classes using the minimum distance algorithm. The overall classification accuracy was $83.5 \%$ and individual class accuracies exceeded $70 \%$ in all cases. Classes that were spectrally similar included persistent emergent, non-persistent emergent, scrub/shrub and mixed deciduous forest.

Green et al. (1998) compared Landsat TM, SPOT XS and CASI (eight spectral bands with $1 \mathrm{~m}$ spatial resolution) airborne data for mapping mangrove and nonmangrove vegetation using several methods: visual interpretation, unsupervised classification of the raw data, supervised maximum likelihood classification of the raw data and, classification of band ratios and principal components.

Discrimination between mangrove and non-mangrove vegetation over a large 
area was best using the PCA/band ratio classification of Landsat TM data, producing an overall accuracy of $92 \%$. For detailed mangrove mapping, the CASI PCA/band ratio method produced the best overall accuracy of $85 \%$. Multi-date (September 1998 and September 2000) CASI imagery was used by Thomson et al. (2004) to classify intertidal salt marsh areas in The Netherlands and assess the reliability of detecting change. Data were recorded in fourteen spectral bands in the visible and near infrared portions of the spectrum with a spatial resolution of $2.5 \mathrm{~m}$. A maximum likelihood classifier was used with 15 classes. They found that the classified maps showed the actual spatial heterogeneity of the vegetation communities within the salt marsh areas. The overall classification accuracies for the 1998 and 2000 data were $75.8 \%$ and $60.6 \%$. Spectral overlap tended to occur between adjacent marsh classes and between classes associated within the tidal shore gradient.

Dechka et al. (2002) used multi-date, May and July 2000, Ikonos panchromatic (1m pixels) and multispectral ( $4 \mathrm{~m}$ pixels) imagery to gain an understanding of the spectral separability of wetland and upland classes in finer resolution data. Combinations of multispectral bands were fused with the panchromatic image to achieve higher resolution datasets of $1 \mathrm{~m} \times 1 \mathrm{~m}$ pixel size. A broad level classification of nine classes produced an overall classification accuracy of $47 \%$. Classes were then defined according to the dominant vegetation communities. Fused data from the month of May produced the worst result while July fused data produced accuracies in the $80 \%$ range. The best results were obtained 
from a multi-temporal combination of May and July plus textures, although the added cost of acquiring multi-temporal imagery could not be justified by classification accuracy increases of less than $10 \%$.

Pan sharpened multispectral Ikonos imagery was used by Olmanson et al. (2002) to map aquatic vegetation. The data were stratified into submerged and emergent categories and 2 separate unsupervised classifications were conducted. This preliminary study identified that Ikonos imagery could be used to successfully identify 3 classes of emergent vegetation and 4 classes of submerged vegetation.

\subsubsection{Use of Vegetation Indices in Image Classification}

Few studies were found that used vegetation indices in wetland classification, and of those, NDVI was the only index which was used.

Multispectral SPOT data were used by Lee et al. (1992) to map coastal wetlands in northeastern Florida. NDVI and the first two PCs were used in a maximum likelihood classification. From visual comparison of these transformations to the raw band SPOT data, NDVI appeared to best distinguish marsh types while the PCs appeared to differentiate upland classes, such as sand dunes and developed areas. For 10 classes, the overall classification accuracy was $87.8 \%$. 
Hunter and Power (2002) used CASI imagery recorded in fifteen spectral bands ranging from the blue to near infrared and having a pixel size of $1 \mathrm{~m}$ for classifying intertidal habitat in two marshes. Ten different bandsets were used including combinations of spectral bands, principal components (PCs) and NDVI in maximum likelihood and spectral angle mapper classifications. Spectral angle mapper is a classification technique specifically designed for hyperspectral data where the proportion of each class is determined by the angle between the vectors representing the pixel and the mean of each training class. Twelve classes were used, though several of the classes were specifically unique to each marsh area. The highest overall accuracy, $66 \%$ and $52 \%$ for the two marshes, resulted from a maximum likelihood classification using $\mathrm{PC} 2, \mathrm{PC} 3, \mathrm{PC} 4$ and NDVI, where the VI specifically increased classification accuracy. Though overall accuracy was low, they concluded that several intertidal marsh classes could be well discriminated, such as sea couch and marsh herbs, reed, bare ground, mud and water.

\subsubsection{Use of Texture in Image Classification}

The following papers were reviewed to determine if texture measures improved wetland classification accuracy.

Arzandeh and Wang (2002) used single date Radarsat imagery with $8 \mathrm{~m}$ spatial resolution and evaluated the effects of varying inter-pixel distance, inter-pixel angle and window size for texture extraction on wetland classification for a 
southern Ontario marsh site. For comparative purposes they also used a resampled Landsat TM image (bands 3,4 and 5) with $12.5 \mathrm{~m}$ pixels. They found that a combination of Mean, Contrast, Standard Deviation and Angular Second Moment textures using an inter-pixel distance of 2 with a directionally invariant inter-pixel angle, and a $17 \times 17$ window significantly improved the Radarsat classification accuracy from $71 \%$ to $88 \%$ for a two class classification of wetland and non-wetland. The best result was, however, obtained from classification of the Landsat image with an overall accuracy of $97 \%$.

Franklin and Peddle (1990) used multispectral SPOT HRV imagery and compared classification accuracies for seven classes derived from spectral data alone, entropy and homogeneity textural data alone (21x21 window size), and spectral bands combined with entropy of band 2 in the right diagonal orientation and homogeneity of band 3 in the left diagonal orientation. They found that spectral bands combined with texture produced classification accuracies of $86.7 \%$ compared to $51.1 \%$ for spectral data alone and $48.9 \%$ for textural data alone. The general trend was that homogeneous classes were accurately classified using spectral data alone whereas the use of texture increased classification accuracies for classes with spectral variability, particularly organic terrain. 


\subsubsection{Use of Principal Components in Image Classification}

Due to the statistical redundancy of information contained in multi spectral image bands PCA is often performed and principal components (PCs) showing the largest percentage of total scene variance are subsequently used in classification.

Multitemporal Landsat TM imagery and colour infrared aerial photography were evaluated by Gluck et al. (1996) for wetland mapping in northwestern Ontario. Initial unsupervised image classification was performed on 8 channels, representing the green, red, near infrared and middle infrared bands for early spring and summer TM imagery combined, which resulted in confusion of wetlands with cutovers. PCA was then conducted using all four bands from the summer imagery in combination with the spring mid-infrared band. The first three PCs were used in further classification with the first accounting for $92.54 \%$ of the variance and indicating vegetation difference. The second corresponded to moisture differences and represented $4.9 \%$ of the variance whereas the third PC accounted for only $2.17 \%$ of the variance, but proved important for distinguishing wetlands from uplands. This classification produced 250 clusters that were aggregated into 40 classes and then reduced further to represent 11 wetland classes. Using only Landsat TM imagery in the classification procedure produced confusion between gramminoid wetland classes and cutovers and burns. Wetland areas were masked and further classifications were run on just 
the wetland areas producing an overall accuracy of $72 \%$. When spectrally similar wetland classes were combined, overall classification accuracy improved to $81 \%$.

\subsubsection{Studies using Unsupervised Classification}

Landsat MSS with $79 \mathrm{~m}$ pixels in the visible and NIR, and TM imagery with $30 \mathrm{~m}$ pixels in the visible to the mid IR, acquired in mid July, were compared by Ackleson and Klemas (1987) for mapping varying densities of submerged aquatic vegetation (SAV). Land and water areas deeper than $1.9 \mathrm{~m}$ were masked within the unsupervised classifications of both data sources, which reduced the confusion of SAV and deep water. They concluded that TM imagery with its increased radiometric sensitivity, and greater spectral and spatial resolution did not significantly produce higher class confidence for varying SAV densities than MSS data.

IRS multispectral data with $36.5 \mathrm{~m}$ pixels was used by Kindscher et al. (1998) to create a map of non-forested vegetation used for subsequent field sampling. Three visible bands and one NIR band were used to produce 50 clusters that were subsequently aggregated into six wetland meadow types, representing a wet to dry gradient. From field surveys it was concluded that $70 \%$ of the areas identified as the two wettest meadow types were dominated by wetland vegetation. 


\subsubsection{Studies using Supervised Classification}

Arzandeh and Wang (2003) compared multidate Landsat TM (30 m pixels), and single date SPOT (20 m pixels) and Indian Remote Sensing Satellite IRS (23 m pixels) data to monitor Phragmites growth and cattail loss. Spectral bands and a combination of spectral-textural bands were used as the inputs for a supervised maximum likelihood classification with seven classes: cattail marsh, phragmites, tall-grass prairie, upland forest, swamp, water and others (agriculture and built-up areas). Higher overall and class accuracies for all image data were produced with the inclusion of texture information, especially for the Phragmites class. Classification accuracy was also affected by the presence or absence of the midinfrared TM band, which aids in the detection of wetland vegetation, though the acquisition date proved to be more important than the inclusion of the mid infrared band. Landsat TM imagery acquired in mid July produced slightly higher overall accuracy of $89.1 \%$, compared to Landsat TM and IRS data acquired in late spring, both with accuracies of $87.6 \%$. SPOT imagery acquired in late summer produced the lowest overall accuracy of $82.4 \%$. Phenological differences were apparent from the different acquisition dates with mid summer maturity of wetland emergent plants versus young crops in agricultural fields being particularly important for differentiating between wetland classes and agriculture.

Wang et al. (1998) evaluated the use of single-date versus multi-date radar data from the European Remote Sensing Satellite (ERS-1) with range and azimuth 
resolutions of $26 \mathrm{~m}$ and $28 \mathrm{~m}$, and Landsat TM imagery to detect and classify wetlands in southern Ontario. Maximum likelihood classification of cattail marsh, Phragmites marsh, swamp, forest, urban, agriculture and water found that single date March ERS-1 data achieved an accuracy of only $68 \%$. Multi-date ERS-1 data using four and five month combinations improved overall accuracy to over $80 \%$. Four and five month combinations produced overall accuracies of $83.3 \%$ and $85.3 \%$, respectively. Landsat classification using bands 3,4 and 5 acquired in June and August produced overall accuracies of $97 \%$ and $92.9 \%$, respectively.

\subsubsection{Studies using Neural Networks}

In remote sensing ANNs have been used for numerous studies including forest mapping and modelling (Boyd et al., 2002; Skidmore et al., 1997; Jensen et al., 1999), geological mapping (An and Chung, 1994), lithologic classification (Yang et al., 1998), cloud classification (Lewis at el., 1997) and ecological modelling (Lek and Guegan, 1999).

Augusteijn and Warrender (1998) compared Airborne Imaging Radar Synthetic Aperture Radar (AIRSAR) with resampled range and azimuth pixel sizes of $9 \mathrm{~m}$ and Airborne Terrestrial Applications Sensor (ATLAS) data consisting of 3 visible bands, 2 NIR bands and 6 thermal infrared (TIR) bands with a resampled spatial resolution of $9 \mathrm{~m}$. They used a feed forward ANN to distinguish the boundary between upland and wetland and varying degrees of wetness related to the wetland area. They found that the best classification accuracy was produced by 
combining radar and visible/NIR data for a three category classification of most wet, least wet and upland with a training accuracy of $93.7 \%$ and an average test accuracy of $87.3 \%$.

Landsat TM imagery ( 6 bands excluding thermal) was used by Berberoglu et al. (2004) to map Eastern Mediterranean coastal wetlands of Turkey. Eight broad level classes (dune vegetation, wetland vegetation, bulrush, agriculture, forest, sand, salty plain and water) were used to compare maximum likelihood (ML) and ANN classification. The ANN classification had the best overall accuracy of $90.2 \%$ compared to $76.0 \%$ for the ML classifier, and it produced less confusion between the water and wetland classes. The ANN was also found to be better capable of delineating classes of high heterogeneity and spectral complexity. From the above literature, acquisition date was found to be most important for discriminating wetland vegetation with mid summer imagery being best. However, multi-date imagery has typically been found to be better but at increased expense. Optical imagery was found to be generally superior to radar, with high resolution imagery being most capable of mapping detailed wetland classes. The use of texture and PCs in classification has shown a general increase in overall and class accuracies.

\subsection{Biomass and Cover Modelling}

Biomass is generally defined as above ground or below ground living matter, though it can also include the dead litter found within the soil. Traditional field 
measurement techniques, such as biomass harvesting, are considered fundamental in the development and validation of biomass estimation models. Harvesting of above ground plant matter is, however, extremely time consuming and labour intensive as well as difficult to conduct in remote and large areas. Using approaches such as multiple regression analysis remotely sensed data can be used to estimate above ground biomass (AGB) (Lu, 2006).

Though remote sensing has traditionally been used as a tool for land use and land cover mapping, it is increasingly being used for modelling and mapping of biophysical information associated with vegetation structure, such as percent cover, productivity, biomass production and leaf area index. Most models are empirically based using statistical regression of image derived variables, such as raw spectral bands, vegetation indices, textures and principal components, against a given wetland structure variable.

\subsubsection{Forward Stepwise Regression}

For this research forward stepwise regression was used, entering regression starts with no variables in the model and then adds independent variables based on the contribution to prediction they add to the regression model, and as long as they meet the statistical criteria for entry. Independent variables can be dropped from the model if their predictive ability drops to an insignificant level when another independent variable is added (Hair et al., 1998; Tabachnick and Fidell, 1989). 


\subsubsection{Assessment of Model Quality and Predictive Accuracy}

Evaluating the performance of the regression model and assessing the accuracy of the estimated results is a critical step in the modelling procedure. When using multiple regression analysis, evaluating model performance is based on evaluating the following measures: $R^{2}$, the adjusted coefficient of determination $\left(R_{a d j}^{2}\right), R^{2}$ change, standard error of the estimate $(S e)$ and significance $(p)$. The coefficient of determination $\left(R^{2}\right)$ is a measure of the proportion of the variance of the dependent variable about its mean explained by the independent or predictor variable. $R^{2}$ varies between 0 and 1 , where a higher value suggests a better prediction of the dependent variable. As the number of independent variables entered into the model increases, $R^{2}$ also increases.

The adjusted coefficient of determination $\left(R_{a d j}^{2}\right)$ is a modified measure of $R^{2}$ and takes into account the number of independent variables included and the sample size. Despite the addition of more independent variables the $\left(R_{a d j}^{2}\right)$ may decrease if the added independent variables have little explanatory power or if the degrees of freedom becomes too small (Hair et al., 1998).

$R^{2}$ change shows the individual contributions of each independent variable in multiple variable models. If the $R^{2}$ change associated with a variable is large, this indicates that the variable is a good predictor of the dependent variable. 
The standard error of the estimate $(\mathrm{Se})$ is a measure of the variation in the sum of squared residuals between the observed and predicted values. If the independent variable(s) were perfect predictors of the dependent variable $R^{2}=1$ then $S e=0$.

Significance $(p)$ given by SPSS indicates the significance of each predictor at each step of the regression. According to Stevens (1996), if a large number of predictor variables $(>30)$ is used in the regression, this introduces a bias in the $p$ value. These values should only be used as a rough guideline to the usefulness of the predictors entered into the model.

A separate randomly selected validation dataset should be used to assess model predictive accuracy. In this research, the following three measures are calculated to indicate model error: mean error, absolute mean error and Root Mean Square Error (RMSE). Model validation can be done many times with random sampling to derive separate validation datasets, a technique referred to as bootstrapping.

The mean error should be close to 0 and is a measure of model accuracy where values greater or less than 0 indicate a positive or negative bias in the model. It is calculated from the mean difference between predicted and referenced samples. 
The mean absolute error indicates an overall magnitude of error and is calculated from the mean of the absolute differences between predicted and referenced samples.

RMSE is the measure of magnitude of difference between the predicted and actual values for all validation samples. A high $R^{2}$ value or more importantly a low RMSE value indicates a good fit between the developed model and the field plot or validation data (Lu, 2006). The RMSE is more sensitive to extreme values than the mean absolute error (Hardisky et al., 1984).

$R M S E={\sqrt{\sum_{i=1}^{i} \frac{\left(\hat{y_{i}}-y_{\text {ref }}\right)}{n}}}^{2}$

where, $\hat{y}_{i}$ and $y_{\text {ref }}$ are the predicted and reference values respectively, and $n$ indicates the number of samples.

\subsubsection{Previous Biomass and Cover Modelling Studies}

This section focuses on specific studies that have used spectral data, vegetation indices and textures for estimating or predicting wetland biomass and vegetation cover. From a review of the literature it was found that fewer publications exist for wetland biomass and cover modelling than for wetland classification. 


\subsubsection{Use of Vegetation Indices in Biomass and Cover Modelling}

Ratio-based indices such as RVI and NDVI which utilize the characteristic response of vegetation in the red and near infrared portions of the spectrum have been found to be well correlated with above ground biomass (Hardisky et al., 1984; Anderson et al., 1993) and vegetation cover (Purevdorj et al., 1998; Lawrence and Ripple, 1998). While ratio-based VIs have been found useful for cover and biomass modelling, modified indices are also commonly used as they account for variations in reflectance.

Hardisky et al. (1984) compared simulated Landsat TM bands 3,4 and 5 to biomass estimates obtained from vegetation harvesting. NDVI was found to be a better predictor of biomass than a mid infrared index that used a similar formulation to NDVI but with Band 5 substituted for the red band.

Multidate Landsat TM imagery (August 1989, June 1990 and September 1990) was used by Anderson et al. (1993) to compare three vegetation indices: DVI, $\mathrm{RVI}$, and NDVI in prediction of dried green vegetation biomass for grasses and forbs in an area of shortgrass prairie. Univariate models were used to evaluate the relationships between clipped dried green biomass and three data combinations including; a $3 \times 3$ window average for each vegetation index, an unsupervised spectral classification approach, and a greenness class comparison. Dried green biomass was found to be highly correlated with NDVI 
when the data were combined into greenness classes with $R^{2}=0.95$ for August and September and $R^{2}=0.71$ for June.

TAN et al. (2003) used Landsat Enhanced Thematic Mapper $(E T M+)$ data and compared NDVI, DVI and the Green Vegetation Index (GVI) as predictors of wetland biomass. They found that DVI showed the strongest correlation with biomass $\left(R^{2}=0.85\right)$ and the subsequent linear regression model was used to estimate total biomass for the Poyang wetland in China.

Eastwood et al. (1997) compared NDVI, MSAVI, ASVI, the Atmospherically Resistant Vegetation Index (ARVI), and the Global Environmental Monitoring Index (GEMI) (the latter two as defined in the paper) for mapping salt-marsh vegetation cover. They found that all indices showed strong linear relations with measured fractional cover of pioneer salt marsh species. However, MSAVI and GEMI showed the strongest relations with fractional vegetation cover for the same species with $R^{2}=0.97$ and $R^{2}=0.95$, respectively.

Lawrence and Ripple (1998) used Landsat TM data and compared ratio-based vegetation indices, including RVI, NDVI, SAVI, Transformed Soil Adjusted Vegetation Index (TSAVI) and MSAVI to the GVI, which is a band combination derived from a PCA type of orthogonalization process for prediction of vegetation cover. Multiple regressions showed that NDVI had the highest correlation with 
vegetation cover $\left(R^{2}=0.70\right)$ using a fourth order polynomial, followed by TSAVI $\left(R^{2}=0.65\right)$ using a third-degree polynomial.

Purevdorj et al. (1998) used simulated Advanced Very High Resolution Radiometer (AVHRR) data and compared four ratio-based vegetation indices; NDVI, SAVI, MSAVI, and the TSAVI using a second order polynomial regression equation to develop a relation with percent grass cover. TSAVI differs from SAVI and MSAVI as it uses an empirical soil reflectance line and intercept coefficients. It was the best predictor of vegetation cover when soil line information was available, whereas NDVI was the best predictor when the soil coefficients were unknown.

\subsubsection{Use of Texture in Biomass Modelling}

Image textures combined with spectral data have also been found to be useful in above ground biomass estimation. Lu (2005) demonstrated that texture was critical for estimating mature forest biomass, whereas spectral signatures were important for biomass estimation of successional forest. When texture and spectral data were combined, however, the performance of the models improved.

\subsubsection{Use of Principal Components in Biomass Modelling}

Often, from a set of input spectral bands in the visible and infrared, one or two principal components will show vegetation gradients. For example, Zhang (1998) 
found that the first two principal components, derived from Landsat bands 1-4, were highly correlated with submerged vegetation biomass.

From the biomass literature, DVI and NDVI were found to be the best predictors of wetland biomass, whereas MSAVI and NDVI had the highest correlations with vegetation cover. Textures and spectral data were also found to be important for biomass modelling.

In designing the methods for this research, as described in the following chapter, the classification and biomass literature was consulted. For the classification component it was deemed important to use high resolution imagery acquired in mid summer to best discriminate between wetland vegetation and allow for detailed wetland mapping. Textures and PCs were used in classification as they have been shown to increase classification accuracy. For the biomass component seven vegetation indices were selected from the literature, and used in combination with the spectral bands and textures as the independent variables in forward stepwise regression. 


\section{Chapter Three: Methods}

\subsection{Study Area}

The study area for this research (Figure 6) encompasses $101 \mathrm{~km}^{2}$ focusing on three riparian wetlands located along the Rideau River: Barbers Creek marsh, Irish Creek marsh and Kilmarnock marsh. These wetlands are located in the township of Wolford, county of Leeds/Grenville, and are accessible by water and roadway. All are single contiguous riverine wetland areas and have been evaluated by the Ontario Ministry of Natural Resources (OMNR) for potential wetland significance. Barbers Creek marsh and Irish Creek marsh have been assigned provincial significance status and hence provincial protection. All three wetlands also have peripheral or surrounding unevaluated wetland.

Barbers Creek marsh is approximately 188 hectares in size and was evaluated by the OMNR in 1988. It received provincial significance status because it is a regionally significant waterfowl staging area and a locally significant waterfowl production area being an important nesting and feeding area for colonial waterbirds or localized species populations, such as the Great Blue Heron (Ardea herodias). It was comprised of approximately $94 \%$ marsh and $6 \%$ swamp, surrounded by row crop agriculture, pasture, abandoned land, deciduous forest, urban or cottage development and open water. As of 1988 human disturbance was absent from this wetland. 
Irish Creek was first evaluated in 1982 and re-evaluated in 1984. The wetland was found to be a regionally significant waterfowl staging area and an important spawning ground for Northern Pike (Esox lucius) and was therefore given provincial significance. The OMNR has also observed provincial species at risk, such as the Least Bittern (/xobrychus exilis), utilizing the wetland. The wetland was approximated to be 91 hectares in size and categorized as marsh type with areas of predominantly deep water. Active and abandoned agriculture as well as deciduous forest surround this wetland. Localized human disturbance was occurring in 1982 primarily due to agricultural activity and an active boat launch within the wetland.

Kilmarnock marsh was evaluated in 1983 and estimated to be 113 hectares. The wetland was not given provincial significance because the evaluation score did not meet the criteria. Kilmarnock marsh was, however, identified as an important waterfowl staging area. The wetland is predominantly marsh with approximately $20 \%$ swamp. The surrounding land is utilized as active row crop agriculture and pasture interspersed with deciduous forest and open water areas. In 1984, the OMNR identified localized disturbance to the wetland from roads and river channelization. 


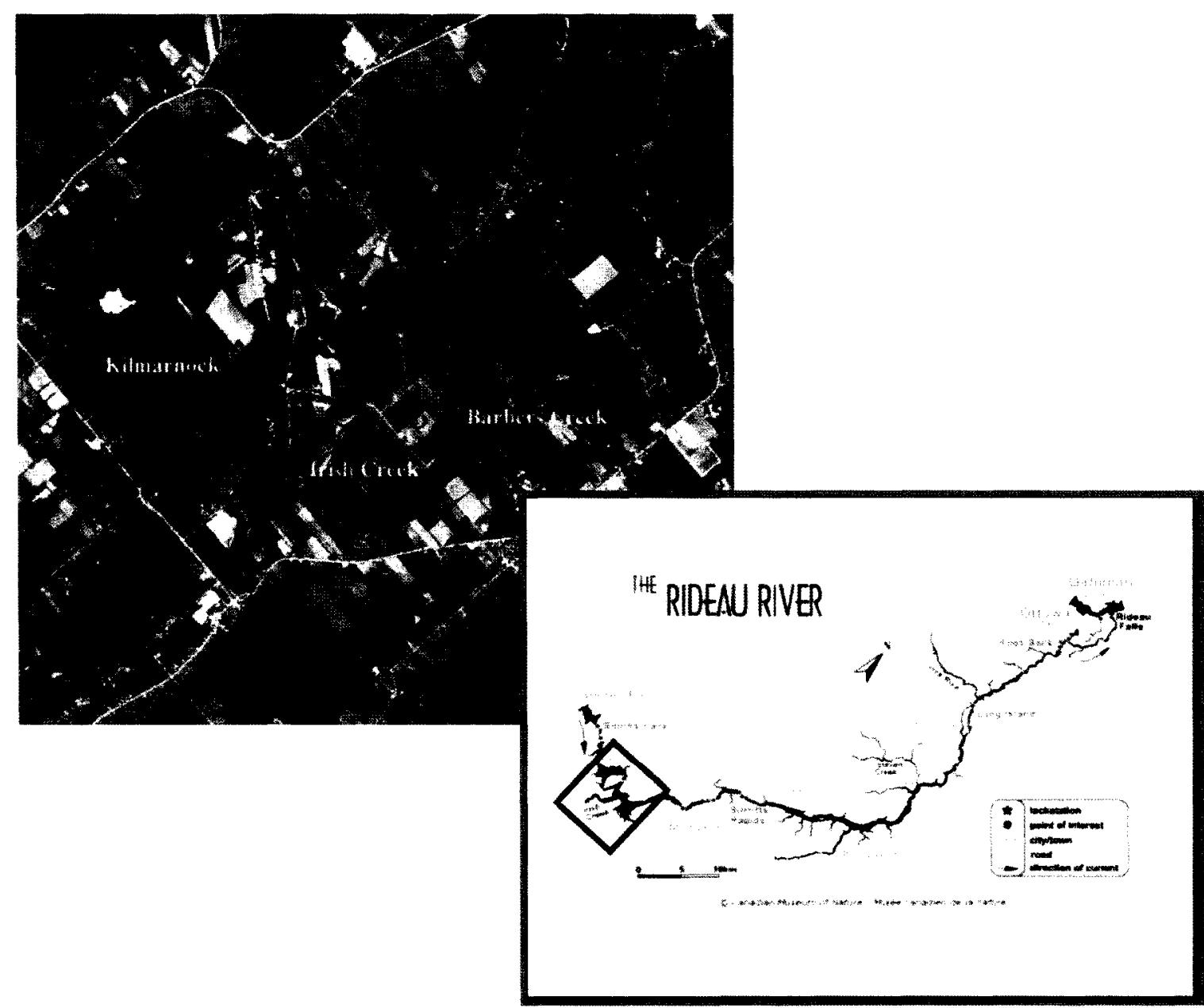

Figure 6. Study Area:

Ikonos image (Aug, 2003) on left shows Kilmarnock, Irish Creek and Barber's Creek marshes delineated. Detailed map of the Rideau River (Museum of Nature, (2006) www.nature.ca/rideau/a/a1-e.html), on right shows location of marshes outlined in red along the Rideau River system.

\subsection{Selection of Field Plots and Field Sampling Methods}

Field data were collected in August 2003 during the time of peak productivity.

\subsubsection{Field Sampling for Image Classification of Wetlands}

For classification of wetland composition, 107 locations were selected based on

the following criteria. A minimum distance of $200 \mathrm{~m}$ between field plots was used 
to minimize spatial autocorrelation when using the data as samples in statistical analyses. This separation distance was selected conservatively because actual spatial autocorrelation was not known. Within Kilmarnock marsh and Irish Creek marsh plots were stationed approximately 200 metres apart, but due to the extensive size of Barbers Creek marsh, plots were situated about 500 metres apart. Where possible the plots were placed in areas that had homogeneous species composition and structure, which was visually assessed, within an area of approximately 12 metres by 12 metres or equivalent to $3 \times 3$ lkonos multispectral pixels. Due to the narrow linear nature of Irish creek marsh, plots were representative of at least a 4 metre by 4 metre homogeneous area. All plots were placed on public land and were accessible by water such that a GPS and a digital camera could be safely transported to each field plot. During the selection process it was important to represent the full range of vegetation cover found within each of the wetlands and to achieve enough sample locations for each class to separately conduct training for classification and validation. Difference in percent cover of vegetation was also considered important during the selection process as it was hoped that it would be a potential indicator of biomass. The spatial coordinates of each location were recorded using a real time differential GPS with accuracy of better than $1 \mathrm{~m}$. At each location, the vegetation within the $4 \mathrm{~m} \times 4 \mathrm{~m}$ surrounding area was identified, photographed and classified as one of: Emergent Terrestrial, Shrub, Grasses/Sedges, Floating Aquatic, Emergent Aquatic, and Forest. An Open Water class was also included. These vegetation classes are an abbreviated version of those used by the 
OMNR for evaluating wetlands. Figures $7 \mathrm{a}$ to $10 \mathrm{~b}$ are example photographs of these classes, excluding open water, and how they appeared on the ground. As shown in Figures $7 \mathrm{a}$ and $7 \mathrm{~b}$ the dominant emergent terrestrial vegetation found within the wetlands was Common cattail (Typha latifolia). Purple loosestrife (Lythrum salicaria), Spotted Joe-Pye Weed (Eupatorium maculatum), Swamp Milkweed (Asclepias incarnata) and Meadow Horsetail (Equisetum pratense) were also prevalent terrestrial emergent's. Speckled Alder (Alnus incana) and Slender Willow (Salix petiolaris), seen in Figures 8a and 8b, as well as Sweet Gale (Myrica gale) and Red Osier Dogwood (Cornus stolonifera) were the dominant shrubs found. Figure 9a shows Common Reed (Phragmites australis) which was the most prevalent emergent aquatic found, although Stiff Arrowhead (Sagittaria rigida), Pickerelweed (Pontederia cordata), and Large-Fruited Burreed (Sparganium eurycarpum) were also seen. The floating vegetation that was identified included Yellow Pond Lily (Nuphar variegatum), Fragrant White Water Lily (Nymphaea odorata) seen in Figure 9b, and Floating-Leaved Pondweed (Potamogeton natans). Figure 10a shows a typical grasses/sedges plot with narrow leaved plants, though grasses were not identified at the species level due to difficulty distinguishing between them. Sedge species which were identified included Cyperus-like sedge (Carex pseudo-cyperus) and Green Sedge (Carex viridula) which each have unique flower clusters. Black Ash (Fraxinus nigra) was the dominant tree cover though Sugar Maple (Acer saccharum), which is an upland species, was also seen (Figure 10b). The peripheral forest surrounding the wetlands was, however, not extensively investigated. 


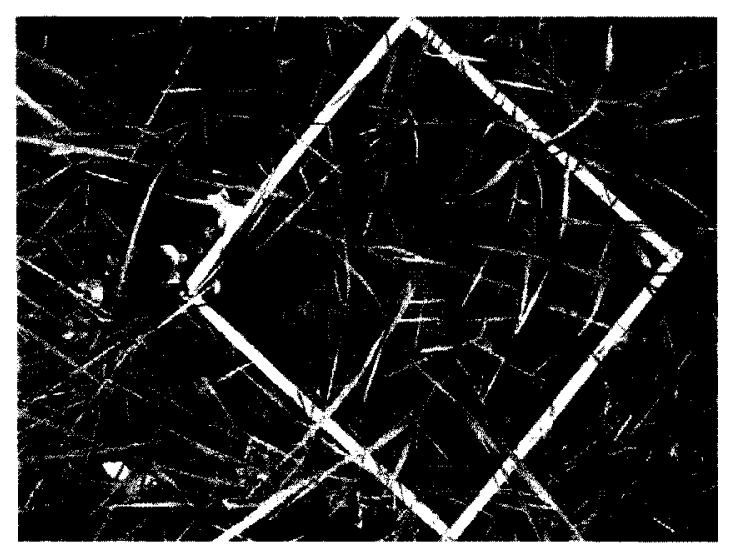

(a) Emergent terrestrial plot: KilB14. Common Cattail (Typha latifolia), Purple Loosestrife (Lythrum salicaria), Sweet Gale (Myrica gale), and ferns.

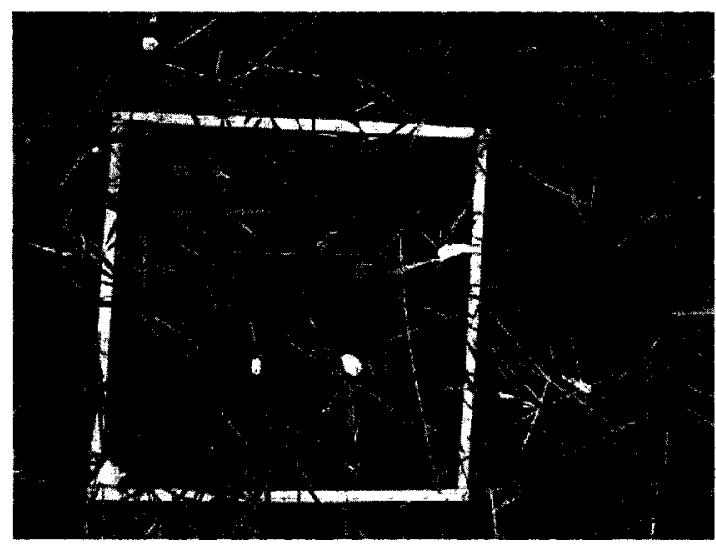

(b) Emergent terrestrial plot: KilB12. Common Cattail (Typha latifolia).

Figure 7. Emergent terrestrial vegetation.

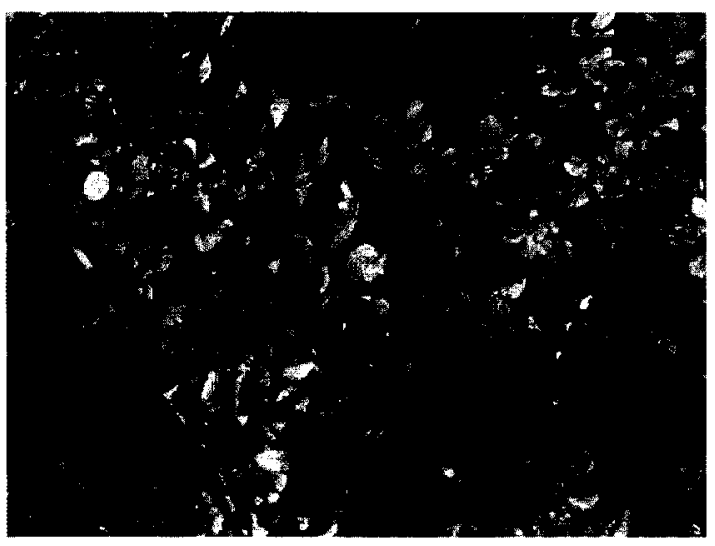

(a) Shrub plot: KilA3.

Speckled Alder (Alnus incana).

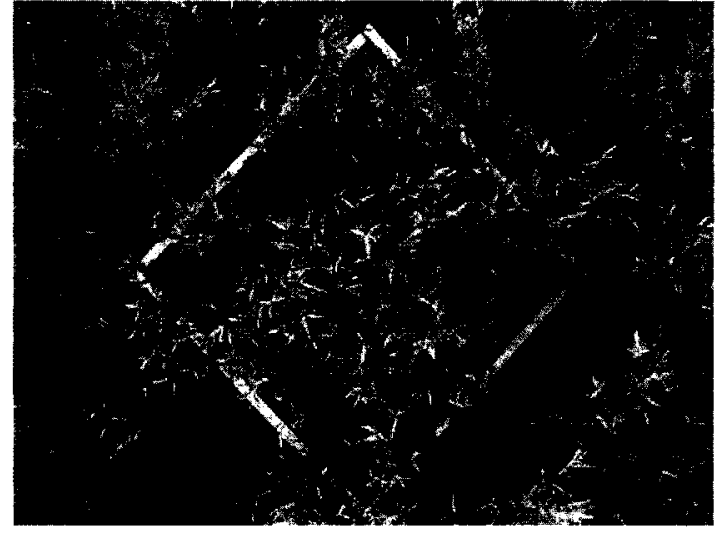

(b) Shrub plot: KilB2.

Slender Willow (Salix petiolaris).

Figure 8. Shrub vegetation. 


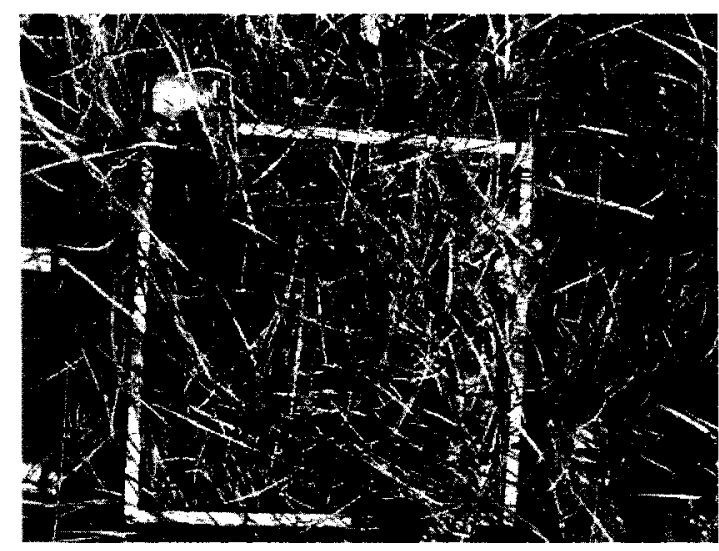

(a) Emergent aquatic plot: Barbers $\mathrm{H} 2 \mathrm{O} 1$.

Common Reed (Phragmites australis).

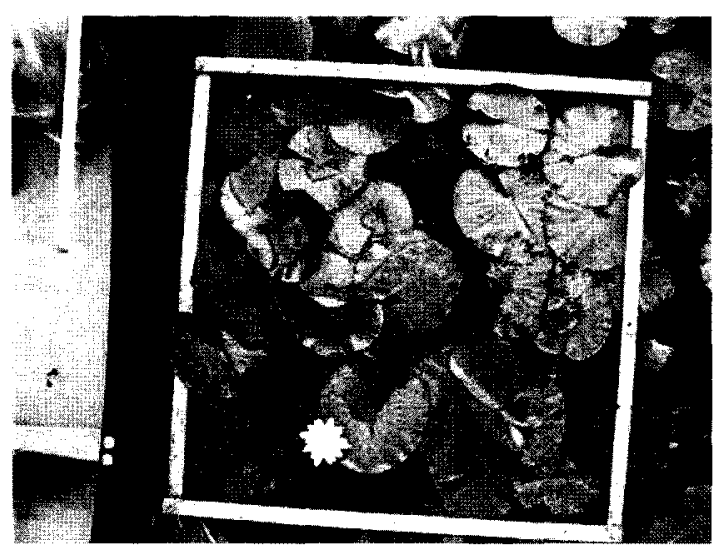

(b) Floating aquatic plot: Barbers $\mathrm{H} 2 \mathrm{O} 3$.

Fragrant White Water Lily (Nymphaea odorata).

Figure 9. Aquatic vegetation.

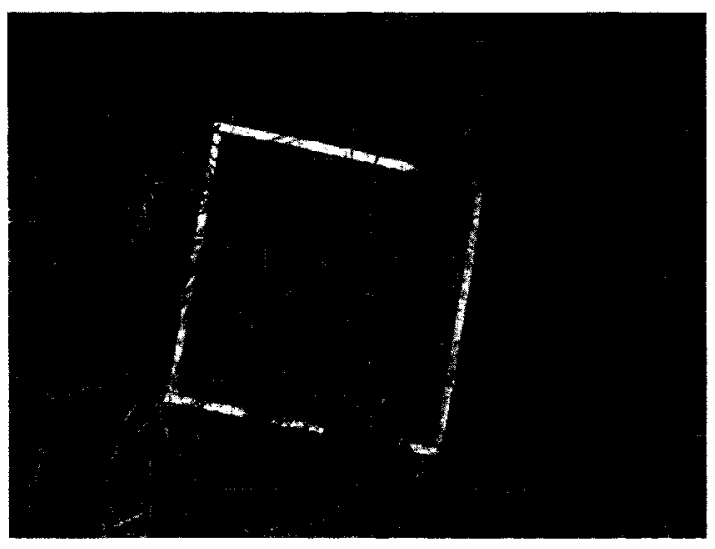

(a) Grasses/Sedges plot: KilB6. Grasses not identified by species, Horsetail (Equisetum arvense), senescent Purple Loosestrife (Lythrum salicaria).

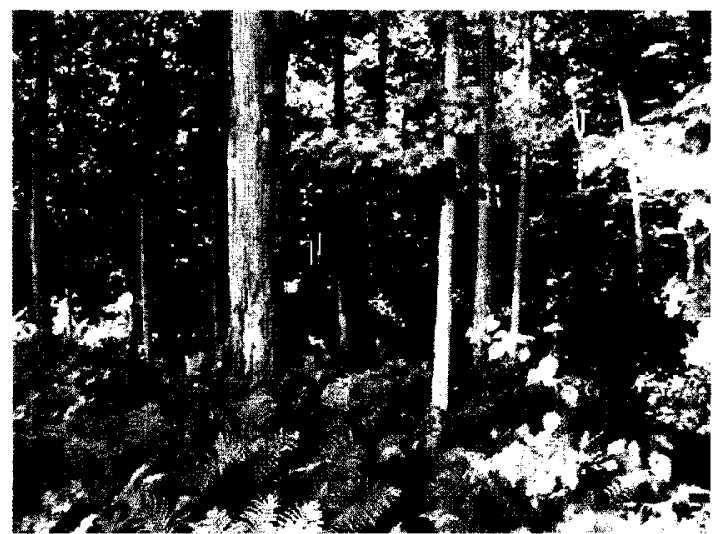

(b) Forest: Barbers7-1. Sugar Maple (Acer saccharum), Sensitive fern (Onoclea sensibilis), Lady fern (Athyrium filix-femina).

Figure 10. Grasses/sedges and forest vegetation.

\subsubsection{Field Sampling for Biomass and Cover Modelling}

For biomass and cover modelling, a subset of 75 of the locations selected for

classification was used. At each location, a $1 \mathrm{~m}$ by $1 \mathrm{~m}$ wooden sampling frame 
was placed over the vegetation. The plants within the frame were identified, average height was measured and percent cover was visually estimated. A digital camera was used to acquire vertically downward colour photographs of each plot. Figures $11 \mathrm{a}$ and $11 \mathrm{~b}$ are examples of photographs acquired during the field campaign representing terrestrial and aquatic plots.

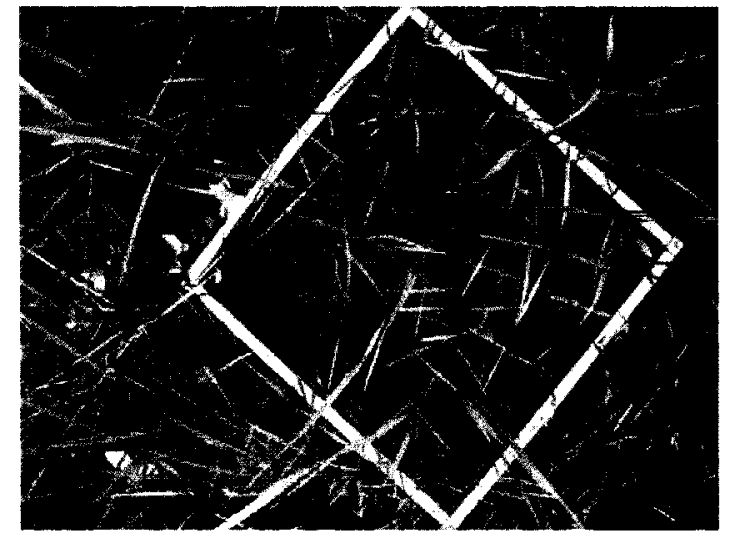

(a) Terrestrial plot photo: Kilmarnock B14.

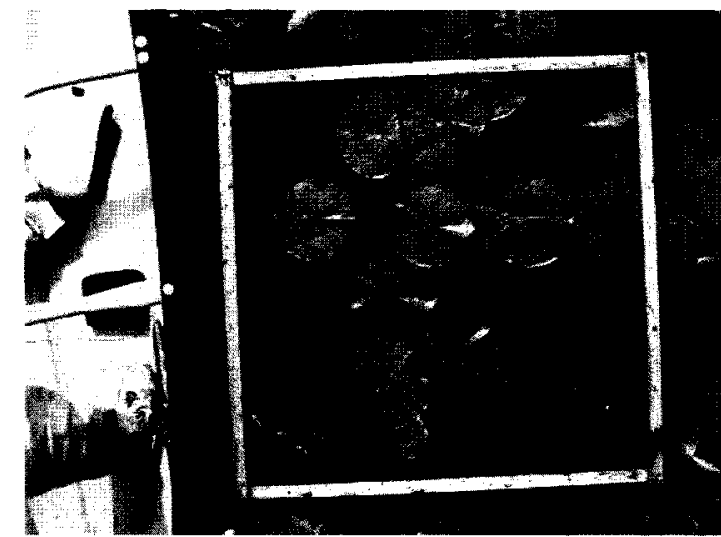

(b) Aquatic plot photo: Kilmarnock A1.

Figure 11. Terrestrial and Aquatic Field Plots.

Due to inclement weather and the subsequent delay of image acquisition during the summer of 2003 , vegetation was not clipped at this stage, but field plots were marked for future reference. Following image data acquisition, all above ground vegetation within the sampling frame was clipped, bagged and transported back to the lab. The vegetation was stored in a refrigerator at a temperature range of $0-5^{\circ} \mathrm{C}$. Plants were chopped and then oven dried at $105^{\circ} \mathrm{C}$ for 24 hours to achieve a dry biomass measure in $\mathrm{g} / \mathrm{m}^{2}$. Separate measurements were made for green and senescent (yellow) vegetation. Within the literature (Cole, 1992; Bartlett and Klemas, 1980; Linthurst and Reimold, 1978; Streever et al., 1998; 
Hill et al., 1997; Cole et al., 2001) a consistent drying time for wetland plants could not be found and, as a result, drying curves were assembled for each vegetation type collected to support the drying time of 24 hours. Figures 12 and 13 show drying curves assembled for floating aquatic and emergent terrestrial vegetation, respectively, where vegetation was weighed hourly for a period of more than 24 hours. The weight curve shown in Figure 12 begins levelling off around 12 hours, while Figure 13 shows some slight variation in weight between $12-23$ hours.

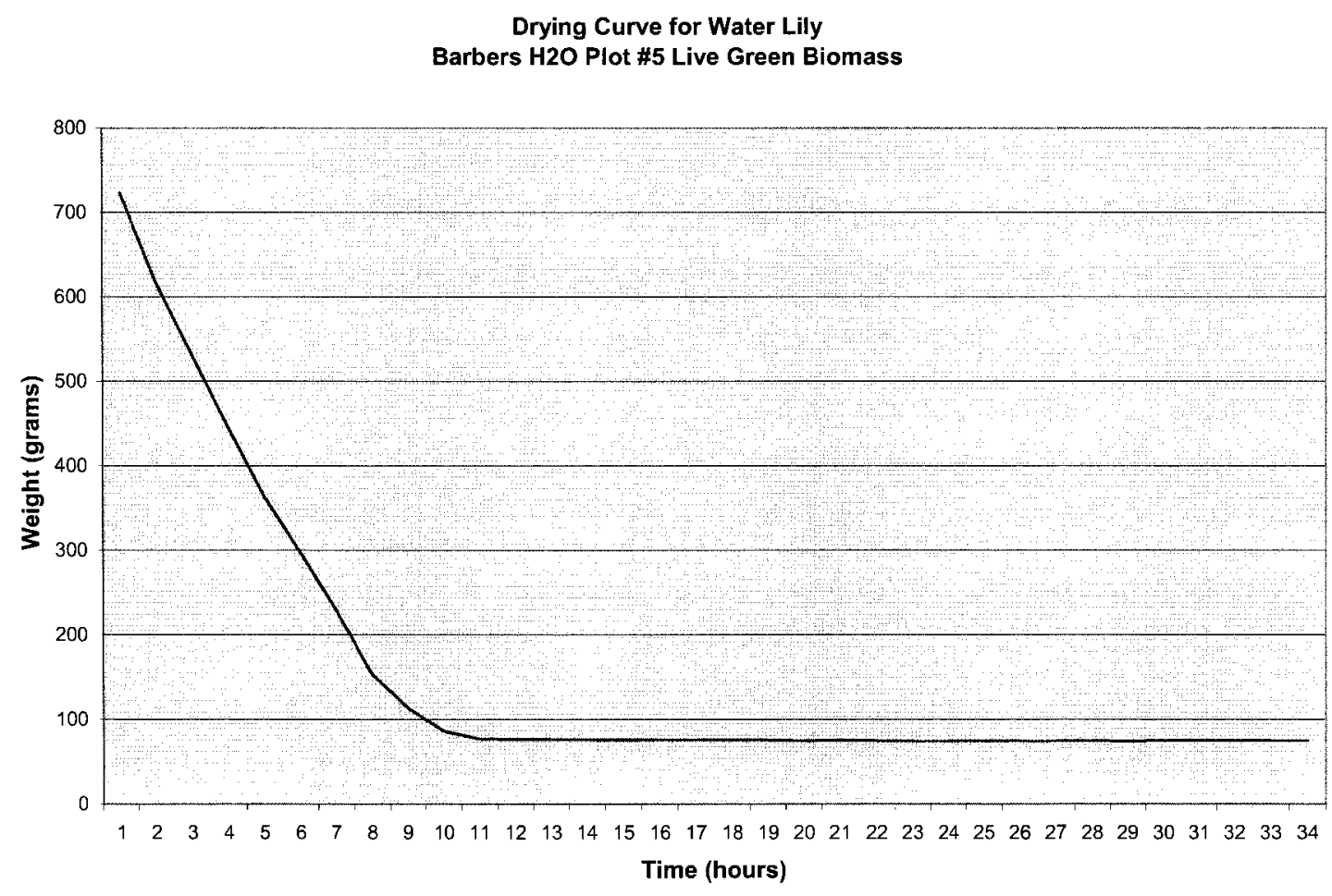

Figure 12. Drying Curve for green floating aquatic vegetation. 


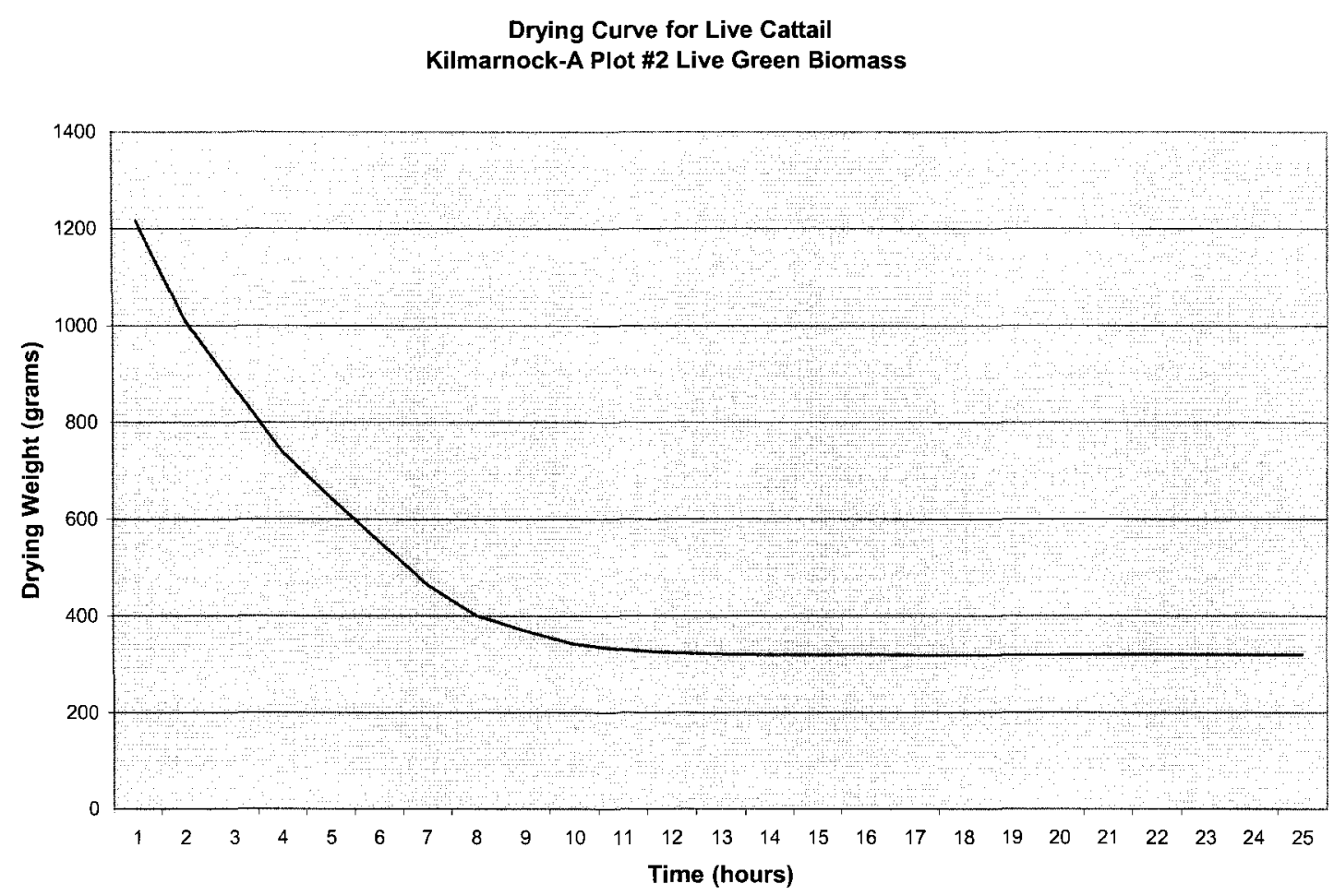

Figure 13. Drying curve for green emergent terrestrial vegetation.

\subsection{Ikonos Data Acquisition}

Ikonos was used as the image source due to its high resolution capabilities with a nominal ground pixel size of 0.82 metres for panchromatic and 3.2 metres for multispectral at nadir viewing. The satellite also has off-nadir viewing capabilities acquiring 1 metre pixel spacing for panchromatic and 4 metres for multispectral channels. Ikonos has an image swath width of 11.3 kilometers at nadir and 13.8 kilometers at 26 degrees off-nadir. The revisit rate of the satellite is between 2-3 days, allowing for the frequent acquisition of imagery for a particular point on the Earth. 
Ikonos multispectral and panchromatic cloud free imagery was acquired on August $25^{\text {th }}, 2003$. Due to persistent cloud cover prior to this date, imagery was not acquired earlier in the season. Peak productivity, however, occurred in August of 2003 so this late acquisition date was not a constraint. Peak productivity was essential for this study because biological features such as plant productivity and biodiversity can be inferred from full growth vegetation and vegetation communities are more easily identifiable from full-growth imagery (Arzandeh and Wang, 2003). Field work was conducted in the 6 weeks before and 2 weeks after image acquisition to ensure that the reference data accurately depicted ground conditions at the time of scene acquisition. Vegetation measurement and biomass sampling was conducted as close to image acquisition (within 2 weeks).

\subsection{Image Georeferencing}

The image provider (Space Imaging) performed a standard geometric correction of the raw image data and re-sampled the image to the Universal Transverse Mercator (UTM) (zone 18, datum NAD 83) projection using cubic convolution interpolation.

The multispectral and panchromatic imagery were georeferenced more precisely using 17 ground control points at intersecting roadways and other landmark features, whose positions were measured using differential GPS. A first order polynomial affine transformation and nearest neighbour resampling were used, 
with Root mean square (RMS) errors of $\{0.05(x), 0.05(y)\}$ and $\{0.14(x), 0.13(y)\}$ pixels for the multispectral and panchromatic images, respectively.

\subsection{Image Data Transformations}

A mask of the three wetland areas used in this study was manually delineated and various data types were derived from the multispectral imagery including: vegetation indices, texture measures and principal components.

\subsubsection{Vegetation Indices}

Due to the limited spectral information available from Ikonos data, only vegetation indices that use the visible or near infrared bands were applied in this research. Vegetation indices were derived as described in Chapter 2 and included: ASVI, DVI, MSAVI, NDVI, RVI, SAVI and TVI (as defined in Chapter 2 and Bannari et al., 1995; Eastwood et al., 1997; Ozesmi et al., 2002; TAN et al., 2003). Some of these are 'soil-adjusted' indices that were selected because the marshes included significant amounts of yellow senescent vegetation and small amounts of bare ground visible from above that were assumed to affect the green vegetation reflectance signal.

\subsubsection{Texture Analysis}

Eight co-occurrence texture measures Homogeneity (HOM), Contrast (CON), Dissimilarity (DIS), Mean (MN), Standard Deviation (STDEV), Entropy (ENTR), 
Angular Second Moment (A2M), and Correlation (COR); and four GLDV measures Angular Second Moment (GLA2M), Entropy (GLENTR), Mean (GLMN) and Contrast (GLCON) were extracted from the green and NIR spectral bands using two window sizes, $3 \times 3$ and $5 \times 5$. These bands were selected due to their visibly greater spatial detail and spectral variance between land cover classes as well as their lower inter-band correlation $(r=0.62)$. The maximum window size of $5 \times 5$ was selected because larger windows may have included image data from other vegetation types or structures.

\subsubsection{Principal Component Analysis}

Table 1 shows the inter-band correlations, with high correlations $(r>0.8)$ between all visible bands. The near IR band was not highly correlated with any of the visible bands.

Table 1. Correlation matrix (showing $r$ values) for Ikonos spectral bands.

\begin{tabular}{|l|c|c|c|c|}
\hline & Blue & Green & Red & NearIR \\
\hline Blue & 1.00 & 0.94 & 0.96 & 0.52 \\
\hline Green & 0.94 & 1.00 & 0.95 & 0.62 \\
\hline Red & 0.96 & 0.95 & 1.00 & 0.57 \\
\hline NearlR & 0.52 & 0.62 & 0.57 & 1.00 \\
\hline
\end{tabular}

Principal Component Analysis (PCA) was conducted to provide orthogonal variables as inputs to the maximum likelihood classifier and to possibly reduce the number of input variables by using only those PCs that together accounted for over $95 \%$ of the total data variance. Using the spectral bands as input, an unstandardized PCA was run on the wetland mask. In unstandardized PCA, the spectral bands with higher variance dominate. Standardized PCA, which does 
not depend on individual band variance was not available in the $\mathrm{PCl}$ software that was used for all the image processing and analysis. The PCs generated from the spectral bands were used in classification with the addition of texture measures (as described below).

After texture measures and vegetation indices were derived another PCA was run on the wetland mask using all image spectral and texture variables as inputs. The principal components accounting for $>95 \%$ cumulative variance were used as independent variables in stepwise multiple regression analysis for biomass modelling.

\subsection{Wetland Vegetation Classification}

An important preliminary step for classification is to determine the image dataset to use as input to the classifier. For this research, when the image dataset was complete, training data were generated for the $3 \times 3$ pixel window at each location where the vegetation had been identified in the field. Single pixel training data were not used as there were not enough samples for some classes.

\subsubsection{Separability Analysis}

Separability analysis was performed using the Bhattacharrya Distance (BD), a distance measure that accounts for class variance-covariance in calculating the statistical separation between pairs of sample training data distributions (Haralick and Fu, 1983; Jensen, 1996). 
In the $\mathrm{PCl}$ algorithm, $\mathrm{BD}$ is scaled to a range of $0-2$, where 0 represents complete overlap between training class distributions and 2 indicates complete separation between classes.

For this research, separability analysis was initially conducted using all training data for seven wetland classes to determine which combination of input variables had the best potential to distinguish between the seven classes. First, each texture measure was combined with the four spectral bands in individual separability analyses. The textures that increased the minimum and average class BD the most were then tested with different spectral datasets including the raw bands, vegetation indices and principal components. Once the best data combinations were determined, separability analysis was conducted again for varying wetland class combinations, which were based on class pairs showing the lowest separability. The goal was to determine the best input variable combination that included variables not highly correlated with each other $(r<$ 0.8). These final variables were used as inputs to several classification tests of varied land cover classes as described below.

\subsubsection{Maximum Likelihood Classification}

For classification, the field and image data were randomly divided into equal training and validation datasets. Maximum likelihood classification was conducted using probability density function bounds of three standard deviations for the training data distributions and equal a priori probabilities for all classes. 
Bounds of three standard deviations were used because each training site had been field verified and there was high certainty that all pixels in each training sample represented the assigned class. Equal a priori probabilities were used because it could not be determined before classification what the class spatial proportions were. Classifications were conducted first for seven wetland classes: Emergent Terrestrial (EM), Shrubs (SHR), Emergent Aquatic (EMAQ), Floating Aquatic (FLAQ), Grasses/Sedges (GS), Forest (FOR) and Open Water (OW). To improve classification accuracy, the EM and SHR classes were merged and classification was repeated for six classes. Further merging was done to create a Terrestrial Marsh (TERm) class, which was composed of EM, SHR and GS, and resulted in a final 5 class classification.

\subsubsection{Neural Network Classification}

Neural network classification was conducted as it is not constrained by the number of input variables or normal data distribution requirements. A multilayer feed forward back-propagating neural network was used to classify the wetland areas. The neural networks were trained using the 5 wetland classes, mentioned previously, and were run on the wetland mask only. Several tests were performed changing the configuration of the networks such as the number of iterations, as well as the momentum and learning rates to achieve convergence towards the acceptable limits for maximum individual and total errors. $\mathrm{PCl}$ (2004) suggests that a smaller learning rate (0.1) reduces the risk of oscillation and non-convergence of the training data. A learning rate of 0.1 and a 
momentum rate of 0.9 were used by Foody et al. (1996) and Pierce et al. (1994). Kavzoglu and Mather (2003) found that a learning rate of 0.1 or 0.2 with a momentum rate of 0.5 or 0.6 resulted in higher classification accuracy. The number of iterations was increased from 1,000 to 100,000 to obtain convergence of the training data, though the lowest achieved maximum individual error (1.43) still exceeded the limit of 0.001 . Spectral and textural data producing the best results for the ML classification were used as inputs for the neural networks though, for some configurations, vegetation indices were included as inputs to determine if they produced higher classification accuracies. The $4^{\text {th }}$ network used the momentum and learning rates proposed by Kavzoglu and Mather (2003), though maximum individual and total errors still exceeded the limits. The number of samples was derived from a random $50 \%$ selection of the 107 training plots used for classification, each consisting of $3 \times 3$ pixels. Table 2 shows the configuration of all neural networks run for this analysis. 
Table 2. Neural network configurations.

\begin{tabular}{|c|c|c|c|c|}
\hline $\begin{array}{l}\text { Neural } \\
\text { Network } \\
\text { Number }\end{array}$ & Inputs & $\begin{array}{l}\text { Momentum } \\
\text { Rate }\end{array}$ & $\begin{array}{l}\text { Learning } \\
\text { Rate }\end{array}$ & $\begin{array}{l}\text { Maximum } \\
\text { Iterations }\end{array}$ \\
\hline 1 & $\begin{array}{l}\text { Spectral bands plus } \\
\text { A2M5grn and CON5nir }\end{array}$ & 0.9 & 0.1 & 1,000 \\
\hline 2 & $\begin{array}{l}\text { PC1-4 (derived from } \\
\text { spec bands) plus } \\
\text { A2M5grn and CON5nir }\end{array}$ & 0.9 & 0.1 & 1,000 \\
\hline 3 & $\begin{array}{l}\text { Spectral bands, } \\
\text { A2M5grn and CON5nir } \\
\text { plus MSAVI, NDVI, } \\
\text { RVI, SAVI and TVI }\end{array}$ & 0.9 & 0.1 & 1,000 \\
\hline 4 & $\begin{array}{l}\text { Spectral bands, } \\
\text { A2M5grn and CON5nir } \\
\text { plus MSAVI, NDVI, } \\
\text { RVI, SAVI and TVI }\end{array}$ & 0.6 & 0.2 & 1,000 \\
\hline 5 & $\begin{array}{l}\text { Spectral bands plus } \\
\text { A2M5grn and CON5nir }\end{array}$ & 0.9 & 0.9 & 1,000 \\
\hline 6 & $\begin{array}{l}\text { Spectral bands plus } \\
\text { A2M5grn and CON5nir }\end{array}$ & 0.9 & 0.1 & 25,000 \\
\hline 7 & $\begin{array}{l}\text { Spectral bands plus } \\
\text { A2M5grn and CON5nir }\end{array}$ & 0.9 & 0.1 & 100,000 \\
\hline 8 & $\begin{array}{l}\text { Spectral bands plus } \\
\text { A2M5grn and CON5nir }\end{array}$ & 0.9 & 0.1 & 100,000 \\
\hline 9 & $\begin{array}{l}\text { Spectral bands plus } \\
\text { A2M5grn and CON5nir }\end{array}$ & 0.9 & 0.1 & 250,000 \\
\hline 10 & $\begin{array}{l}\text { PC1 and PC2 (derived } \\
\text { from spec bands using } \\
\text { entire image) plus } \\
\text { GRN5 TEX }\end{array}$ & 0.9 & 0.1 & 100,000 \\
\hline 11 & $\begin{array}{l}\text { PC1 and PC2 (derived } \\
\text { from spec bands using } \\
\text { entire image) plus } \\
\text { NIR5 TEX }\end{array}$ & 0.9 & 0.1 & 100,000 \\
\hline 12 & $\begin{array}{l}\text { PC1 and PC2 (derived } \\
\text { from spec bands using } \\
\text { wetland mask) plus } \\
\text { GRN5 TEX }\end{array}$ & $0 . \overline{9}$ & 0.1 & 100,000 \\
\hline 13 & $\begin{array}{l}\text { PC1 and PC2 (derived } \\
\text { from spec bands using } \\
\text { wetland mask) plus } \\
\text { NIR5 TEX }\end{array}$ & 0.9 & 0.1 & 100,000 \\
\hline 14 & $\begin{array}{l}\text { Spectral bands, } \\
\text { A2M5grn and CON5nir } \\
\text { plus MSAVI, NDVI, } \\
\text { RVI, SAVI and TVI }\end{array}$ & 0.9 & 0.1 & 100,000 \\
\hline
\end{tabular}

All maps produced by the classifications above were mode filtered to reduce noise. 


\subsubsection{Classification Accuracy Assessment}

Accuracy was assessed using a standard error matrix and $K_{\text {hat }}$ statistic as described in Chapter 2. Due to small numbers of sample sites for some classes, $3 \times 3$ validation windows were used. The pixels within each $3 \times 3$ window were obviously highly autocorrelated (adjacent pixels are more likely similar classes than dissimilar classes), but it was not feasible to visit enough individual sample pixel locations to develop a validation dataset of low spatial autocorrelation.

\subsection{Biomass and Cover Modelling}

All the image variables listed above were extracted for the single pixel at each biomass field plot location. Forward stepwise regression of these image variables against dry biomass and cover was conducted. Probabilities to enter and remove were set at 0.05 and 0.10 , respectively. Scatterplots were analysed to evaluate linearity, which showed nonlinear relationships between many of the independent image variables and the dependent biomass and cover variables. As a result, log transformation of biomass and cover values were deemed appropriate. Multicollinearity was reduced by using only image variables that were not highly correlated with each other as inputs $(r<0.80)$ and where the variance inflation factor (VIF) for each independent variable fell within the desired limit (Allison, 1999; Freund and Wilson, 1998). 
For biomass, seven variations of regressions were conducted that represented combinations of green and senescent vegetation for the terrestrial and aquatic environments, as shown in Table 3.

Table 3. Variations for biomass regression analysis.

\begin{tabular}{|c|c|c|}
\hline $\begin{array}{c}\text { Terrestrial and Aquatic } \\
\text { Plots }\end{array}$ & Terrestrial Plots & Aquatic Plots \\
\hline $\begin{array}{c}\text { Green and Senescent } \\
\text { biomass combined } \\
\text { Green biomass }\end{array}$ & $\begin{array}{c}\text { Green and Senescent } \\
\text { biomass combined } \\
\text { Green biomass }\end{array}$ & Green biomass \\
\hline Senescent biomass & Senescent biomass & \\
\hline
\end{tabular}

Vegetation cover modelling was conducted only for aquatic plots, as cover was too difficult to reliably estimate for the terrestrial plots where vegetation was often vertically bent into the plot from outside or out of the plot from inside. The visual field estimates of cover were used as well as cover estimates derived from maximum likelihood classification of a vertically downward photograph taken at each biomass field plot. The maximum likelihood classifier produced a map for each photo of live vegetation, senescent vegetation, and open water. This process was conducted for all aquatic plots, though it worked best for floating vegetation which was least influenced by shadow and vegetation overlay due to wind.

The two estimates of percent cover were also used as independent variables against dry biomass to determine if percent cover was an indicator of biomass. 


\subsubsection{Biomass Model Assessment and Validation}

Model performance was evaluated based on the adjusted coefficient of determination $\left(R_{a d j}^{2}\right)$ for the model and the $R^{2}$ change produced by each variable; the Se and $p$ values; and the number of variables entered into the model based on the 1:10 variable to sample ratio rule (Stevens, 1996). Model residuals were checked for uniformity and normality. The Variance inflation factor (VIF) was also calculated for each model as $V I F=\frac{1}{1-R^{2}}$ (Freund and Wilson, 1998). It indicates multicollinearity within the model when VIF values exceed the calculated threshold VIF.

For the best model, five separate validation runs of randomly splitting the data into $70 \%$ training and $30 \%$ validation were conducted. Errors were compared for a one variable model (since the MN5grn variable dominated all models) and models with all significant variables entered. Following this, $R^{2}$, Se, mean error, mean absolute error, and RMSE were calculated and averaged for the five validations. The latter three values were used to assess model prediction error and were also expressed as percentages of the mean field measured biomass values for each given dataset. 


\section{Chapter Four: Results}

\subsection{Principal Component Analysis}

PCA conducted using the four spectral bands for the wetland mask area showed that PC1 accounted for $95.81 \%$ of the variance and had a perfect inverse correlation with the NIR band, where darker brightness indicated increased NIR reflectance. From Table 4, the green band had the next highest correlation $(r=-0.64)$ with $P C 1$ indicating that $P C 1$ represents a vegetation gradient. PC2 accounted for $4.01 \%$ of the variance and was highly correlated with the visible bands $(r \geq 0.75)$ showing an increased brightness with visible band reflectance. Roads and bare soil had the highest brightness and vegetation had a mixture of grey tones, which could indicate that PC2 was a moisture gradient for land features only. Some agriculture fields, however, appeared darker than open water which would suggest that PC2 was not a true moisture gradient. PC2 was therefore most likely a vegetation gradient highly correlated with the visible range of the spectrum. PC3 and PC4 accounted for $0.15 \%$ and $0.03 \%$ of the variance respectively, though they were retained for use in further analysis as low variance $\mathrm{PCs}$ can contribute information in a certain area of the image or at specific locations such as edges.

Table 4. PCA of spectral data: Factor loadings table. Correlations shown as $r$ values.

\begin{tabular}{|l|c|c|c|c|}
\hline & PC1 & PC2 & PC3 & PC4 \\
\hline Blue & -0.55 & 0.80 & -0.07 & -0.24 \\
\hline Green & -0.64 & 0.75 & 0.14 & 0.01 \\
\hline Red & -0.60 & 0.78 & -0.17 & 0.03 \\
\hline NIR & -1.00 & -0.03 & 0.00 & 0.00 \\
\hline
\end{tabular}


PCA conducted using all image spectral and texture variables also produced 2 significant components where PC1 and PC2 accounted for $96.84 \%$ and $3.02 \%$ of the variance respectively. This is because unstandardized PCA using the variance-covariance matrix is dominated by high variance variables. The textures varied only within a mean range of $0.07-6.3 \mathrm{DN}$, with the MN5nir texture variable contributing the most, though it was found to be highly correlated with the NIR band $(r=0.93)$. The mean DN values for the visible bands ranged from 167.68-272.10 with the NIR band showing the highest mean of 549.46DN. Consequently, the NIR band also dominated PC1 and the visible bands dominated PC2 as above. It was concluded that unstandardized PCA with spectral plus low variance textures does not produce PCs showing textural information, but rather is dominated by spectral information. Achieving PCs representing spectral and texture variables together was not possible without standardizing all input bands or exporting all the data and conducting standardized PCA in another software package. Neither of these was attempted due to the large amount of additional processing and analysis that would be required. Instead, in wetland classification and biomass modelling input variables were used that were not highly correlated with each other $(r<0.8)$.

\subsection{Separability Analysis}

Separability analysis was used, as described in section 3.6.1, to determine the best combination of image data, including spectral bands, principal components, 
textures and vegetation indices to be used in ML classification and to support the merging of wetland classes that showed the lowest separability.

\subsubsection{Spectral Bands versus Principal Components}

Using all spectral bands produced higher separability results than using any single band. Separability tests had to be conducted with more than one variable so the best two textures, determined from subsequent texture tests (section 4.2.2), were added to the spectral data. As shown in Table 5 using all four spectral bands combined with A2M5grn and CON5nir produced higher separabilities than individual spectral bands with these two textures or the spectral bands alone.

Table 5. Separability results for different combinations of spectral bands and 7 classes.

\begin{tabular}{|l|c|c|}
\hline & $\begin{array}{c}\text { Minimum } \\
\text { Separability }\end{array}$ & $\begin{array}{c}\text { Average } \\
\text { Separability }\end{array}$ \\
\hline All Spectral bands & 0.34 & 1.42 \\
\hline $\begin{array}{l}\text { Blue band combined with } \\
\text { A2M5grn and CON5nir }\end{array}$ & 0.23 & 1.21 \\
\hline $\begin{array}{l}\text { Green band combined with } \\
\text { A2M5grn and CON5nir }\end{array}$ & 0.17 & 1.18 \\
\hline $\begin{array}{l}\text { Red band combined with } \\
\text { A2M5grn and CON5nir }\end{array}$ & 0.38 & 1.19 \\
\hline $\begin{array}{l}\text { NIR band combined with } \\
\text { A2M5grn and CON5nir }\end{array}$ & 0.22 & 1.05 \\
\hline $\begin{array}{l}\text { All spectral bands combined } \\
\text { with A2M5grn and CON5nir }\end{array}$ & 0.61 & 1.68 \\
\hline
\end{tabular}

Table 6 shows separability results comparing the spectral bands and PCs combined with A2M5grn and CON5nir for different wetland classes. All four spectral PCs in combination with A2M5grn and CON5nir produced higher 
separabilities than using only PC1 and PC2 with these textures, so all four PCs

were retained for classification. The spectral band combination and PC1-4

combination had similar if not identical results for all wetland class combinations.

Table 6. Separability results for spectral bands and PCs combined with A2M5grn and CON5nir with varying number of wetland classes.

\begin{tabular}{|c|c|c|c|c|}
\hline & $\begin{array}{l}\text { Number of } \\
\text { Wetland } \\
\text { Classes }\end{array}$ & $\begin{array}{c}\text { Minimum } \\
\text { Separability }\end{array}$ & $\begin{array}{c}\text { Average } \\
\text { Separability }\end{array}$ & $\begin{array}{l}\text { Class Pair with } \\
\text { Minimum } \\
\text { Separability }\end{array}$ \\
\hline \multirow{5}{*}{$\begin{array}{l}\text { Spectral } \\
\text { bands } \\
\text { combined } \\
\text { with } \\
\text { A2M5grn } \\
\text { and } \\
\text { CON5nir }\end{array}$} & $\begin{array}{l}7 \text { classes ALL } \\
\text { TRN }\end{array}$ & 0.61 & 1.68 & SHR and OW \\
\hline & $\begin{array}{c}6 \text { classes with } \\
\text { EM and SHR } \\
\text { merged }\end{array}$ & 1.22 & 1.87 & $\begin{array}{c}\text { EM/SHR merged } \\
\text { and GS }\end{array}$ \\
\hline & $\begin{array}{c}6 \text { class with } \\
\text { SHR and GS } \\
\text { merged }\end{array}$ & 0.49 & 1.82 & $\begin{array}{c}\mathrm{EM} \text { and } \mathrm{SHR} / \mathrm{GS} \\
\text { merged }\end{array}$ \\
\hline & $\begin{array}{l}5 \text { class with } \\
\text { EM, EMAQ and } \\
\text { GS merged }\end{array}$ & 0.45 & 1.81 & $\begin{array}{l}\text { EM/EMAQ/GS } \\
\text { merged and SHR }\end{array}$ \\
\hline & $\begin{array}{l}5 \text { class with } \\
\text { EM, SHR and } \\
\text { GS merged }\end{array}$ & 1.63 & 1.91 & TERm and EMAQ \\
\hline \multirow{5}{*}{$\begin{array}{l}\text { PC1-PC4 } \\
\text { combined } \\
\text { with } \\
\text { A2M5grn } \\
\text { and } \\
\text { CON5nir }\end{array}$} & $\begin{array}{c}7 \text { classes ALL } \\
\text { TRN }\end{array}$ & 0.61 & 1.70 & EM and SHR \\
\hline & $\begin{array}{l}6 \text { classes with } \\
\text { EM and SHR } \\
\text { merged }\end{array}$ & 1.21 & 1.87 & $\begin{array}{c}\text { EM/SHR merged } \\
\text { and GS }\end{array}$ \\
\hline & $\begin{array}{l}6 \text { class with } \\
\text { SHR and GS } \\
\text { merged }\end{array}$ & 0.49 & 1.82 & $\begin{array}{c}\text { EM and SHR/GS } \\
\text { merged }\end{array}$ \\
\hline & $\begin{array}{l}5 \text { class with } \\
\text { EM, EMAQ and } \\
\text { GS merged }\end{array}$ & 0.45 & 1.81 & $\begin{array}{l}\text { EM/EMAQ/GS } \\
\text { merged and SHR }\end{array}$ \\
\hline & $\begin{array}{l}5 \text { class with } \\
\text { EM, SHR and } \\
\text { GS merged }\end{array}$ & 1.63 & 1.91 & TERm and EMAQ \\
\hline
\end{tabular}




\subsubsection{Determining the Best Texture Variables for Classification}

Table 7 shows the separability results comparing a small subset of $3 \times 3$ and $5 \times$ 5 textures. In general, separability was higher for textures using a $5 \times 5$ window size compared to a $3 \times 3$ window size, with the exception of MN3nir discussed later. As a result $3 \times 3$ textures were discarded from further classification analysis.

Table 7. Separability results for selected $3 \times 3$ and $5 \times 5$ textures based on 7 classes.

\begin{tabular}{|l|c|c|c|c|}
\hline \multirow{2}{*}{} & \multicolumn{2}{|c|}{ Minimum Separability } & \multicolumn{2}{c|}{$\begin{array}{c}\text { Average } \\
\text { Separability }\end{array}$} \\
\cline { 2 - 5 } & $\mathbf{3 \times 3}$ & $\mathbf{5 \times 5}$ & $\mathbf{3 \times 3}$ & $\mathbf{5 \times 5}$ \\
\hline $\begin{array}{l}\text { Spectral bands } \\
+ \text { HOM-grn }\end{array}$ & 0.47 & 0.54 & 1.47 & 1.49 \\
\hline $\begin{array}{l}\text { Spectral bands } \\
+ \text { HOM-nir }\end{array}$ & 0.49 & 0.51 & 1.46 & 1.48 \\
\hline $\begin{array}{l}\text { Spectral bands } \\
\text { + STDEV-grn }\end{array}$ & 0.42 & 0.45 & 1.49 & 1.51 \\
\hline $\begin{array}{l}\text { Spectral bands } \\
+ \text { STDEV-nir }\end{array}$ & 0.45 & 0.50 & 1.48 & 1.49 \\
\hline
\end{tabular}

Table 8 shows the 5 highest ranked textures each combined with the spectral bands. MN5nir ranked first due to this texture showing the highest minimum separability, followed by A2M5grn, CON5nir, A2M5nir, and MN3nir. MN5nir and MN3nir were, however, not used in ML classification because they were highly correlated to each other $(r=0.99)$, to $\mathrm{NIR}(r=0.94$ and $r=0.96$, respectively) and to $\mathrm{PC1}(\mathrm{r}=-0.93$ and $\mathrm{r}=-0.96$, respectively). 
Table 8. Individual textures showing highest separability based on 7 classes.

\begin{tabular}{|l|c|c|}
\hline & $\begin{array}{c}\text { Minimum } \\
\text { Separability }\end{array}$ & $\begin{array}{c}\text { Average } \\
\text { Separability }\end{array}$ \\
\hline $\begin{array}{l}\text { Spectral bands + } \\
\text { MN5nir }\end{array}$ & 0.62 & 1.52 \\
\hline $\begin{array}{l}\text { Spectral bands + } \\
\text { A2M5grn }\end{array}$ & 0.56 & 1.53 \\
\hline $\begin{array}{l}\text { Spectral bands + } \\
\text { CON5nir }\end{array}$ & 0.52 & 1.52 \\
\hline $\begin{array}{l}\text { Spectral bands + } \\
\text { A2M5nir }\end{array}$ & 0.53 & 1.51 \\
\hline $\begin{array}{l}\text { Spectral bands + } \\
\text { MN3nir }\end{array}$ & 0.55 & 1.51 \\
\hline
\end{tabular}

For determining texture combinations it was found that A2M5grn and CON5nir increased separability the most. These two textures were selected for classification as they were not highly correlated with each other $(r=-0.47)$, nor with the four spectral bands $(r \leq 0.31)$, and produced higher minimum and average separabilities.

\subsubsection{Determining Appropriate Vegetation Indices for Classification}

Separability tests were also run using the vegetation indices combined individually with visible bands, A2M5grn and CON5nir. Only the visible bands were used as it was found that all indices, except ASVI, were highly correlated with the NIR band, PC1, and with each other. Data combinations including MSAVI, TVI, RVI and ASVI ranked highest among the vegetation indices and were also comparable to the results achieved from the spectral band and PC combinations for 5 classes (Table 9). 


\subsubsection{Merging Wetland Classes based on Separability}

Separability analysis was initially performed using seven wetland classes (EM, SHR, FLAQ, EMAQ, OW, FOR and GS), though this produced the lowest average and minimum separabilities (Tables 6 and 9). Class pairs showing minimum separability were combined, including EM with SHR and SHR with GS. Further testing of these two 6 class sets, showed that the merging of EM and SHR resulted in higher minimum and average separabilities, while the merging of SHR and GS produced lower separabilities and therefore this combination was not used for further classification analysis. Despite the overall increased separability for 6 classes it was felt that further merging was necessary as some wetland classes, such as GS and EMAQ, had small sample sizes or were difficult to spectrally distinguish. Different merging tests were performed to determine the best combination of five wetland classes. Looking at the class photos (examples given in chapter 3), it appears that EM, EMAQ and GS would be spectrally similar and therefore should be merged. This combination, however, produced the lowest minimum separability, as seen in Table 6 . The best combination for 5 classes consisted of Terrestrial marsh (EM, SHR and GS combined), FLAQ, EMAQ, OW and FOR. These classes do not correspond exactly to those of the Ontario Wetland Evaluation System but they are the classes that are separable using lkonos spectral and textural information.

Table 9 shows the separability results for the top three data combinations for varying number of wetland classes, showing a dominance of vegetation indices, 
particularly MSAVI for all class combinations. For 5 classes the PC1-4 and spectral band combinations tied for first, followed by the ASVI combination, and tied for third were the RVI and MSAVI combinations.

Table 9. Separability results for top three data combinations for 7,6 and 5 wetland classes based on $50 \%$ training $3 \times 3$ clusters.

\begin{tabular}{|c|c|c|c|c|}
\hline & $\begin{array}{c}\text { Wetland } \\
\text { Classes Used } \\
\text { During } \\
\text { Classification }\end{array}$ & $\begin{array}{c}\text { Minimum } \\
\text { Separability }\end{array}$ & $\begin{array}{c}\text { Average } \\
\text { Separability }\end{array}$ & $\begin{array}{l}\text { Class Pair } \\
\text { with } \\
\text { Minimum } \\
\text { Separability }\end{array}$ \\
\hline $\begin{array}{l}\text { MSAVI } \\
\text { combination* }\end{array}$ & \multirow{3}{*}{7 classes } & 0.56 & 1.79 & EM and SHR \\
\hline $\begin{array}{l}\text { RVI } \\
\text { combination }\end{array}$ & & 0.55 & 1.79 & EM and SHR \\
\hline $\begin{array}{l}\text { TVI } \\
\text { combination }\end{array}$ & & 0.54 & 1.79 & EM and SHR \\
\hline $\begin{array}{l}\text { ASVI } \\
\text { combination }\end{array}$ & \multirow{3}{*}{$\begin{array}{c}6 \text { classes } \\
\text { (EM and SHR } \\
\text { merged) }\end{array}$} & 1.46 & 1.87 & $\begin{array}{c}\text { EM/SHR and } \\
\text { FLAQ }\end{array}$ \\
\hline $\begin{array}{l}\text { MSAVI } \\
\text { combination }\end{array}$ & & 1.43 & 1.87 & $\begin{array}{c}\text { EM/SHR and } \\
\text { GS }\end{array}$ \\
\hline $\begin{array}{l}\text { TVI } \\
\text { combination }\end{array}$ & & 1.42 & 1.87 & $\begin{array}{c}\text { EM/SHR and } \\
\text { FLAQ }\end{array}$ \\
\hline $\begin{array}{l}\text { PC1-4, } \\
\text { A2M5grn and } \\
\text { CON5nir }\end{array}$ & \multirow{5}{*}{$\begin{array}{c}5 \text { classes } \\
\text { (EM, SHR, GS } \\
\text { merged })\end{array}$} & 1.63 & 1.91 & $\begin{array}{c}\text { TERm and } \\
\text { EMAQ }\end{array}$ \\
\hline $\begin{array}{l}\text { Spectral bands, } \\
\text { A2M5grn and } \\
\text { CON5nir }\end{array}$ & & 1.63 & 1.91 & $\begin{array}{c}\text { TERm and } \\
\text { EMAQ }\end{array}$ \\
\hline $\begin{array}{l}\text { ASVI } \\
\text { combination }\end{array}$ & & 1.46 & 1.88 & $\begin{array}{c}\text { TERm and } \\
\text { FLAQ }\end{array}$ \\
\hline $\begin{array}{l}\mathrm{RVI} \\
\text { combination }\end{array}$ & & 1.43 & 1.89 & $\begin{array}{c}\text { TERm and } \\
\text { FLAQ }\end{array}$ \\
\hline $\begin{array}{l}\text { MSAVI } \\
\text { combination }\end{array}$ & & 1.43 & 1.88 & $\begin{array}{c}\text { TERm and } \\
\text { FLAQ }\end{array}$ \\
\hline
\end{tabular}

${ }^{*}$ Combination denotes that each vegetation index was combined with visible bands, A2M5grn and CON5nir.

\subsection{Classification Analysis}

Results produced from the ML and neural network classifications are presented and compared in the following sections. 


\subsubsection{Maximum Likelihood Classification}

Classifications results are presented for the top three data combinations derived from the separability analysis for 7,6 and 5 classes. The error matrices and classified maps are presented only for those classifications with the highest overall accuracy in each class combination.

\subsubsection{Classification using Seven Classes}

Based on the separability analysis for 7 classes, the MSAVI combination ranked first followed by the RVI and TVI combinations, respectively. The error matrix and the classified map for the MSAVI classification are shown below.

\section{1) MSAVI Combination}

The overall classification accuracy for the 7 class MSAVI combination was $61.3 \%$ and the computed $\mathrm{K}_{\text {hat }}$ statistic was 0.47 .

Table 10. Error matrix for 7 class MSAVI classification.

Rows contain number of pixels assigned as reference data and columns contain number of pixels assigned as classified data.

\begin{tabular}{|l|c|c|c|c|c|c|c|c|}
\hline & EM & SHR & FLAQ & EMAQ & OW & FOR & GS & Row Total \\
\hline EM & 155 & 21 & 6 & 16 & 0 & 0 & 0 & 198 \\
\hline SHR & 30 & 51 & 0 & 23 & 0 & 8 & 5 & 117 \\
\hline FLAQ & 0 & 0 & 36 & 0 & 0 & 0 & 0 & 36 \\
\hline EMAQ & 7 & 8 & 0 & 0 & 0 & 0 & 3 & 18 \\
\hline OW & 0 & 0 & 0 & 0 & 45 & 0 & 0 & 45 \\
\hline FOR & 0 & 23 & 0 & 0 & 0 & 0 & 4 & 27 \\
\hline GS & 25 & 0 & 2 & 0 & 0 & 0 & 0 & 27 \\
\hline $\begin{array}{l}\text { Column } \\
\text { Total }\end{array}$ & 217 & 103 & 44 & 39 & 45 & 8 & 12 & 468 \\
\hline
\end{tabular}


Table 10 shows the error matrix for the 7 class MSAVI classification. Errors of omission (across the table rows) for the emergent terrestrial class occurred in misclassification predominantly as shrub and emergent aquatic, as well as lesser confusion with floating aquatic. Errors of commission (down the table columns) for emergent terrestrial occurred when shrub and grasses/sedges were incorrectly classified as emergent terrestrial. Shrub class errors of omission occurred in misclassification predominantly as emergent terrestrial and emergent aquatic. Errors of commission resulted when forest and emergent terrestrial were incorrectly classified as shrubs. Floating aquatic was well classified, although small errors of commission occurred with emergent terrestrial and grasses/sedges. Emergent aquatic was completely misclassified predominantly as shrubs and emergent terrestrial, while open water was classified correctly with no errors of omission or commission. Forest was entirely misclassified showing errors of omission and commission predominantly with shrubs. Grasses/sedges were also completely misclassified showing errors of omission as grasses/sedges were confused with emergent terrestrial and floating aquatic. Errors of commission occurred when shrub, forest and emergent aquatic were incorrectly classified as grasses/sedges.

The producer and user accuracies for the 7 class MSAVI combination are given in Table 11 with the resulting map shown in Figure 14. If all classes are considered equally important, the average producer and user accuracies are only $43.3 \%$ and $46.0 \%$. 
Table 11. Producer and user accuracies for 7 class MSAVI classification.

\begin{tabular}{|l|c|c|}
\hline & Producer's Accuracy (\%) & User's Accuracy (\%) \\
\hline Emergent Terrestrial & 71.4 & 78.3 \\
\hline Shrubs & 49.5 & 43.6 \\
\hline Floating Aquatics & 81.8 & 100.0 \\
\hline Emergent Aquatic & 0.0 & 0.0 \\
\hline Open Water & 100.0 & 100.0 \\
\hline Forest & 0.0 & 0.0 \\
\hline Grasses/Sedges & 0.0 & 0.0 \\
\hline
\end{tabular}

From visual assessment of Figure 14 it appears that the emergent aquatic class, shown in red, is generally located in areas where emergent terrestrial and shrub vegetation, shown in brown and pink, were observed in the field. Emergent aquatic vegetation should occur in closer proximity to areas of open water and floating aquatic vegetation, as was seen in the field.

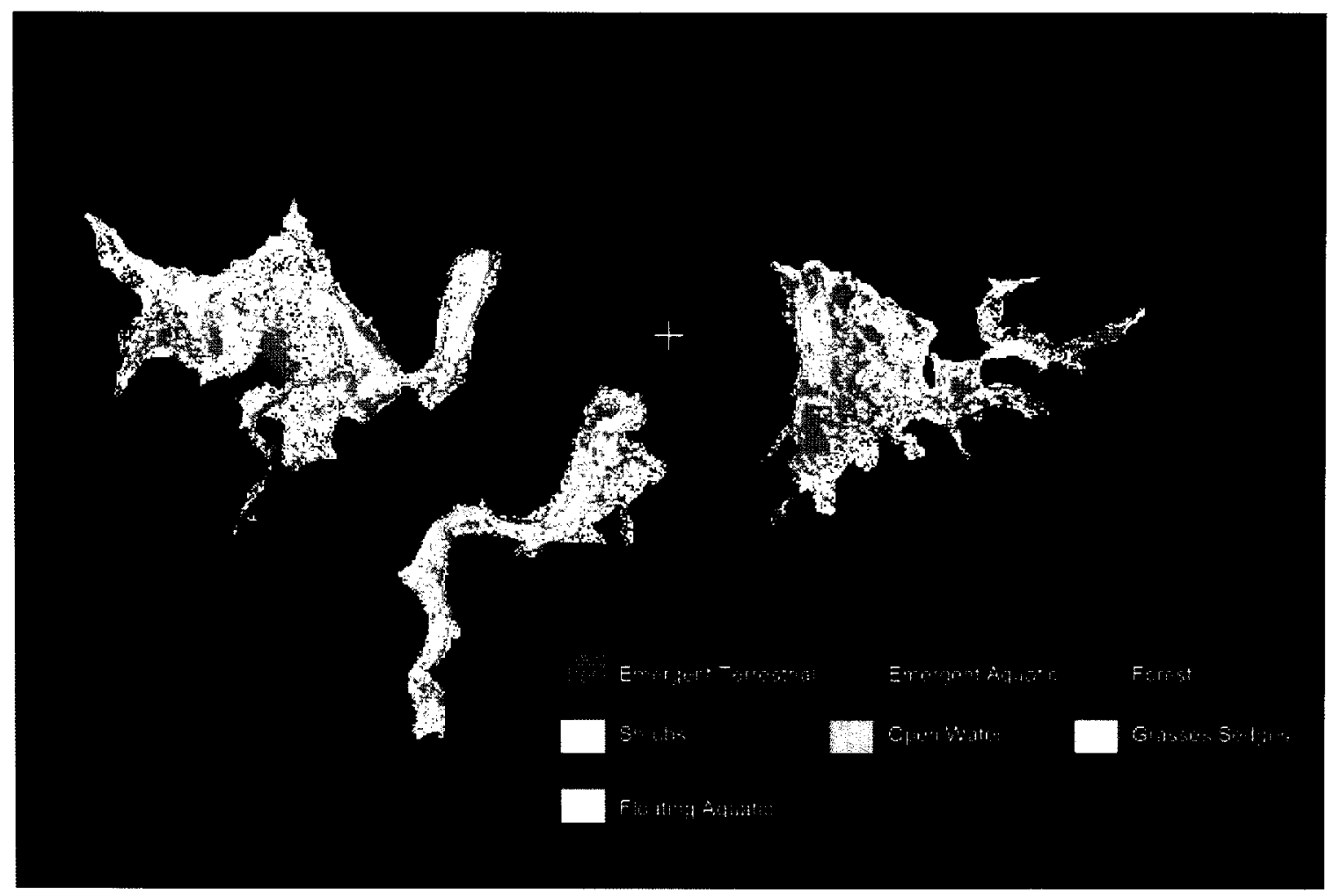

Figure 14. MSAVI classification for 7 classes with mode filter applied. 
2) RVI Combination

The RVI combination achieved an overall classification accuracy of $61.1 \%$ and a $K_{\text {hat }}$ statistic of 0.46 . The patterns of confusion between classes mirrored those of the MSAVI classification.

\section{3) TVI Combination}

An overall accuracy of $60.3 \%$ with a $K_{\text {hat }}$ statistic of 0.45 was achieved for the 7 class TVI classification. The significant difference for the TVI classification compared to the other 7 class combinations was that open water was confused with shrubs, which resulted in lower user accuracy for this class. All other class confusions, stated previously, also existed for the TVI classification.

From all classifications using 7 classes, shrubs, emergent aquatic and grasses/sedges were consistently confused with emergent terrestrial vegetation, which results from a spatial dominance of the emergent terrestrial class, particularly Common cattail (Typha latifolia), while shrubs, emergent aquatic and grasses/sedges were much less common.

\subsubsection{Classification using Six Classes}

From the separability analysis for six classes, with emergent terrestrial and shrubs merged, the ASVI, MSAVI and TVI combinations ranked first through third, respectively. The highest overall classification accuracy was, however, achieved from the TVI combination which will be discussed first and in the most 
detail, followed by MSAVI and lastly by ASVI which achieved the lowest overall classification accuracy.

1) TVI Combination

The TVI combination achieved an overall accuracy of $71.6 \%$ and a $\mathrm{K}_{\text {hat }}$ statistic of 0.44 . The large difference between the overall accuracy and the $K_{\text {hat }}$ statistic exists because the overall accuracy is affected by unequal sample sizes between classes, where emergent terrestrial/shrub has the largest number of reference pixels and is also well classified. The $\mathrm{K}_{\text {hat }}$ statistic is, however, not affected by this. If class sample sizes reflect the actual aerial proportions, then overall accuracy is a good indicator of map accuracy.

Table 12. Error matrix for 6 class TVI classification.

Rows contain number of pixels assigned as reference data and columns contain number of pixels assigned as classified data.

\begin{tabular}{|l|c|c|c|c|c|c|c|}
\hline & EM/SHR & FLAQ & EMAQ & OW & FOR & GS & Row Total \\
\hline EM/SHR & 262 & 6 & 37 & 0 & 7 & 3 & 315 \\
\hline FLAQ & 0 & 36 & 0 & 0 & 0 & 0 & 36 \\
\hline EMAQ & 16 & 0 & 0 & 0 & 0 & 2 & 18 \\
\hline OW & 8 & 0 & 0 & 37 & 0 & 0 & 45 \\
\hline FOR & 21 & 0 & 1 & 0 & 0 & 5 & 27 \\
\hline GS & 23 & 4 & 0 & 0 & 0 & 0 & 27 \\
\hline $\begin{array}{l}\text { Column } \\
\text { Total }\end{array}$ & 330 & 46 & 38 & 37 & 7 & 10 & 468 \\
\hline
\end{tabular}

Table 12 shows the error matrix for the 6 class TVI classification.

Errors of omission for the combined emergent terrestrial/shrub class occurred in misclassification with all classes, except open water, particularly as emergent aquatic. Errors of commission for emergent terrestrial/shrub occurred when grasses/sedges, forest, emergent aquatic and open water were incorrectly 
classified as emergent terrestrial/shrub. Errors of commission for floating aquatic occurred when emergent terrestrial/shrub was incorrectly classified as floating aquatic. Errors of omission for the emergent aquatic class occurred in misclassification as predominantly emergent terrestrial/shrub, as well as lesser confusion with grasses/sedges. Errors of commission for emergent aquatic occurred when predominantly emergent terrestrial/shrub was incorrectly classified as emergent aquatic. Open water was well classified, although it was confused with emergent terrestrial/shrub resulting in a lower user accuracy. Forest was entirely misclassified showing errors of omission and commission with emergent terrestrial/shrub. Grasses/sedges were also completely misclassified showing errors of omission with emergent terrestrial/shrub, as well as lesser confusion with floating aquatic. Errors of commission occurred when forest, emergent terrestrial/shrub and emergent aquatic were incorrectly classified as grasses/sedges.

Based on Table 13 the average producer and user accuracies for the 6 class TVI classification are $42.9 \%$ and $44.2 \%$.

Table 13. Producer and user accuracies for 6 class TVI classification. Rows contain reference data and columns contain classified data.

\begin{tabular}{|l|c|c|}
\hline & Producer's Accuracy (\%) & User's Accuracy (\%) \\
\hline $\begin{array}{l}\text { Emergent Terrestrial/ } \\
\text { Shrub }\end{array}$ & 79.4 & 83.2 \\
\hline Floating Aquatic & 78.3 & 100.0 \\
\hline Emergent Aquatic & 0.0 & 0.0 \\
\hline Open Water & 100.0 & 82.2 \\
\hline Forest & 0.0 & 0.0 \\
\hline Grasses/Sedges & 0.0 & 0.0 \\
\hline
\end{tabular}


From Figure 15 the emergent aquatic class, shown in red was again found in areas where emergent terrestrial and shrub vegetation, shown in brown, were seen in the field.

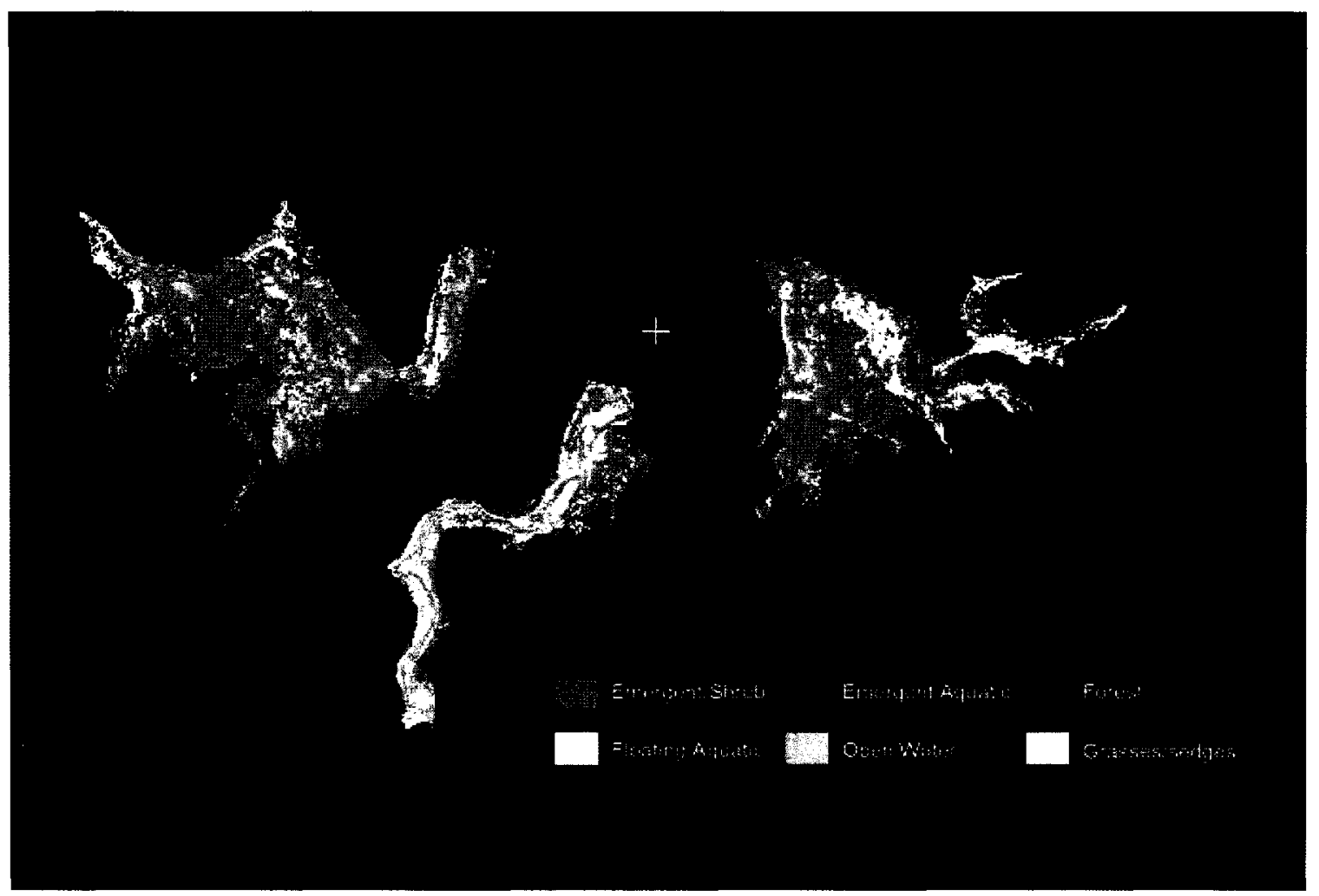

Figure 15. TVI classification for 6 classes with mode filter applied.

2) MSAVI Combination

For the MSAVI combination an overall accuracy of $71.2 \%$ and a $\mathrm{K}_{\text {hat }}$ statistic of 0.45 were achieved, with similar patterns of class confusion as the MSAVI classification.

3) ASVI Combination

An overall accuracy of $69.9 \%$ and a $K_{\text {hat }}$ statistic of 0.42 were achieved for the ASVI classification. The significant difference for the ASVI classification 
compared to the other 6 class combinations was that some forest pixels were correctly classified resulting in higher producer and user accuracies for this class. Another significant difference was that errors of commission occurred when floating aquatic was incorrectly classified as emergent terrestrial/shrub.

From all classifications using six classes, emergent aquatic was consistently confused with combined emergent terrestrial/shrub and grasses/sedges. Forest was also consistently confused with combined emergent terrestrial/shrub.

\subsubsection{Classification using Five Classes}

Based on the 5 class separability analysis with emergent terrestrial, shrubs and grasses/sedges merged, the following combinations ranked from first to third: the PC 1-4 and spectral band combinations tied for first, followed by the ASVI combination, and tied for third were the RVI and MSAVI combinations. The highest overall classification accuracy resulted from the spectral band, A2M5grn and CON5nir combination, which will be discussed first and in the most detail.

1a) Spectral bands, A2M5grn and CON5nir Combination

An overall accuracy of $84.8 \%$ and a $\mathrm{K}_{\text {hat }}$ statistic of 0.66 were achieved for the spectral bands, A2M5grn and CON5nir combination. 
Table 14. Error matrix for 5 class Spectral bands, A2M5grn and CON5nir classification.

Rows contain number of pixels assigned as reference data and columns contain number of pixels assigned as classified data.

\begin{tabular}{|l|c|c|c|c|c|c|}
\hline & TERm & FLAQ & EMAQ & OW & FOR & Row Total \\
\hline TERm & 309 & 18 & 0 & 1 & 14 & 342 \\
\hline FLAQ & 2 & 34 & 0 & 0 & 0 & 36 \\
\hline EMAQ & 16 & 2 & 0 & 0 & 0 & 18 \\
\hline OW & 0 & 0 & 0 & 45 & 0 & 45 \\
\hline FOR & 18 & 0 & 0 & 0 & 9 & 27 \\
\hline $\begin{array}{l}\text { Column } \\
\text { Total }\end{array}$ & 345 & 54 & 0 & 46 & 23 & 468 \\
\hline
\end{tabular}

Table 14 shows the error matrix for the 5 class spectral band, A2M5grn and CON5nir classification. Errors of omission for the terrestrial marsh class occurred in misclassification as floating aquatic and forest. Dominant errors of commission for terrestrial marsh occurred when forest and emergent aquatic were incorrectly classified as terrestrial marsh. Errors of commission for floating aquatic occurred as terrestrial marsh was incorrectly classified as floating aquatic. Errors of omission for the emergent aquatic class occurred in misclassification as predominantly terrestrial marsh, as well as lesser confusion with floating aquatic. In general, open water was very well classified. Forest had low producer and user accuracy due to confusion of forest with terrestrial marsh.

From Table 15 the average producer and user accuracies for the 5 class spectral band, A2M5grn and CON5nir classification are $63.6 \%$ and $57.9 \%$. 
Table 15. Producer and user accuracies for 5 class spectral bands, A2M5grn and CON5nir classification.

\begin{tabular}{|l|c|c|}
\hline & Producer's Accuracy (\%) & User's Accuracy (\%) \\
\hline Terrestrial Marsh & 89.6 & 90.4 \\
\hline Floating Aquatic & 63.0 & 94.4 \\
\hline Emergent Aquatic & 0.0 & 0.0 \\
\hline Open Water & 97.8 & 100.0 \\
\hline Forest & 39.1 & 33.3 \\
\hline
\end{tabular}

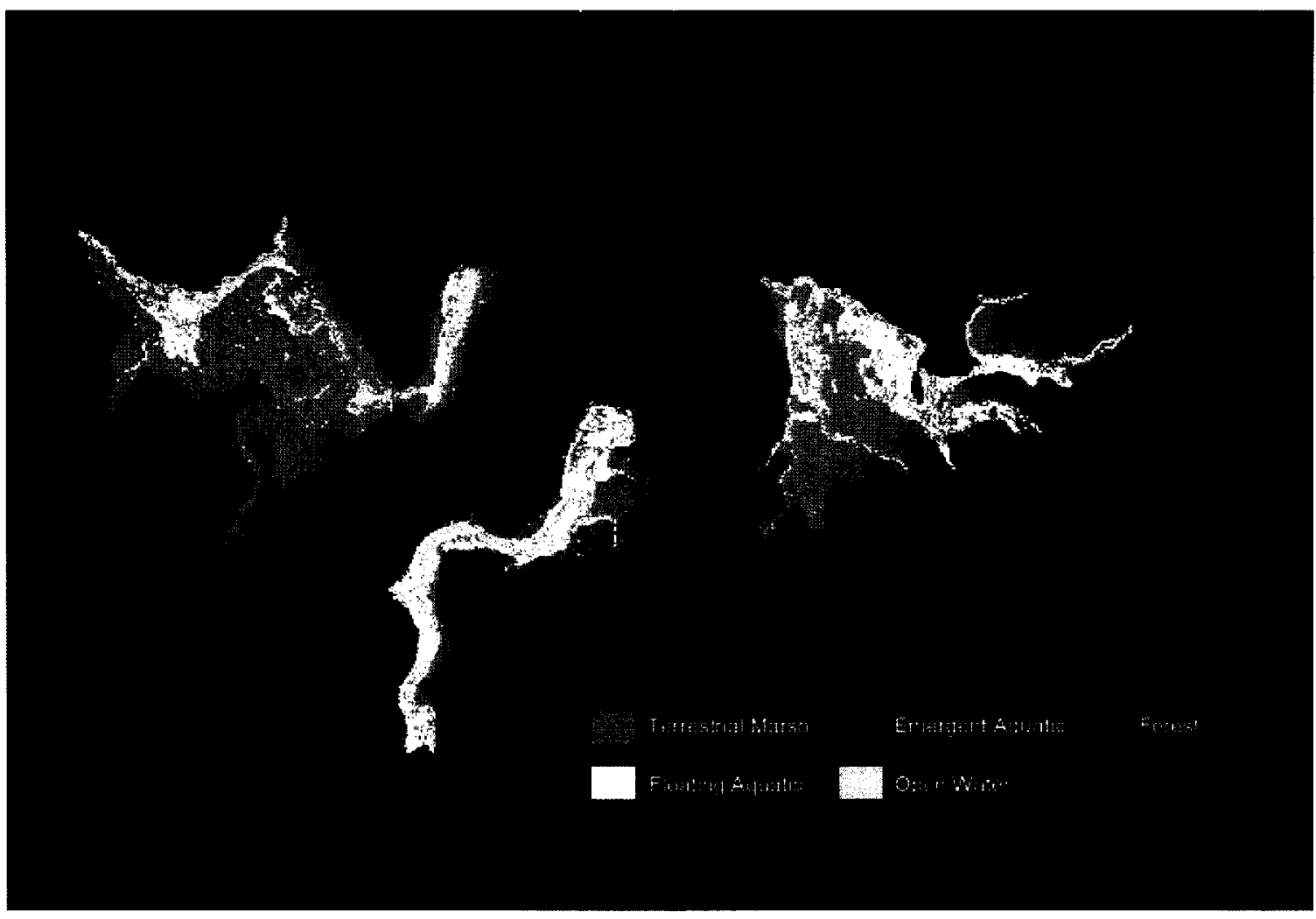

Figure 16. Spectral band classification for 5 classes with mode filter applied.

Even though none of the validation samples for the emergent aquatics were classified correctly (Tables 14 and 15), the locations of the pixels assigned to this class, shown in red in Figure 16, correspond well with the locations in which this vegetation class was observed in the field. In addition, the largest percentage of emergent aquatic vegetation, dominated by Common Reed (Phragmites 
australis), that was found during the field campaign occurred in Kilmarnock marsh and was either dense cover or interspersed with open water, as shown in Figures $17 \mathrm{a}$ and $17 \mathrm{~b}$. Field samples were predominantly taken from areas of dense emergent aquatic vegetation to minimize the confusion between floating aquatic and emergent aquatic vegetation. This type of dense aquatic cover corresponds to the area in Figure 16 which was classified as emergent aquatic. From Figure 16 the largest visual representation of the emergent aquatics class is found in Kilmarnock marsh and secondly in a finger of Barbers creek marsh.

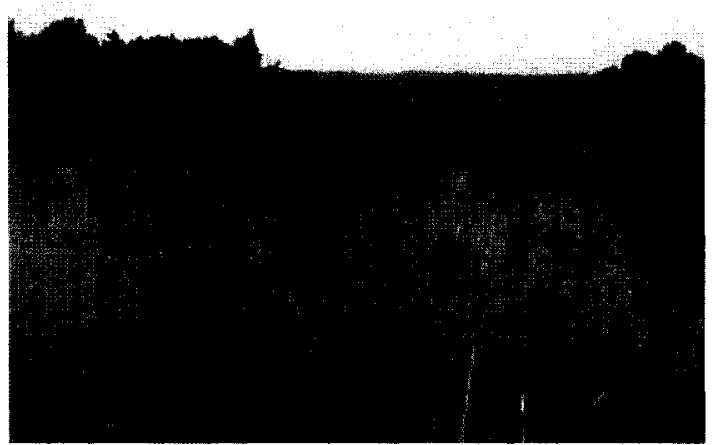

(a) Emergent aquatic vegetation interspersed with open water in Kilmarnock marsh August 2003.

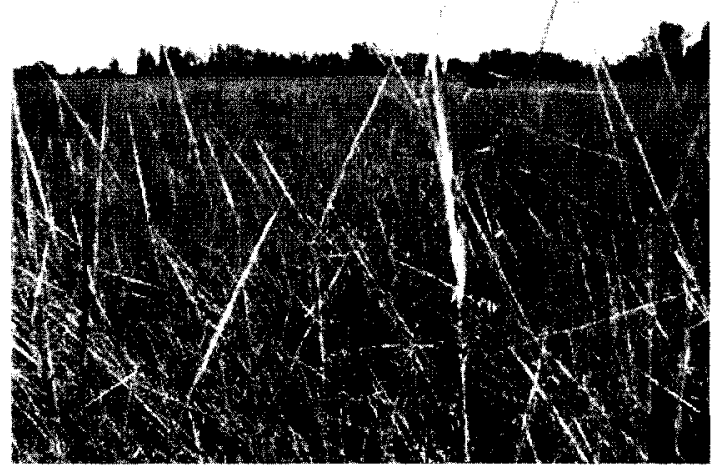

(b) Dense emergent aquatic vegetation identified in Kilmarnock marsh August 2003.

Figure 17. Emergent aquatic vegetation.

1b) PC1-4, A2M5grn and CON5nir Combination

An overall classification accuracy of $83.1 \%$ and a $\mathrm{K}_{\text {hat }}$ statistic of 0.63 were achieved for the PC1-4, A2M5grn and CON5nir combination. The significant difference for the PC1-4 combination, compared to the spectral band combination, was that terrestrial marsh was incorrectly classified as emergent aquatic, resulting in lower producer accuracy. 
2) RVI Combination and MSAVI combination

For the RVI and MSAVI combinations overall accuracies of $78.4 \%$ and $77.6 \%$, and Khat statistics of 0.53 and 0.52 were achieved, respectively. For both the $\mathrm{RVI}$ and MSAVI combinations the most significant difference compared to the other 5 class combinations was the complete misclassification of forest as terrestrial marsh. Another difference was that these combinations attained the highest producer and user accuracies for floating aquatic.

3) ASVI Combination

The ASVI combination resulted in an overall classification accuracy of $75.0 \%$ and a $K_{\text {hat }}$ statistic of 0.46 . Compared to the other 5 class combinations the most significant difference for the ASVI classification was the lower producer and user accuracies for forest and floating aquatic. In general, there was significant confusion discriminating between forest and terrestrial marsh, and floating aquatic and terrestrial marsh.

From all classifications using 5 classes, emergent aquatic and forest were consistently confused with terrestrial marsh.

\subsubsection{Summary of Classification Results}

From assessment of all of the error matrices for the 7,6 and 5 classes, the emergent aquatic class was consistently confused with terrestrial marsh vegetation, which included emergent terrestrial, shrubs and grasses/sedges. 
The predominant misclassification of emergent aquatic as terrestrial marsh for all classifications can be explained by the structural and subsequent spectral similarities between Common reed (Phragmites australis) and Common cattail (Typha latifolia) both dominant vegetation covers in each class respectively.

From Figures $18 \mathrm{a}$ and $18 \mathrm{~b}$ both vegetation species have similar flat leaf structure and form large dense colonies. Common cattail (Typha latifolia) was typically taller than Common reed (Phragmites australis), though this would have little or no influence on vegetation reflectance. The predominant difference between the two species is the environment in which they grow, with Common reed (Phragmites australis) growing in open water areas compared to Common cattail (Typha latifolia) growing on densely floating mats more similar to a terrestrial environment. 


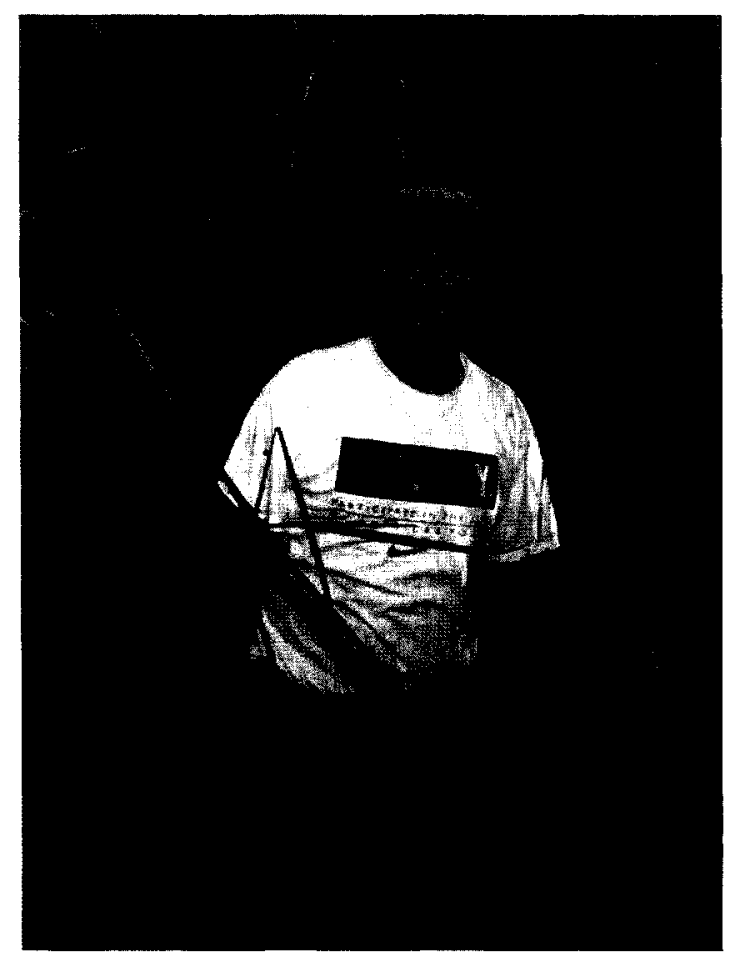

(a). Common Cattail (Typha latifolia) vegetation.

Figure 18. Emergent terrestrial versus emergent aquatic vegetation.

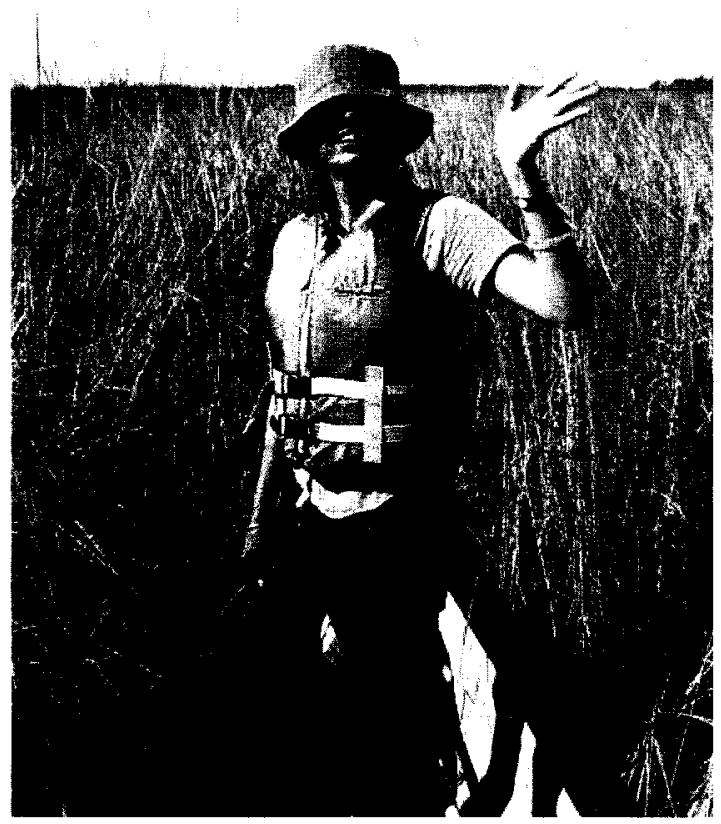

(b). Common Reed (Phragmites australis) vegetation.

In addition, as can be seen from Table 16, fewer training and validation samples

existed for emergent aquatic which, besides forest, was the most poorly

represented class due to few areas being found on the ground compared to the

dominance of samples representing terrestrial marsh.

Table 16. Number of pixels per wetland class for 5 classes using approximately $50 \%$ training and $50 \%$ validation $3 \times 3$ clusters.

\begin{tabular}{|l|c|c|}
\hline & $\begin{array}{c}\text { Number of pixels per } \\
\text { wetland class for 5 } \\
\text { classes using 50\% } \\
\text { Training 3 } \mathbf{3}\end{array}$ & $\begin{array}{c}\text { Number of pixels per } \\
\text { wetland class for 5 } \\
\text { classes using 50 \% } \\
\text { Validation 3 x 3 }\end{array}$ \\
\hline Terrestrial Marsh & 351 & 342 \\
\hline Floating Aquatic & 45 & 36 \\
\hline Emergent Aquatic & 27 & 18 \\
\hline Open Water & 54 & 45 \\
\hline Forest & 18 & 27 \\
\hline
\end{tabular}


As expected, the classification results showed that overall accuracy significantly improved as classes were merged, with the highest accuracy obtained using 5 classes as was also seen from the separability analysis. Higher separability, however, did not always result in higher overall classification accuracy. For 6 classes, the TVI combination, ranked third by separability, resulted in the highest overall classification accuracy. For this research, separability provided an ideal starting method for selecting textures and determining which spectral data combined with those textures should be used for classification. It also supported the merging of wetland classes that were found to be either spectrally similar or that had small sample sizes. It should be noted, however, that the results produced from separability analysis did not correspond exactly to those for classification accuracy. Separability analysis can aid in input variable selection and give a general idea of relative potential for classification accuracy, but it was not a good indicator of final absolute accuracy.

\subsubsection{Additional Maximum Likelihood Classifications}

Following the results presented above, additional ML classifications were conducted using input variable combinations that had not ranked in the top three from separability analysis, to determine if higher classification accuracies could be achieved.

Since 5 classes were shown to produce significantly better classification results, compared to 6 and 7 classes, this class combination was selected for these 
classification tests. Classifications were run for the following vegetation indices (DVI, NDVI, SAVI and TVI) individually combined with A2M5grn and CON5nir. These additional VI classifications showed an improvement in overall accuracy compared to the ASVI, RVI and MSAVI combinations, identified as the best combinations using separability analysis. The TVI combination produced the highest overall classification accuracy of $87.8 \%$ and the highest $K_{\text {hat }}$ statistic of 0.72. The error matrix, producer and user accuracies and a classified map are presented below.

Table 17. Error matrix for 5 class TVI classification.

Rows contain number of pixels assigned as reference data and columns contain number of pixels assigned as classified data.

\begin{tabular}{|l|c|c|c|c|c|c|}
\hline & TERm & FLAQ & EMAQ & OW & FOR & Row Total \\
\hline TERm & 321 & 10 & 2 & 1 & 8 & 342 \\
\hline FLAQ & 0 & 36 & 0 & 0 & 0 & 36 \\
\hline EMAQ & 10 & 8 & 0 & 0 & 0 & 18 \\
\hline OW & 0 & 0 & 0 & 45 & 0 & 45 \\
\hline FOR & 17 & 1 & 0 & 0 & 9 & 27 \\
\hline $\begin{array}{l}\text { Column } \\
\text { Total }\end{array}$ & 348 & 55 & 2 & 46 & 17 & 468 \\
\hline
\end{tabular}

Table 17 shows the error matrix for the 5 class TVI classification. Comparing the TVI classification to the 5 class spectral band combination, discussed previously, the significant differences are the higher producer and user accuracies for the terrestrial marsh and forest classes. The same class confusions, discussed earlier, also occurred for the TVI classification. Table 18 shows the producer and user accuracies for the 5 class TVI classification with average producer and user accuracies of $61.7 \%$ and $65.4 \%$. 
Table 18. Producer and user accuracies for 5 class map derived from TVI classification.

\begin{tabular}{|l|c|c|}
\hline & Producer's Accuracy (\%) & User's Accuracy (\%) \\
\hline Terrestrial Marsh & 92.2 & 93.8 \\
\hline Floating Aquatic & 65.5 & 100.0 \\
\hline Emergent Aquatic & 0.0 & 0.0 \\
\hline Open Water & 97.8 & 100.0 \\
\hline Forest & 52.9 & 33.3 \\
\hline
\end{tabular}

The spatial distribution of the emergent aquatic class, shown in red in Figure 19, is comparable to that seen in Figure 16 and corresponds well with general observations from the field.

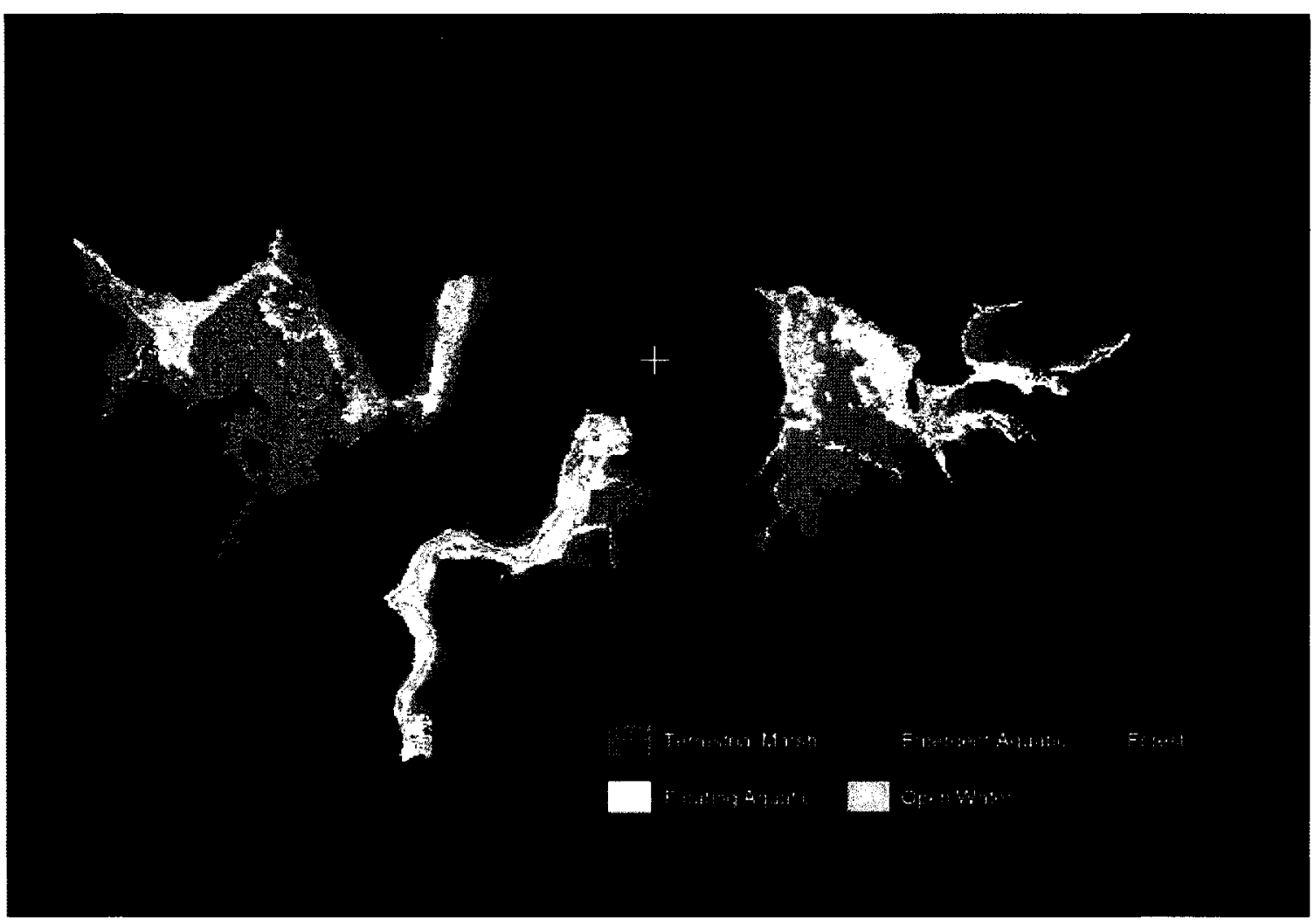

Figure 19. TVI classification for 5 classes with mode filter applied. 


\subsubsection{Neural Network Classification}

Unlike ML classification neural networks are not statistical in nature and can handle a greater number of input variables as well as correlation between variables. Through the classification process the best combination of inputs are generally determined. Due to the extensive scope of this research, neural network classification was limited and therefore inputs paralleled those used in the best ML classifications, although a greater number of inputs was used in several configurations. None of the fourteen neural networks fully converged to achieve both the maximum allowable individual $(0.001)$ and total $(0.01)$ errors. As shown in Table 19, neural network 10 was the only one to meet the total error parameter, though its individual error far exceeded the allowable limit. The smallest individual error was achieved by network 12 which, even after 100,000 iterations, still did not converge. 
Table 19. Neural network convergence.

\begin{tabular}{|c|c|c|c|}
\hline $\begin{array}{l}\text { Neural } \\
\text { Network } \\
\text { Number }\end{array}$ & Inputs & $\begin{array}{l}\text { Highest Individual } \\
\text { Class Error }\end{array}$ & $\begin{array}{l}\text { Total Error } \\
\text { Achieved }\end{array}$ \\
\hline 1 & $\begin{array}{l}\text { Spectral bands plus } \\
\text { A2M5grn and CON5nir }\end{array}$ & 2.07 & 0.14 \\
\hline 2 & $\begin{array}{l}\text { PC1-4 (derived from } \\
\text { spec bands) plus } \\
\text { A2M5grn and CON5nir }\end{array}$ & 2.18 & 0.12 \\
\hline 3 & $\begin{array}{l}\text { Spectral bands, } \\
\text { A2M5grn and CON5nir } \\
\text { plus MSAVI, NDVI, } \\
\text { RVI, SAVI and TVI }\end{array}$ & 2.17 & 0.12 \\
\hline 4 & $\begin{array}{c}\text { Spectral bands, } \\
\text { A2M5grn and CON5nir } \\
\text { plus MSAVI, NDVI, } \\
\text { RVI, SAVI and TVI }\end{array}$ & 1.91 & 0.09 \\
\hline 5 & $\begin{array}{l}\text { Spectral bands plus } \\
\text { A2M5grn and CON5nir }\end{array}$ & 2.08 & 0.23 \\
\hline 6 & $\begin{array}{l}\text { Spectral bands plus } \\
\text { A2M5grn and CON5nir }\end{array}$ & 2.00 & 0.10 \\
\hline 7 & $\begin{array}{l}\text { Spectral bands plus } \\
\text { A2M5grn and CON5nir }\end{array}$ & 2.06 & 0.08 \\
\hline 8 & $\begin{array}{l}\text { Spectral bands plus } \\
\text { A2M5grn and CON5nir }\end{array}$ & 1.91 & 0.07 \\
\hline 9 & $\begin{array}{l}\text { Spectral bands plus } \\
\text { A2M5grn and CON5nir }\end{array}$ & 1.94 & 0.06 \\
\hline 10 & $\begin{array}{l}\text { PC1 and PC2 (derived } \\
\text { from spec bands using } \\
\text { entire image) plus } \\
\text { GRN5 TEX }\end{array}$ & 1.63 & 0.01 \\
\hline 11 & $\begin{array}{l}\text { PC1 and PC2 (derived } \\
\text { from spec bands using } \\
\text { entire image) plus } \\
\text { NIR5 TEX }\end{array}$ & 1.66 & 0.03 \\
\hline 12 & $\begin{array}{c}\text { PC1 and PC2 (derived } \\
\text { from spec bands using } \\
\text { wetland mask) plus } \\
\text { GRN5 TEX }\end{array}$ & 1.43 & 0.02 \\
\hline 13 & $\begin{array}{l}\text { PC1 and PC2 (derived } \\
\text { from spec bands using } \\
\text { wetland mask) plus } \\
\text { NIR5 TEX }\end{array}$ & 1.93 & 0.03 \\
\hline 14 & $\begin{array}{l}\text { Spectral bands, } \\
\text { A2M5grn and Cor5nir } \\
\text { plus MSAVI, NDVI, } \\
\text { RVI, SAVI and TVI }\end{array}$ & 1.74 & 0.05 \\
\hline
\end{tabular}

Overall classification accuracies were generally lower for the neural networks compared to the ML classifications using the same 5 wetland classes. Neural 
Network 14 achieved the highest overall accuracy of $84.4 \%$ and a Kat statistic of

0.64. Table 20 shows the corresponding error matrix.

Table 20. Error matrix for 5 class neural network (\#14) classification.

Rows contain number of pixels assigned as reference data and columns contain number of pixels assigned as classified data.

\begin{tabular}{|l|c|c|c|c|c|c|}
\hline & TERm & FLAQ & EMAQ & OW & FOR & Row Total \\
\hline TERm & 313 & 6 & 10 & 0 & 13 & 342 \\
\hline FLAQ & 0 & 36 & 0 & 0 & 0 & 36 \\
\hline EMAQ & 18 & 0 & 0 & 0 & 0 & 18 \\
\hline OW & 1 & 0 & 0 & 44 & 0 & 45 \\
\hline FOR & 21 & 4 & 0 & 0 & 2 & 27 \\
\hline $\begin{array}{l}\text { Column } \\
\text { Total }\end{array}$ & 353 & 46 & 10 & 44 & 15 & 468 \\
\hline
\end{tabular}

In comparison to the best ML 5 class classifications, neural network 14 had similar class confusions, although the network achieved lower producer and user accuracies for forest and higher producer accuracy for floating aquatic. From Table 21 when all classes are considered equally important the average producer and user accuracies are only $56.1 \%$ and $59.4 \%$ for neural network 14 .

Table 21. Producer and user accuracies for 5 class map derived from neural network (\#14).

\begin{tabular}{|l|c|c|}
\hline & Producer's Accuracy (\%) & User's Accuracy (\%) \\
\hline Terrestrial Marsh & 88.67 & 91.52 \\
\hline Floating Aquatic & 78.26 & 100.00 \\
\hline Emergent Aquatic & 0.00 & 0.00 \\
\hline Open Water & 100.00 & 97.78 \\
\hline Forest & 13.33 & 7.41 \\
\hline
\end{tabular}

From visual assessment of Figure 20 , as for the MSAVI 7 class classification, the location of pixels assigned to the emergent aquatic class, shown in red, 
correspond to locations in which emergent terrestrial and shrub vegetation were observed in the field.

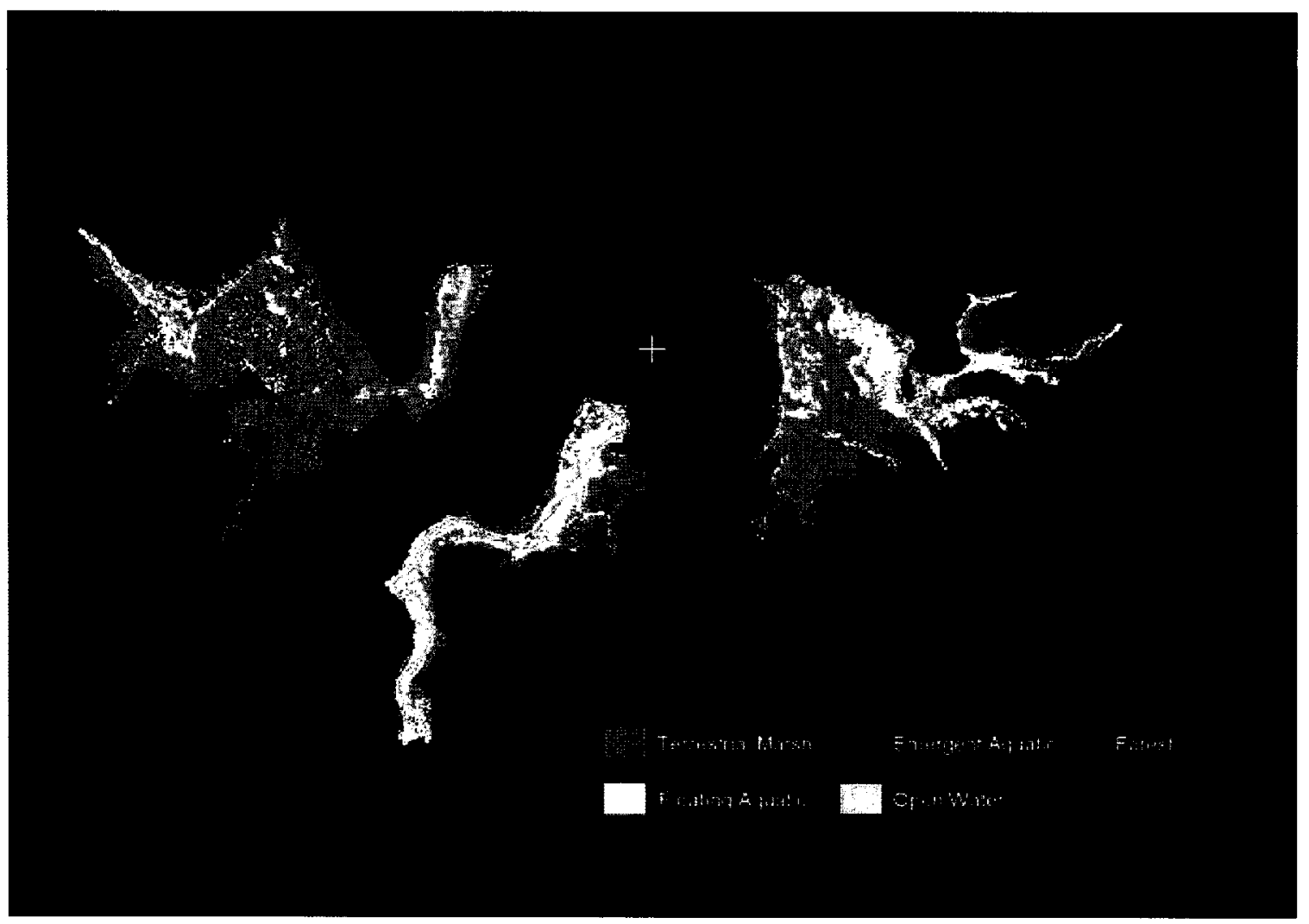

Figure 20. Neural Network 14 for five wetland classes.

\subsection{Biomass and Cover Modelling}

\subsubsection{Biomass Modelling}

Significant regression models $(p \leq 0.05)$ were created for many of the biomass datasets (combinations of senescent + green for both aquatic and terrestrial environments), however, most had Adjusted $R^{2}$ values of less than 0.3 and were therefore not analyzed further. Table 22 shows the Adjusted $R^{2}$ values for the linear and log transformed models of total aquatic + terrestrial biomass stratified as all biomass, green biomass and senescent biomass. Following derivation of 
these models, analysis of scatterplots between biomass and the image variables was conducted. Although trends were difficult to discern in most cases, several showed distinct curvilinearity. Log transformation of biomass significantly improved the Adjusted $R^{2}$ of the models, except for total senescent biomass.

Table 22. Variance accounted for by models of total combined biomass, total green biomass and total senescent biomass.

\begin{tabular}{|c|c|}
\hline Y Variable & Adjusted $\boldsymbol{R}^{2}$ \\
\hline Total green and senescent biomass & 0.257 \\
\hline Total green biomass & 0.385 \\
\hline Total senescent biomass & 0.183 \\
\hline $\log$ (Total green and senescent biomass) & 0.623 \\
\hline $\log$ (Total green biomass) & 0.639 \\
\hline $\log$ (Total senescent biomass) & 0.069 \\
\hline
\end{tabular}

In almost all models, the MN5grn texture was the first variable entered and it dominated the variance accounted for. Other variables entered in the non-log transformed models included COR3nir, MN3nir, STDEV5nir, blue band brightness, MSAVI and ASVI. In the log transformed models, some of these and additional variables were entered including GLA2M3grn and HOM5nir. For the combined green and senescent log biomass model, six variables were entered, which seems adequate for predictive purposes given the number of samples (75) was more than 10 times the number of variables entered into the model (Stevens, 1996). For the log green biomass model the same six variables were entered and for the senescent model only one variable was entered. Multicollinearity analysis of the log biomass models showed that for both the combined and green biomass models, HOM5nir was inversely correlated with STDEV5nir $(r=-0.83)$ and was entered into the model after STDEV5nir. The VIF 
values for HOM5nir and STDEV5nir were 3.42 and 4.18 , respectively, for both models. These exceeded the calculated thresholds of 2.65 for the log combined model and 3.01 for the log green model. In assessing model prediction, in the following section, it was also found that models including both of these variables grossly over-estimated biomass. HOM5nir was therefore dropped and both regressions were rerun. The VIF for these two models then fell to 2.57 and 2.56 , respectively (Freund and Wilson, 1998). The modelling results indicate that image variables are most strongly related to log biomass with the image texture variables proving to be the strongest predictors. The results for log green biomass, which was the best model produced, are listed in Table 23 showing the contribution of each variable towards $R^{2}$.

Table 23. $R^{2}$ contribution of independent variables in log green biomass model. Se is given in log units and in $\mathrm{g} / \mathrm{m} 2$.

\begin{tabular}{|c|c|c|c|c|c|}
\hline Model Variables & $R^{2}$ & Adjusted $R^{2}$ & $R^{2}$ Contribution & $\mathrm{Se}$ & $p$ \\
\hline $\begin{array}{l}\text { log green biomass } \\
\text { model }\end{array}$ & 0.61 & 0.58 & & $0.24 / 1.73$ & $<0.02$ \\
\hline MN5grn & & & 0.431 & & \\
\hline MN3nir & & & 0.043 & & \\
\hline STDEV5nir & & & 0.051 & & \\
\hline GLA2M3grn & & & 0.053 & & \\
\hline ASVI & & & 0.032 & & \\
\hline
\end{tabular}

The log model equation, stated below, was applied to the lkonos imagery to map green biomass, with log biomass being converted back to biomass in $\mathrm{g} / \mathrm{m}^{2}$, within each of the three marshes.

$$
y=5.863-0.269 X_{1}+0.148 X_{2}-0.244 X_{3}-0.394 X_{4}-1.979 X_{5}
$$

where, $y$ is log green biomass, $X_{1}$ is MN5grn, $X_{2}$ is MN3nir, $X_{3}$ is STDEV5nir, $X_{4}$ is GLA2M3grn and $X_{5}$ is ASVI. 
A gradient map showing biomass was produced, as well as a map showing aggregated classes of low $\left(0-1000 \mathrm{~g} / \mathrm{m}^{2}\right)$, medium $\left(1001-2000 \mathrm{~g} / \mathrm{m}^{2}\right)$ and high $\left(2001-3000 \mathrm{~g} / \mathrm{m}^{2}\right)$ biomass for the three wetlands (Figures 21 and 22). Open water is also shown. The spatial distribution of the three biomass classes, in Figure 22, matches well with that which was observed in the field with lower biomass found in aquatic areas next to open water and higher biomass in terrestrial marsh areas.

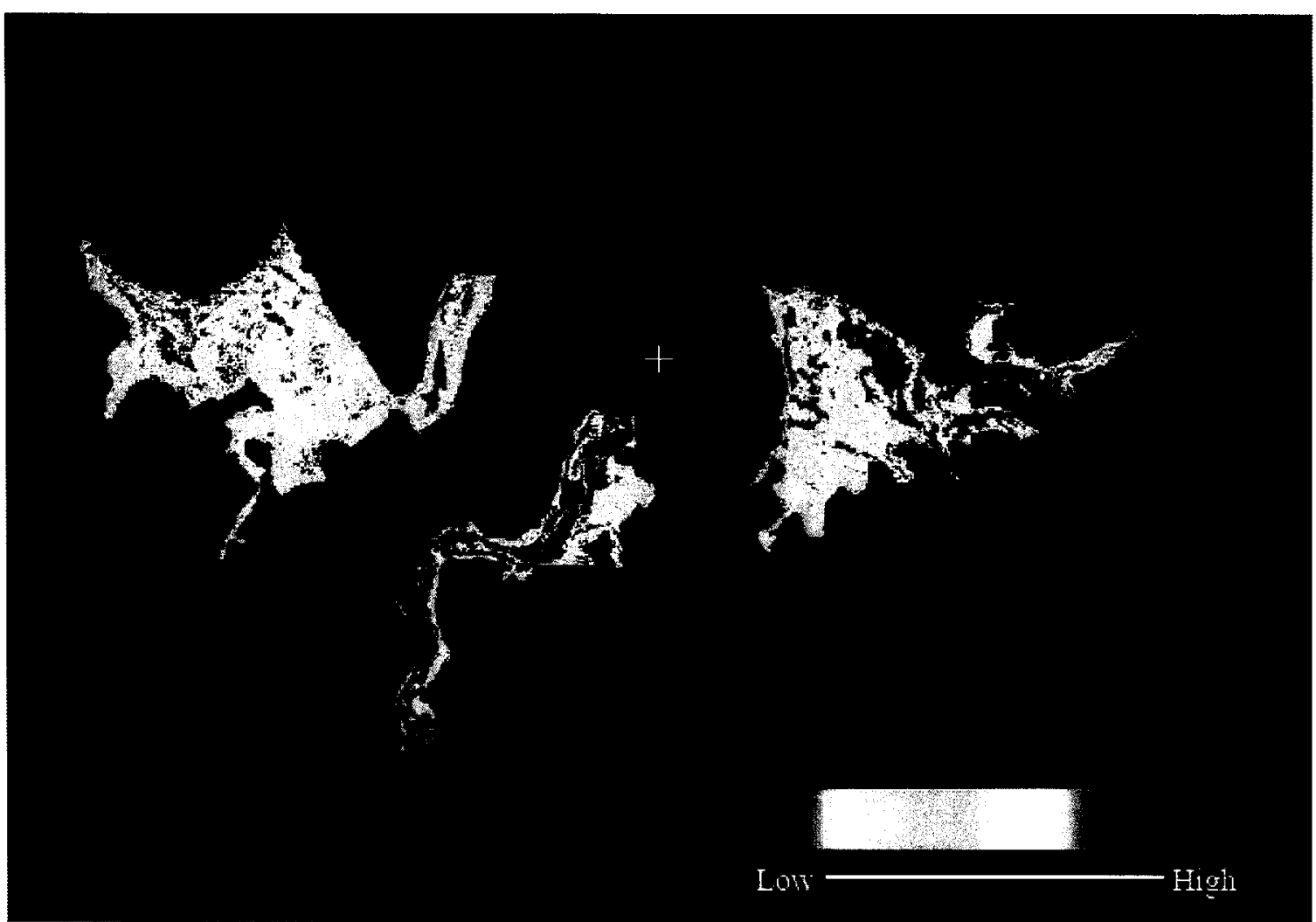

Figure 21. Gradient map of biomass.

Low biomass shown as blue grades to high biomass as bright pink. 


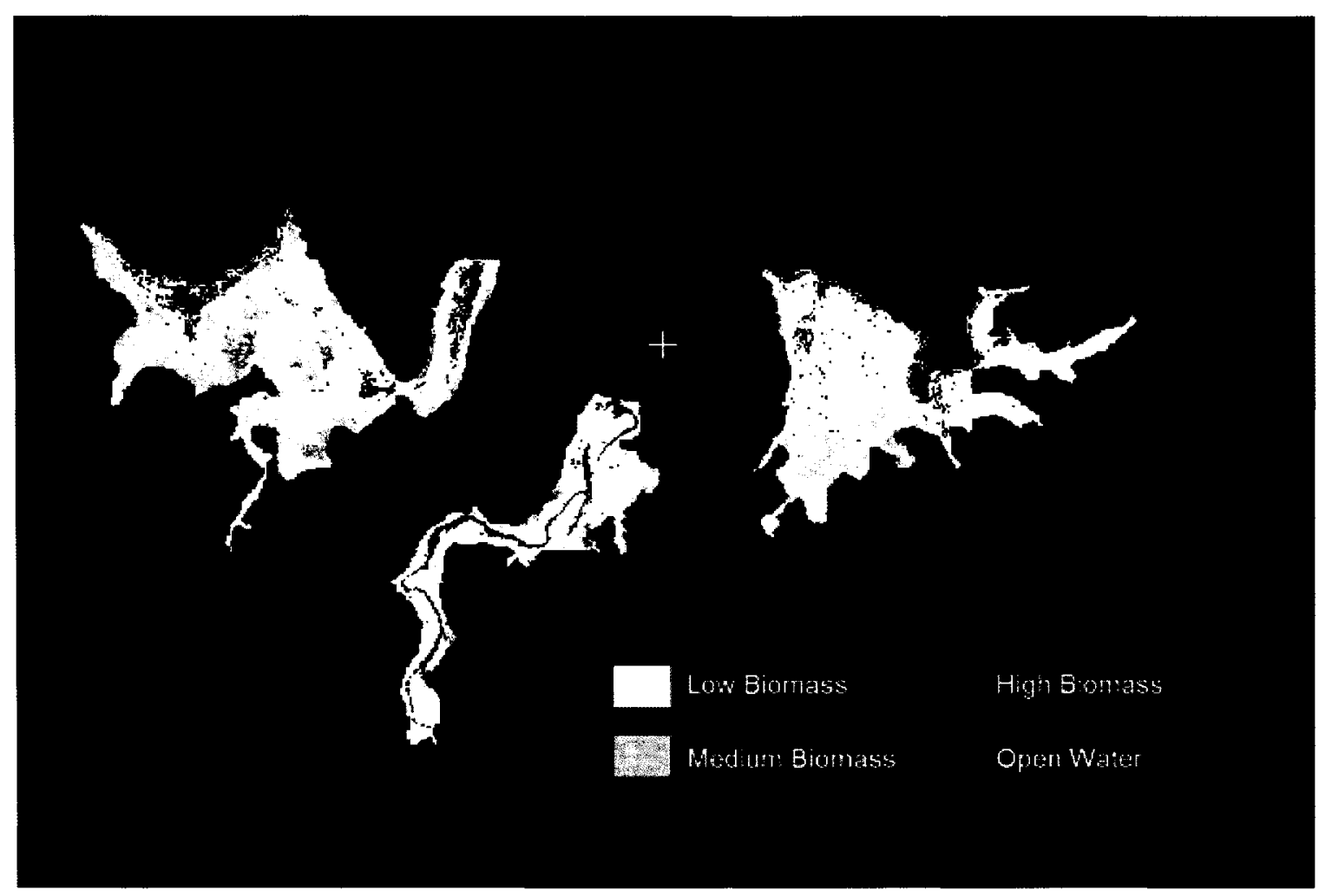

Figure 22. Biomass map showing three levels of biomass.

\subsubsection{Biomass Model Assessment and Validation}

As the log green model (with HOM5nir excluded due to multicollinearity)

produced the best results it was validated in five additional regressions and assessed for accuracy. Biomass was predicted from the regression equation for the sample plots not used in modelling and the three error measures, mean error, mean absolute error, and RMSE were calculated. Errors were compared for a one variable model (since MN5grn dominated all models) and models with all significant variables entered. The model and validation results are shown in Tables 24 and 25 with errors expressed as percentages of the mean field measured biomass. As can be seen from Tables 24 and 25 the mean errors for 
the single and multiple variables, indicate a moderate negative model bias of 5$14 \%$ and $1-18 \%$, respectively, where on average predicted biomass is less than field measured biomass. The mean absolute error and RMSE were quite high and as a result, biomass was aggregated into three classes of low, medium and high biomass to produce Figure 22 .

Table 24. Single variable model validation results.

MN5grn was entered for all models except \#2, where MN3grn was entered. Se is shown in log units (above) and $\mathrm{g} / \mathrm{m}^{2}$ (below).

Errors are expressed as percentages of the mean field measured biomass.

\begin{tabular}{|l|c|c|c|c|c|c|c|}
\hline Validation & $\boldsymbol{R}^{2}$ & $\begin{array}{c}\text { Adj } \\
\boldsymbol{R}^{2}\end{array}$ & $\mathbf{S e}$ & $\begin{array}{c}\text { Mean } \\
\text { Error (\%) }\end{array}$ & $\begin{array}{c}\text { Mean Abs. } \\
\text { Error (\%) }\end{array}$ & $\boldsymbol{R M S E ~ ( \% )}$ & $\boldsymbol{p}$ \\
\hline 1 & 0.34 & 0.33 & 0.30 & -11.17 & 37.81 & 56.09 & 0.000 \\
\hline 2 & 0.54 & 0.53 & 0.25 & -13.52 & 48.42 & 65.23 & 0.000 \\
\hline 3 & 0.42 & 0.40 & 0.28 & -5.15 & 40.88 & 54.46 & 0.000 \\
\hline 4 & 0.40 & 0.39 & 0.27 & -14.97 & 39.64 & 53.87 & 0.000 \\
\hline 5 & 0.33 & 0.32 & 0.31 & -10.22 & 34.31 & 42.83 & 0.000 \\
\hline Average & $\mathbf{0 . 4 1}$ & $\mathbf{0 . 3 9}$ & $\mathbf{0 . 2 8}$ & -11.01 & $\mathbf{4 0 . 2 1}$ & $\mathbf{5 4 . 5 0}$ & $\mathbf{0 . 0 0 0}$ \\
\hline
\end{tabular}

Table 25. Multiple variable model validation results.

Se is shown in log units and $\mathrm{g} / \mathrm{m}^{2}$.

Errors are expressed as percentages of the mean field measured biomass.

\begin{tabular}{|l|c|c|c|c|c|c|c|}
\hline Validation & $\boldsymbol{R}^{2}$ & Adj $\boldsymbol{R}^{2}$ & $\mathbf{S e}$ & $\begin{array}{c}\text { Mean } \\
\text { Error (\%) }\end{array}$ & $\begin{array}{c}\text { Mean Abs. } \\
\text { Error (\%) }\end{array}$ & $\begin{array}{c}\text { RMSE } \\
(\%)\end{array}$ & $\boldsymbol{p}$ \\
\hline 1 & 0.52 & 0.48 & 0.26 & -1.21 & 30.18 & 49.20 & 0.026 \\
\hline 2 & 0.54 & 0.53 & 0.25 & -13.52 & 48.42 & 65.23 & 0.000 \\
\hline 3 & 0.72 & 0.69 & 0.21 & -1.74 & 52.88 & 69.12 & 0.020 \\
\hline 4 & 0.58 & 0.56 & 0.23 & -18.50 & 46.43 & 63.61 & 0.001 \\
\hline 5 & & & 1.70 & & & & \\
\hline Average & 0.47 & 0.44 & 0.28 & -3.08 & 45.06 & 65.29 & 0.011 \\
\hline
\end{tabular}




\subsubsection{Cover Modelling}

Percent cover was visually estimated during the field campaign, though estimates of tall vegetation were based on a more horizontal viewing perspective and as a result, field photographs were classified to achieve a more accurate vertical depiction of percent cover. An example of classification of floating aquatic vegetation is shown in Figures 23a and 23b. The classes in Figure 23b are live vegetation, senescent vegetation and open water. Calculated estimates of percent cover were tabulated from the classified images. Figures $24 a$ and $24 b$ show an emergent aquatic plot and its corresponding classified image. From visual assessment, the classification appears quite representative of live vegetation cover and open water, though as can be seen in Figure 24a the vegetation is leaning towards the top left corner of the photo. Table 26 compares the visual and calculated estimates of percent cover for the two representative plots from Figures $23 a$ and $24 a$. It is apparent that they are nearly identical for floating vegetation, while those for emergent terrestrial vegetation differ quite dramatically. 


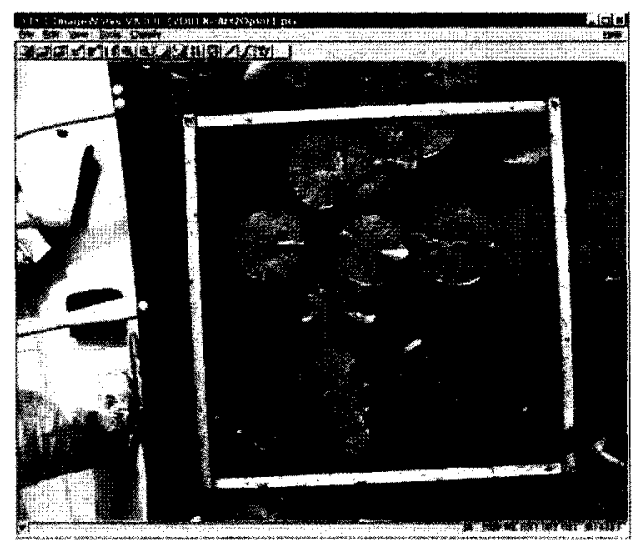

(a) KilA Water plot 1.

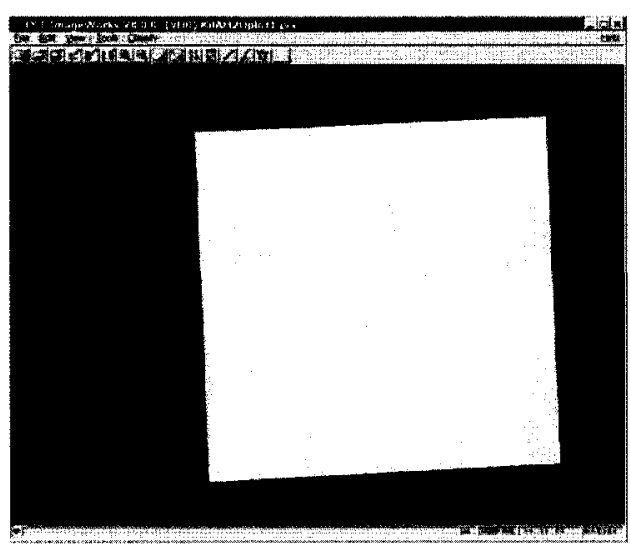

(b) KilA Water plot 1 classified. Green is live vegetation, Yellow is senescent vegetation and Blue is open water.

Figure 23. Floating aquatic plot and corresponding classified image.

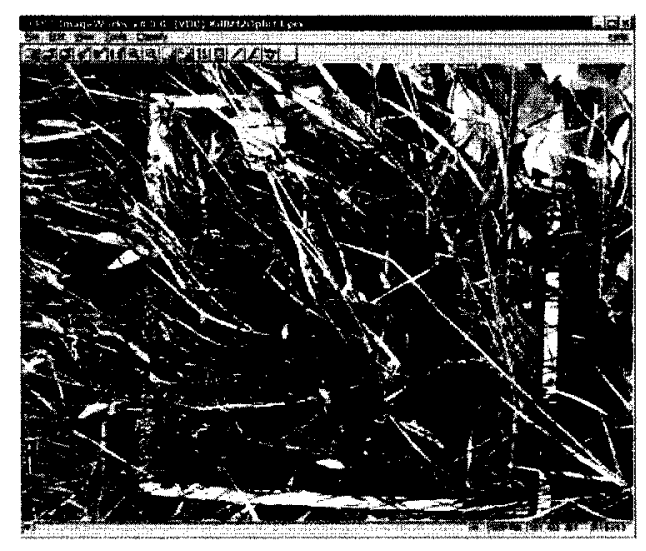

(a) KilB Water plot 3.

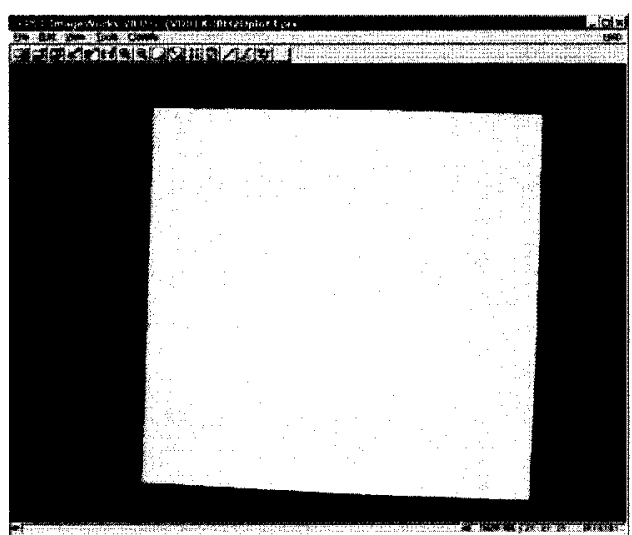

(b) KilB Water plot 3 classified. Green is live vegetation and Blue is open water.

Figure 24. Emergent aquatic plot and corresponding classified image. 
Table 26. Comparing field estimates and calculated estimates of percent cover.

\begin{tabular}{|c|c|c|c|c|c|c|}
\hline Plot & $\begin{array}{c}\text { FE } \\
\text { \%Cover } \\
\text { Green }\end{array}$ & $\begin{array}{c}\text { CE } \\
\text { \%Cover } \\
\text { Green }\end{array}$ & $\begin{array}{c}\text { FE } \\
\text { \%Cover } \\
\text { Yellow }\end{array}$ & $\begin{array}{c}\text { CE } \\
\text { \%Cover } \\
\text { Yellow }\end{array}$ & $\begin{array}{c}\text { FE } \\
\text { \%over } \\
\text { Open } \\
\text { Water }\end{array}$ & $\begin{array}{c}\text { CE } \\
\% \text { Cover } \\
\text { Open } \\
\text { Water }\end{array}$ \\
\hline KilA1 & 54.00 & 54.84 & 6.00 & 5.96 & 40.00 & 39.20 \\
\hline KilB3 & 90.00 & 79.56 & 0.00 & 0.00 & 10.00 & 20.44 \\
\hline
\end{tabular}

When the two estimates of percent cover were used as independent variables against green biomass, calculated percent cover was the only variable entered into the model, though the Adjusted $R^{2}$ was only 0.347 and the Se was very high (76.35 log units or $2.23 \mathrm{~g} / \mathrm{m}^{2}$ ). When log green biomass was used as the dependent variable the Adjusted $R^{2}$ increased to 0.481 and the Se significantly decreased to $0.18 \mathrm{log}$ units or $1.51 \mathrm{~g} / \mathrm{m}^{2}$. This shows that cover is somewhat related to biomass, but that it is mostly a complementary measure of vegetation quantity.

Both estimates of cover were also used as the dependent variables in forward stepwise regression against all image variables. Field cover produced the most significant regression models $(p<0.05)$ for the green aquatic environment. Following derivation of these models, analysis of scatterplots between field cover and the image variables was conducted. Although trends were difficult to discern in most cases, several showed distinct curvilinearity. Log transformation of field cover significantly improved the Adjusted $R^{2}$ of the models as shown in Table 27.

Table 27. Variance accounted for by models of aquatic green field cover.

\begin{tabular}{|c|c|}
\hline Y Variable & Adjusted $\boldsymbol{R}^{2}$ \\
\hline Total green field cover & 0.471 \\
\hline $\log$ (Total green field cover) & 0.595 \\
\hline
\end{tabular}


Variables entered in the non-log field cover model included ASVI, A2M5nir and HOM3grn, and for the log model A2M3nir, ENTR3nir and ASVI were entered. Multicollinearity analysis of the log field cover model indicated that Entr3nir was inversely correlated with A2M3nir $(r=0.96)$ and was entered into the model after the first variable A2M3nir. The VIF for A2M3nir and Entr3nir were 13.897 and 13.903 for the log field cover model with these values exceeding the calculated threshold of 2.90 (Freund and Wilson, 1998). After dropping Entr3nir and rerunning the regression, the VIF for this model fell to 1.92, although the Adjusted $R^{2}$ was also reduced to 0.421 . Cover models were not validated and assessed for accuracy because they produced poorer results compared to the biomass models. 


\section{Chapter Five: Discussion and Conclusions}

This chapter is divided into four sections; the first section focuses on the image and field data component, section two discusses wetland vegetation classification, section three focuses on biomass and cover modelling, and the final section gives the overall conclusions of this study. Within the first three sections the two primary objectives of this thesis (stated on p.2) are evaluated by discussing the significant findings in relation to the existing literature, examining the limitations of this study, and making recommendations for future research.

\subsection{Data Collection}

Image acquisition date has been found to be an important factor for wetland mapping. Spring and summer Ikonos imagery was used by Dechka et al. (2002) to map detailed prairie wetland vegetation with July imagery producing the best classification result of $80 \%$, compared to the May result of $50 \%$. Due to cloud cover earlier in the summer of 2003 , image acquisition for this thesis was delayed. Despite the late summer acquisition an overall classification accuracy of $88 \%$ was achieved, although there was significant confusion between emergent aquatic and emergent terrestrial vegetation. Earlier summer acquisition could have improved the discrimination between these two classes as Common reed (Phragmites australis), the dominant emergent aquatic vegetation, matures in late summer compared to Common cattail (Typha latifolia), the dominant emergent terrestrial vegetation, which matures in early summer. Multi- 
temporal imagery could also aid in discriminating between spectrally similar vegetation classes, although at increased cost.

An integral part of any remote sensing research is the collection of field data which should coincide with image acquisition. Lee and Lunetta (1996) have stated that ground reference data are essential for reliability and confidence estimates. One of the strengths of this research was the large field component which occurred from July to early September during the summer of 2003 with biomass harvesting coinciding with image acquisition. For the classification component 107 locations were used, with a subset of 75 of these being used for biomass analysis. The $200 \mathrm{~m}$ distance between field plots was estimated as a suitable interval to minimize the effects of spatial autocorrelation. Emergent aquatic vegetation, a dominant class within Kilmarnock marsh, was less common in the other two wetlands which resulted in the small sample size for this class. More frequent sampling of emergent aquatic should have been conducted in Kilmarnock marsh, though spatial autocorrelation associated with closer sampling distance is unknown. Spatial dependence in class type and biomass should be studied further and integrated into sampling design in future research.

\subsection{Wetland Vegetation Classification}

The use of high resolution Ikonos imagery was fundamental for the detailed mapping objective of this research. Green et al. (1998) found that high resolution 
imagery was more capable of mapping detailed wetland classes compared to moderate resolution Landsat and SPOT imagery.

Although Ikonos imagery has greater spatial detail it lacks spectral detail, which limits the vegetation indices that can be applied. From the literature, the only vegetation index that had been used for wetland classification purposes was NDVI (Lee and Park, 1992; Hunter and Power, 2002). In this research, however, seven vegetation indices were compared for use in wetland classification. The NDVI combination produced an overall classification accuracy of $87.61 \%$, and the TVI combination produced a similar accuracy of $87.82 \%$. Of the vegetation indices evaluated DVI, NDVI and TVI, were found to be useful for discriminating between different wetland vegetation types and improving classification accuracy relative to using the spectral band or PC combinations. The use of vegetation indices in classification should be analysed further.

An important component of image classification is the selection of input data channels. Textural data have been found to improve classification accuracy, though the number of textures which should generally be used in analysis is unknown. This research, and that done by Arzandeh and Wang (2002), found that the inclusion of textures in classification was important for wetland mapping. In this research, due to the large number of image textures $(3 \times 3$ and $5 \times 5$ for both green and NIR) considered for classification, separability analysis was used to select the two best textures that were also uncorrelated with each other and 
other image variables. From this analysis Angular Second Moment extracted from the green band, and Contrast extracted from the NIR band, both using $5 \times 5$ windows, were found to be the best textures to discriminate between class pairs. Arzandeh and Wang (2002) also found that Angular Second Moment and Contrast were important textures in mapping marshes, although they also concluded that four texture measures used in combination produced better accuracy than two textures combined. A subsequent limitation to this thesis is that only two textures were used in combination with other image data. Further analysis could be conducted to determine if incorporation of additional textures would improve classification accuracies.

The use of all four PCs derived from the spectral bands produced a significantly higher overall classification result of $83.12 \%$ compared to using only PC1 and PC2, accounting for the highest percentage of the variance, which resulted in an accuracy of $62.18 \%$. Gluck et al. (1996) found that low variance PCs were important for distinguishing wetland from upland. Although this thesis research concentrated on mapping wetland classes a forest class was included, which was best distinguished from the wetland classes using all PCs in classification.

In this research, only unstandardized PCA was used, which resulted in the dominance of higher variance spectral bands. The use of standardized PCA could result in low variance variables contributing more towards individual PCs which would represent more significant spectral and spatial information. 
Supervised classifications run with 7 wetland classes produced poor overall and individual class accuracies. Four subsequent merging tests were performed grouping: emergent terrestrial and shrubs; shrub and grasses/sedges; emergent terrestrial, emergent aquatic and grasses/sedges; and emergent terrestrial, shrub and grasses/sedges. The best six class and five class combinations were used in subsequent classifications. Gluck et al. (1996) used Landsat TM imagery to map regional wetlands in north western Ontario and found that merging of spectrally similar wetland classes improved classification accuracy by about $10 \%$. This thesis also showed improved accuracy as spectrally similar wetland classes were combined, where merging from 7 to 5 wetland classes resulted in overall accuracy increases of $26.50 \%$ (best 7 class versus best 5 class), with the best classification achieved from a 5 class combination of TVI, visible bands, A2M5grn and CON5nir. A significant limitation of the classification component was the small sample sizes acquired for grasses/sedges, emergent aquatic and shrub classes due to spatially representative field sampling, which resulted in class confusion and required subsequent merging of these classes with more dominant classes. This resulted in less detailed wetland mapping at a local scale than was anticipated, as it was initially proposed from field analysis that 7 wetland classes (emergent terrestrial, shrub, floating aquatic, emergent aquatic, open water, forest and grasses/sedges) could be mapped for the three marshes of interest. For example, in all classifications emergent aquatic was confused with terrestrial marsh vegetation. In the future, additional tests might be performed to determine if merging these two classes would significantly improve 
classification accuracy. Using different sensors with greater spectral resolution, and examining different acquisition dates could be used to improve discrimination of spectrally similar classes.

The classification results of this thesis differ from those of Berberoglu et al. (2004) who used Landsat TM imagery and compared ML and neural network classifications, and found that neural network classification produced the best overall accuracy of $90.20 \%$ compared to $76.0 \%$ for the ML classifier. They also found that the neural network produced less confusion between water and two wetland classes (wetland vegetation and bulrushes) and was better at delineating classes of high heterogeneity and spectral complexity. In the present study, neural networks did not produce superior results, with the best overall classification resulting from a ML classifier combination using TVI, visible bands, A2M5grn and CON5nir for 5 classes (TERm, FLAQ, EMAQ, OW and FOR) producing a high overall accuracy of $87.82 \%$ and a moderate $K_{\text {hat }}$ statistic of 0.72 , compared to an overall accuracy or $84.40 \%$ and a $K_{\text {hat }}$ statistic of 0.64 for the best neural network classification. The ML classifier was simpler to apply than neural networks, which require time consuming experimentation to configure the network in order to minimize both individual and total errors.

Accuracy assessment for the classifications was performed using standard error matrices and $K_{\text {hat }}$ statistics with $3 \times 3$ validation datasets. The use of $3 \times 3$ validation windows does, however, introduce an inherent bias as the pixels within 
each window are spatially autocorrelated and do not represent independent samples. The use of $1 \times 1$ validation datasets was not feasible, particularly for the emergent aquatic and forest classes where there were only five validation samples for each class which was considered an insufficient sample size. In the future, sampling design should be altered to ensure that adequate sample sizes for each class can be achieved, resulting in adequate numbers of training and validation sites for rigorous single pixel accuracy assessment.

\subsection{Biomass and Cover Modelling}

Regression analysis was applied with spectral and spatial image variables as the independent variables and combinations of green and senescent biomass as the dependent variable. Regression analysis using the same independent variables against cover as the dependent variable was also conducted, but results were poorer. It was found that MN5grn dominated all biomass models and that textures contributed more to the models than spectral data or vegetation indices. From the biomass datasets (combinations of senescent and green for both aquatic and terrestrial environments) which were used, log green biomass produced the best model and was adequate for use in predictive biomass mapping.

Two maps were produced showing a gradient of high to low biomass, and three levels of biomass shown as low, medium and high for each wetland. Biomass was scaled to three categories as result of high RMSE and mean absolute error. 
The three level biomass map indicates that the estimated biomass values correspond well with the expected spatial distribution with lower biomass in the aquatic areas next to open water and higher biomass in the terrestrial marsh areas. This research also found that multicollinearity within regression models can distort prediction capabilities by producing models that highly over-estimate biomass. Assessment of the log green biomass model with no collinearity showed that on average, it slightly underestimated biomass.

Regression modelling was conducted by Hardisky et al. (1984) using NDVI as an independent variable and harvested biomass in $\mathrm{g} / \mathrm{m}^{2}$ as the dependent variable for predicting short and tall Spartina alterniflora biomass in a salt marsh environment. From all model evaluations they determined that on average live biomass was underestimated. The short population models ( $n=139)$, achieved a $R^{2}$ of 0.43 , a mean absolute error of $93 \mathrm{~g} / \mathrm{m}^{2}$ and a RMSE of $122 \mathrm{~g} / \mathrm{m}^{2}$. Whereas, the tall population models $(n=46)$, achieved a $R^{2}=0.71$, a mean absolute error of $175 \mathrm{~g} / \mathrm{m}^{2}$ and a RMSE of $228 \mathrm{~g} / \mathrm{m}^{2}$. These are similar error magnitudes to those of this study, although they could not be expressed as a percent relative to mean biomass due to a lack of reported data.

Using the averages derived from the multiple variable validation results the log green model used in this research $(n=24)$, achieved a $R^{2}$ of 0.57 . The mean absolute error and RMSE were $213 \mathrm{~g} / \mathrm{m}^{2}$ and $298 \mathrm{~g} / \mathrm{m}^{2}$, respectively. Using the averages from the five validations does not, however, give a clear indication of 
model accuracy. For example, the first validation run achieved a $R^{2}$ of 0.52 , a mean absolute error of $127 \mathrm{~g} / \mathrm{m}^{2}$ and a RMSE of $207 \mathrm{~g} / \mathrm{m}^{2}$, with the error values better comparing to those achieved by Hardisky et al. (1984) for the tall population model. The higher RMSE compared to the mean absolute error for the log green model validation indicates that a few large differences between field measured and predicted biomass existed in the model dataset. Extreme outlier values resulted from plots with very high biomass. Due to multicollinearity within the initial log green biomass model an independent variable was dropped from the model dataset which resulted in a decreased $R^{2}$ value. Future research could focus on the influence of stratifying vegetation according to height or dominant vegetation class for biomass modelling.

Previous literature (Lawrence and Ripple, 1998; Purevdorj et al., 1998) has shown non-linear relations between image variables and vegetation cover. Lawrence and Ripple (1998) compared linear, log transformation and polynomial regressions and found that NDVI had the highest correlation to herbaceous vegetation cover $\left(R^{2}=0.70\right)$ using a fourth order polynomial, and Purevdorj et al. (1998) found that TSAVI was the best predictor of grassland vegetation cover using a second order polynomial $\left(R^{2}=0.92\right)$. In contrast, Eastwood et al. (1997) found that MSAVI showed a strong linear relation with salt marsh vegetation cover $\left(R^{2}=0.97\right)$. In comparison, a linear regression produced the best result for modelling cover in this thesis, showing a moderate correlation of $\left(R^{2}=0.55\right)$ for 
ASVI and two textures (A2M5nir and HOM3grn) to aquatic wetland vegetation cover.

\subsection{Overall Conclusions}

Using high resolution Ikonos imagery three classes of wetland were successfully mapped: terrestrial marsh, floating aquatic and open water. In all classifications emergent aquatic was incorrectly classified, though it was found to visually coincide with areas on the ground assigned to that class.

In this study, maximum likelihood classification outperformed neural network classification, with the best classification from a combination using the visible bands, A2M5grn, CON5nir and TVI producing a high overall accuracy of $87.82 \%$ and a moderate $K_{\text {hat }}$ statistic of 0.72 .

Mapping of specific wetland classes could improve monitoring of essential habitat for many animal, bird and fish species. Detailed wetland mapping can also provide effective visual archives for monitoring of individual wetlands that are not easily obtainable from field investigations due to deep water and unstable terrain or wetlands under private land ownership. Thematic land cover maps derived from image classification can identify spatial patterns of vegetation and can be used as a tool to identify wetlands areas susceptible to urban development and agricultural pressure. 
For the modeling component, biomass models produced better results than cover models. For all biomass models, the MN5grn texture dominated, and textures were found to contribute more towards the models than either raw spectral data or vegetation indices. The best model was found to be log green biomass for combined terrestrial and aquatic plots, and was validated and assessed for accuracy. On average, this model slightly underestimated biomass and had an absolute error of about $40 \%$. The regression equation was applied to the imagery to produce two maps showing a gradient of biomass and three levels of biomass. The three level map was an adequate representation of biomass as seen in the field with low biomass occurring in areas next to open water and high biomass being found in terrestrial areas.

Evaluations conducted under the OWES typically occur only once for a given wetland despite the dynamics of these ecosystems, which are directly influenced by surrounding hydrological conditions that impact wetland productivity. Changes in wetland classes and in their spatial distribution (heterogeneity) within a given wetland could be monitored yearly or on a less frequent basis using the classification methods applied in this research.

Poor biological productivity results in lower survival rates for dependent secondary and tertiary members of the food chain. Although the biomass model used in this research could not be directly transferred to another study due to differences in wetland type or vegetation composition the methods used could be 
employed by the OWES to acquire more quantitative measures of biomass as an indicator of wetland productivity.

An advantage to remote sensing based studies is that they are spatially explicit, showing spatial distributions of classes and productivity. The classification and biomass methods used in this thesis could benefit monitoring of individual wetlands to determine the spatial distributions of wetland classes and productivity for both small and large scale wetland studies. The larger the wetland complex the more beneficial these methods, as ground sampling does not need to increase in proportion to wetland size but rather it needs to be representative of the vegetation types present.

Future research in high resolution wetland mapping and biomass modelling could investigate other sensors such as hyperspectral, radar or lidar which have been shown to have potential in other studies. These could be integrated with temporal data and/or more advanced data analysis methods including spectral unmixing, other spatial techniques (semivariogram analysis), and data fusion. 


\section{References}

Ackleson S.G., and Klemas V. 1987. Remote Sensing of Submerged Aquatic Vegetation in Lower Chesapeake Bay: A Comparison of Landsat MSS to TM Imagery. Remote Sensing of Environment, 22:235-248.

Allison P.D. 1999. Multiple Regression: A Primer. Pine Forge Press: Thousand Oaks, California. 202p.

An P., and Chung C.F. 1994. Neural Network Approach for Geological Mapping: Technical Background and Case Study. Canadian Journal of Remote Sensing, 20:293-301.

Anderson G.L., Hanson J.D., and Haas R.H. 1993. Evaluating Landsat Thematic Mapper Derived Vegetation Indices for Estimating Above-Ground Biomass on Semiarid Rangelands. Remote Sensing of Environment, 45:165175.

Arzandeh S., and Wang J. 2002. Texture Evaluation of Radarsat Imagery for Wetland Mapping. Canadian Journal of Remote Sensing, 28:653-666.

Arzandeh S., and Wang J. 2003. Monitoring the Change of Phragmites Distribution Using Satellite Data. Canadian Journal of Remote Sensing, 29:2435.

Augusteijn M.F., and Warrender C.E. 1998. Wetland Classification Using Optical and Radar Data and Neural Network Classification. International Journal of Remote Sensing, 19:1545-1560.

Austin J.M., Mackey B.G., and Van Neil K.P. 2003. Estimating Forest Biomass Using Satellite Radar: An Exploratory Study in a Temperate Australian Eucalyptus Forest. Forest Ecology and Management, 176:575-583.

Avery T.E., and Berlin G.L. 1992. Fundamentals of Remote Sensing and Airphoto Interpretation. $5^{\text {th }}$ Edition. Macmillan Publishing Company: New York, NY. $472 p$.

Bannari A., Morin D., and Bonn F. 1995. A Review of Vegetation Indices. Remote Sensing Reviews, 13:95-120.

Baraldi A., and Parmiggiani F. 1995. An Investigation of the Textural Characteristics Associated with Gray Level Co-occurrence Matrix Statistical Parameters. IEEE Transactions on Geoscience and Remote Sensing, 33:293304. 
Bartlett D.S., and Klemas V. 1980. Quantitative Assessment of Tidal Wetlands Using Remote Sensing. Environmental Management, 4:337-345.

Berberoglu S., Yilmaz K.T., and Ozkan C. 2004. Mapping and Monitoring of Coastal Wetlands of Cukurova Delta in the Eastern Mediterranean Region. Biodiversity and Conservation, 13:615-633.

Boyd D.S., Foody G.M., and Ripple W.J. 2002. Evaluation of Approaches for Forest Cover Estimation in the Pacific Northwest, USA, Using Remote Sensing. Applied Geography, 22:375-392.

Campbell J.B. 1996. Introduction to Remote Sensing. $2^{\text {nd }}$ Edition. Guilford Press: New York, NY. 622p.

Clausi D.A. 2002. An Analysis of Co-occurrence Texture Statistics as a Function of Grey Level Quantization. Canadian Journal of Remote Sensing, 28:45-62.

Clevers J.P.W. 1986. The Application of a Vegetation Index in Correcting the Infrared Reflectance for Soil Background. International Archives of Photogrammetry and Remote Sensing, 26:221-226. Balkema, Rotterdam, Boston.

Cole C.A. 1992. Wetland Vegetation Ecology on a Reclaimed Coal Surface Mine in Southern Illinois, USA. Wetlands Ecology and Management, 2:135-142.

Cole C.A., Brooks R.P., and Wardrop D.H. 2001. Assessing the Relationship Between Biomass and Soil Organic Matter in Created Wetlands of Central Pennsylvania, USA. Ecological Engineering, 17:423-428.

Congalton, R.G. 1991. A Review of Assessing the Accuracy of Classifications of Remotely Sensed Data. Remote Sensing of Environment, 37:35-46.

Cosmopoulos P., and King D.J. 2004. Temporal Analysis of Forest Structural Condition at an Acid Mine Site Using Multispectral Digital Camera Imagery. International Journal of Remote Sensing, 25:1-17.

Crist E.P., and Cicone R.C. 1984. Comparisons of the Dimensionality and Feature of Simulated Landsat 4 MSS and TM Data. Remote Sensing of Environment, 14:235-246.

Dechka J.A., Franklin S.E., Watmough M.D., Bennett R.P., and Ingstrup D.W. 2002. Classification of Wetland Habitat and Vegetation Communities Using Multi-Temporal Ikonos Imagery in Southern Saskatchewan. Canadian Journal of Remote Sensing, 28:679-685. 
Eastwood J.A., Yates M.G., Thomson A.G., and Fuller R.M. 1997. The Reliability of Vegetation Indices for Monitoring Saltmarsh Vegetation Cover. International Journal of Remote Sensing, 18:3901-3907.

Environment Canada. 1986. Land Use Change in Canada-Wetlands In Canada: A Valuable Resource. Lands Directorate Fact Sheet 86-4.

Foody G.M., Lucas R.M., Curran P.J., and Honzak M. 1996. Estimation of the Areal Extent of Land Cover Classes that Only Occur at a Sub-Pixel Level. Canadian Journal of Remote Sensing, 22:428-432.

Franklin S.E., and Peddle D.R. 1990. Classification of SPOT HRV Imagery and Texture Features. International Journal of Remote Sensing, 11:551-556

Freund R.J., and Wilson W.J. 1998. Regression Analysis: Statistical Modeling of a Response Variable. Academic Press: San Diego, California. 444p.

Gibson P.J., and Power C.H. 2000. Introductory Remote Sensing: Digital Image Processing and Applications. Routledge: London, UK. 249p.

Gluck M., Rempel R., and Uhlig P.W.C. 1996. An Evaluation of Remote Sensing for Regional Wetland Mapping Applications. Forest Research Report No.137. Ontario Forest Research Institute, Sault Ste Marie, Ontario, Canada. $33 p$.

Green E.P., Clark C.D., Mumby P.J., Edwards A.J., and Ellis A.C. 1998. Remote Sensing Techniques for Mangrove Mapping. International Journal of Remote Sensing, 19:935-956.

Griffiths G.H., Smith J.M., Veitch N., and Aspinall R. 1993. The Ecological Interpretation of Satellite Imagery with Special Reference to Bird Habitats. In: Haines-Young R., Green D.R., and Cousins S. (eds). Landscape Ecology and Geographic Information Systems. Taylor and Francis Ltd: London, UK. Pp.255272.

Hair J.F.Jr., Anderson R.E., Tatham R.L., and Black W.C. 1998. Mulitvariate Data Analysis. $5^{\text {th }}$ Edition. Prentice Hall: Upper Saddle River, New Jersey. 730p.

Hammer D.A. 1997. Creating Freshwater Wetlands. $2^{\text {nd }}$ Edition. CRC Press Incorporated: Boca Raton, Florida. 406p.

Haralick R.M., Shanmugan K., and Dinstein I. 1973. Textural Features for Image Classification. IEEE Transactions on Systems, Man and Cybernetics, 3:610-621. 
Haralick R.M., and Fu K. 1983. Pattern Recognition and Classification. Manual of Remote Sensing, Vol.1:793-805. R.Colwell (ed). American Society of Photogrammetry: Falls Church, VA.

Hardisky M.A., Daiber F.C., Roman C.T., and Klemas V. 1984. Remote Sensing of Biomass and Annual Net Aerial Primary Productivity of a Salt Marsh. Remote Sensing of Environment, 16:91-106.

Hebert P.D.N. (ed). 2002a. Canada's Aquatic Environments. Wetlands. Website URL: www.aquatic.uoguelph.ca/wetlands/chapter2/bogs.htm.

Hebert P.D.N. (ed). 2002b. Canada's Aquatic Environments. Wetlands. Website URL: www.aquatic.uoguelph.ca/wetlands/chapter2/fens.htm.

Hebert P.D.N. (ed). 2002c. Canada's Aquatic Environments. Wetlands. Website URL: www.aquatic.uoguelph.ca/wetlands/chapter2/swamps.htm.

Hebert P.D.N. (ed). 2002d. Canada's Aquatic Environments. Wetlands. Website URL: www.aquatic.uoguelph.ca/wetlands/chapter2/shallow.htm.

Herr A.M., and Queen L.P. 1993. Crane Habitat Evaluation Using GIS and Remote Sensing. Photogrammetric Engineering and Remote Sensing, 59:15311538.

Heute A.R. 1988. A Soil-Adjusted Vegetation Index. Remote Sensing of Environment, 25:295-309.

Hill D.T., Payne V.W.E., Rogers J.W., and Kown S.R. 1997. Ammonia Effects on the Biomass Production of Five Constructed Wetland Plant Species. Bioresource Technology, 62:109-113.

Hodgson M.E., Jensen J.R., Mackey H.E.J., and Coulter M.C. 1988. Monitoring Wood Stork Foraging Habitat Using Remote Sensing and Geographical Information Systems. Photogrammetric Engineering and Remote Sensing, 45:1601-1607.

Hunter E.L., and Power C.H. 2002. An Assessment of Two Classification Methods for Mapping Thames Estuary Intertidal Habitats Using CASI Data. International Journal of Remote Sensing, 23:2989-3008.

Jensen J.R. 1983. Biophysical Remote Sensing. Annals of the Association of American Geographers, 73:111-132.

Jensen J.R., Christensen E.J., and Sharitz R. 1984. Nontidal Wetland Mapping in South Carolina Using Airborne Multi-spectral Scanner Data. Remote Sensing of Environment, 16:1-12. 
Jensen J.R., Hodgson M.E., and Christensen E. 1986. Remote Sensing Inland Wetlands: A Multispectral Approach. Photogrammetric Engineering and Remote Sensing, 52:87-100.

Jensen J.R., Cowen D.J., Althausen J.D., Narumalani S., and Weatherbee O. 1993. An Evaluation of the CoastWatch Change Detection Protocol in South Carolina. Photogrammetric Engineering and Remote Sensing, 59:1039-1046.

Jensen J.R. 1996. Introductory Digital Image Processing A Remote Sensing Perspective. $2^{\text {nd }}$ Edition. Prentice Hall: Upper Saddle River, New Jersey. 316p.

Jensen J.R., Qui F., and Ji M. 1999. Predictive Modelling of Coniferous Forest Age Using Statistical and Artificial Neural Network Approaches Applied to Remote Sensor Data. International Journal of Remote Sensing, 20:2805-2822.

Kaiser H.F. 1960. The Application of Electronic Computers to Factor Analysis. Educational and Psychological Measurement, 20:141-151.

Kasischke E.S., and Bourgeau-Chavez L.L. 1997. Monitoring South Florida Wetlands Using ERS-1 SAR Imagery. Photogrammetric Engineering and Remote Sensing, 63:281-291.

Kauth R.J., and Thomas G.S. 1976. The Tasseled Cap-A Graphic Description of the Spectral Temporal Development of Agricultural Crops as seen by Landsat. Proceedings, Symposium on Machine Processing of Remotely Sensed Data, 4B41-4B51. Purdue University: West Lafayette, Indiana.

Kavzoglu T., and Mathers P.M. 2003. The Use of Backpropagating Artificial Neural Networks in Land Cover Classification. International Journal of Remote Sensing, 24:4907-4938.

Kindscher K., Fraser A., Jakubauskas M.E., and Debinski D.M. 1998. Identifying Wetland Meadows in Grand Teton National Park Using Remote Sensing and Average Wetland Values. Wetlands Ecology and Management, 5:265-273.

Kushwaha S.P.S., Dwivedi R.S., and Rao B.R.M. 2000. Evaluation of Various Digital Image Processing Techniques for Detection of Coastal Wetlands Using ERS-1 SAR Data. International Journal of Remote Sensing, 21:565-579.

Larson J.S., and Newton R.B. 1981. The Value of Wetlands to Man and Wildlife. SP-125. Department of Forestry and Wildlife Management, University of Massachusetts, Amherst. Cooperative Extension Service, University of Massachusetts, US Department of Agriculture and County Extension Services Cooperating. 
Lawrence R.L., and Ripple W.J. 1998. Comparisons Among Vegetation Indices and Bandwise Regression In a Highly Disturbed, Heterogeneous Landscape: Mount St.Helens Washington. Remote Sensing of Environment, 64:91-102.

Lee J.K., Park R.A., and Mausel P.W. 1992. Application of Geoprocessing and Simulation Modeling to Estimate Impacts of Sea level Rise on the Northeast Coast of Florida. Photogrammetric Engineering and Remote Sensing, 58:15791586.

Lee K.H., and Lunetta R.S. 1996. Wetland Detection Methods. In: Lyon JG and McCarthy $\mathrm{J}$ (eds). Wetland and Environmental Applications of GIS. Lewis Publishers: New York, NY: 249-284.

Lek S., and Guegan J.F. 1999. Artificial Neural Networks as a Tool in Ecological Modelling: An Introduction. Ecological Modelling, 120:65-73.

Lewis H.G., Cote S., and Tatnall A.R.L. 1997. Determination of Spatial and Temporal Characteristics as an Aid to Neural network Cloud Classification. International Journal of Remote Sensing, 18:899-915.

Lewis W.M.Jr. 2001. Wetlands Explained: Wetland Science, Policy and Politics In America. Oxford University Press Incorporated: New York, NY. 147p.

Lillesand T.M., and Kiefer R.W. 2000. Remote Sensing and Image Interpretation. $4^{\text {th }}$ Edition. John Wiley and Sons Incorporated: New York, NY. $724 p$.

Linthurst R.A., and Reimold R.J. 1978. An Evaluation of Methods for Estimating the Net Aerial Primary Productivity of Estuarine Angiosperms. Journal of Applied Ecology, 15:919-931.

Lu D. 2005. Aboveground Biomass Estimation Using Landsat TM Data in the Brazilian Amazon. International Journal of Remote Sensing, 26:2509-2525.

Lu D. 2006. The Potential and Challenge of Remote Sensing-based Biomass Estimation. International Journal of Remote Sensing, 27:1297-1328.

Luman D.E. 1990. The Potential for Satellite-Based Remote Sensing Update of the Illinois Portion of the National Wetlands Inventory. Quarterly Report Submitted to the Illinois Department of Conservation, IL.

Lunetta R.S., and Balogh M.E. 1999. Application of Multi-Temporal Landsat 5 TM Imagery for Wetland Identification. Photogrammetric Engineering and Remote Sensing, 65:1303-1310. 
Lyon J.G., and McCarthy J. Introduction to Wetland Applications. In: Lyon JG, and McCarthy J. 1995. Wetland and Environmental Applications of GIS. CRC Press Incorporated: Boca Raton, Florida . Pp.27-30.

McBean E.A., Mulamoottil G., Novak Z., and Bowen G. Urban Intensification and Environmental Sustainability: the Maintenance of Infiltration Gradients. In: Mulamoottil G., Warner B.G., and McBean E.A. 1996. Wetlands Environmental Gradients, Boundaries and Buffers. CRC Press Incorporated: Boca Raton, Florida. Pp.67-77.

Mitsch W.M., and Gosselink J.G. 1993. Wetlands. $2^{\text {nd }}$ Edition. Van Nostrand Reinhold: New York, NY. 722p.

Mitsch W.M., and Gosselink J.G. 2000. Wetlands. $3^{\text {rd }}$ Edition. John Wiley and Sons Incorporated: New York, NY. 920p.

Musuem of Nature. 2006. History and Geography of the Rideau River. The Nature of the Rideau River. Website URL: www.nature.ca/rideau/a/a1-e.html.

National Wetlands Working Group Canada Committee on Ecological Land Classification. 1988. Wetlands of Canada. Ecological Land Classification Series, No.24. Polyscience Publications Incorporated: Montreal, Quebec. 452p.

Newmaster S.G., Harris A.G., and Kershaw L.J. 1997. Wetland Plants of Ontario. Lone Pine Publishing: Edmonton, Alberta. 240p.

Olmanson L.G., Bauer M.E., and Brezonik P.L. 2002. Aquatic Vegetation Surveys Using High-Resolution Ikonos Imagery. Pecora 15/Land Satellite Information IV/ISPRS Commission I/FIEOS Conference Proceedings.

Ontario Ministry of Natural Resources. 1993. Ontario Wetland Evaluation System Southern Manual. $3^{\text {rd }}$ Edition. Ontario Ministry of Natural Resources. $178 \mathrm{p}$.

Ozesmi S.L., and Bauer M.E. 2002. Satellite Remote Sensing of Wetlands. Wetlands Ecology and Management, 10:381-402.

PCl, Geomatics. 2004. Website URL: www.pcigeomatics.com.

Pearson R.L., and Miller L.D. 1972. Remote Mapping of Standing Crop Biomass for Estimation of the Productivity of the Shortgrass Prairie, Pawnee National Grasslands, Colorado. Proceedings of the $8^{\text {th }}$ International Symposium on Remote Sensing of the Environment, II:1355-1379.

Perry C.R., and Lautenschlager L.F. 1984. Functional Equivalence of Spectral Vegetation Indices. Remote Sensing of Environment, 14:169-182. 
Pierce L.E., Sarabandi K., and Ulaby F.T. 1994. Application of an Artificial Neural Network in Canopy Scattering Inversion. International Journal of Remote Sensing, 15:3263-3270.

Purevdorj T.S., Tateishi R., Ishiyama T., and Honda Y. 1998. Relationship Between Percent Vegetation Cover and Vegetation Indices. International Journal of Remote Sensing, 19:3519-3535.

Qi J., Chehbouni A., Heute A.R., Kerr Y.H., and Sorooshian S. 1994a. Modified Soil Adjusted Vegetation Index (MSAVI). Remote Sensing of Environment, 48:119-126.

Qi J., Kerr J., and Chehbouni A. 1994b. External Factor Consideration in Vegetation Index Development. $6^{\text {th }}$ International Symposium on Physical Measurements and Signatures in Remote Sensing, held in Val d'Isere, France, on 17-21 January 1994 (Toulouse, France: CNES), 723-730.

Ramsey E.W., and Laine S.C. 1997. Comparison of Landsat Thematic Mapper and High Resolution Photography to Identify Change in Complex Coastal Wetlands. Journal of Coastal Research, 13:281-292.

Rees W.G. 2001. Physical Principles of Remote Sensing. $2^{\text {nd }}$ Edition. Cambridge University Press: New York, NY. 343p.

Rogers A.S., and Kearney M.S. 2003. Reducing Signature Variability in Unmixing Coastal Marsh Thematic Mapper Scenes Using Spectral Indices. International Journal of Remote Sensing, 25:2317-2335.

Rosenfield G.H., and Fitzpatrick-Lins K. 1986. A Coeffiecient of Agreement as a Measure of Thematic Classification Accuracy. Photogrammetric Engineering and Remote Sensing, 52:223-227.

Rouse J.W. 1973. Monitoring the Vernal Advancement and Retrogradation of Natural Vegetation. NASAVGSFCT Type I/ Report, Greenbelt, MD, USA.

Rumelhart D.E., Hinton G.E., and Williams R.J. 1986. Learning Internal Representations by Error Propogation. Parellel Distributed Processing: Explorations in the Microstructure of Cognition. In: Rumelhart D.E., and McClelland J.L. (eds). Foundations. MIT Press: Cambridge, Massachusetts. 318-362p.

Skidmore A.K., Turner B.J., Brinkhof W., and Knowles E. 1997. Performance of a Neural Network: Mapping Forests Using GIS and Remotely Sensed Data. Photogrammetric Engineering and Remote Sensing, 63:501-514. 
Snell E. 1987. Wetland Distribution and Conversion in Southern Ontario.

Working Paper No.48. Inland Water and Land Directorate Environment Canada.

Sokol J. 2003. Monitoring Northern Atlantic Canadian Wetlands Using Remote

Sensing Techniques. MA thesis Carleton University (unpublished). 163p.

Stevens J.M. 1996. Applied Multivariate Statistics for the Social Sciences, $3^{\text {rd }}$

Edition. Lawrence Erlbaum Associates Publishers: Mahwah, New Jersey. 659p.

Streever W.J., Genders A.J., and Cole M.A. 1998. A Closed Chamber $\mathrm{CO}_{2}$ Flux Method for Estimating Marsh Productivity. Aquatic Botany, 62:33-44.

Tabachnick B.G., and Fidell L.S. 1989. Using Multivariate Statistics. $2^{\text {nd }}$ Edition. Harper Collins Publishers: New York, NY. 746p.

TAN Q., Shao Y., Yang S., and Wei Q. 2003. Wetland Vegetation Biomass Estimation Using Landsat-7 ETM+ Data. IEEE, 2629-2631p.

Thomson A.G., Huiskes A., Cox R., Wadsworth R.A., and Boorman L.A. 2004. Short-term Vegetation Succession and Erosion Identified by Airborne Remote Sensing of Westerschelde Salt Marshes, the Netherlands. International Journal of Remote Sensing, 25:4151-4176.

Twolan-Strutt L. 1995. Wetlands and Woodlots. Issues Paper, No.1995-1. North American Wetlands Conservation Council Canada. 24p.

Wang J., Shang J., Brisco B., and Brown R.J. 1998. Evaluation of Multidate ERS-1 and Multispectral Landsat Imagery for Wetland Detection in Southern Ontario. Canadian Journal of Remote Sensing, 24:60-68.

Williams M. 1990. Wetlands A Threatened Landscape. Basil Blackwell Ltd: Oxford, UK. 419p.

Yang G., Collins M.J., and Gong P. 1998. Multisource Data Selection for Lithologic Classification with Artificial Neural Networks. International Journal of Remote Sensing, 19:3675-3680.

Zhang X. 1998. On the Estimation of Biomass of Submerged Vegetation Using Landsat Thematic Mapper (TM) Imagery: A Case Study of the Honghu Lake, PR China. International Journal of Remote Sensing, 19:11-20. 